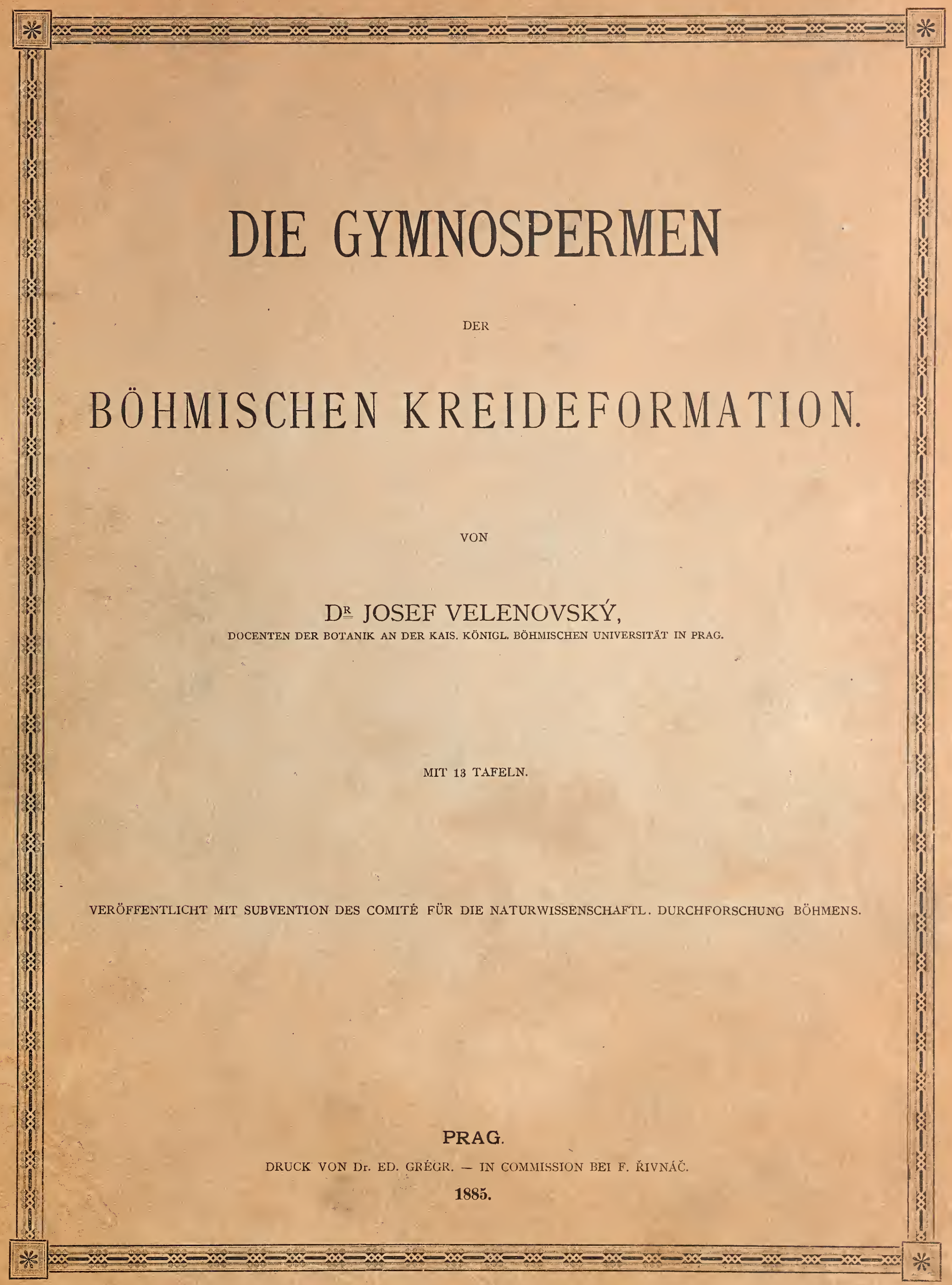




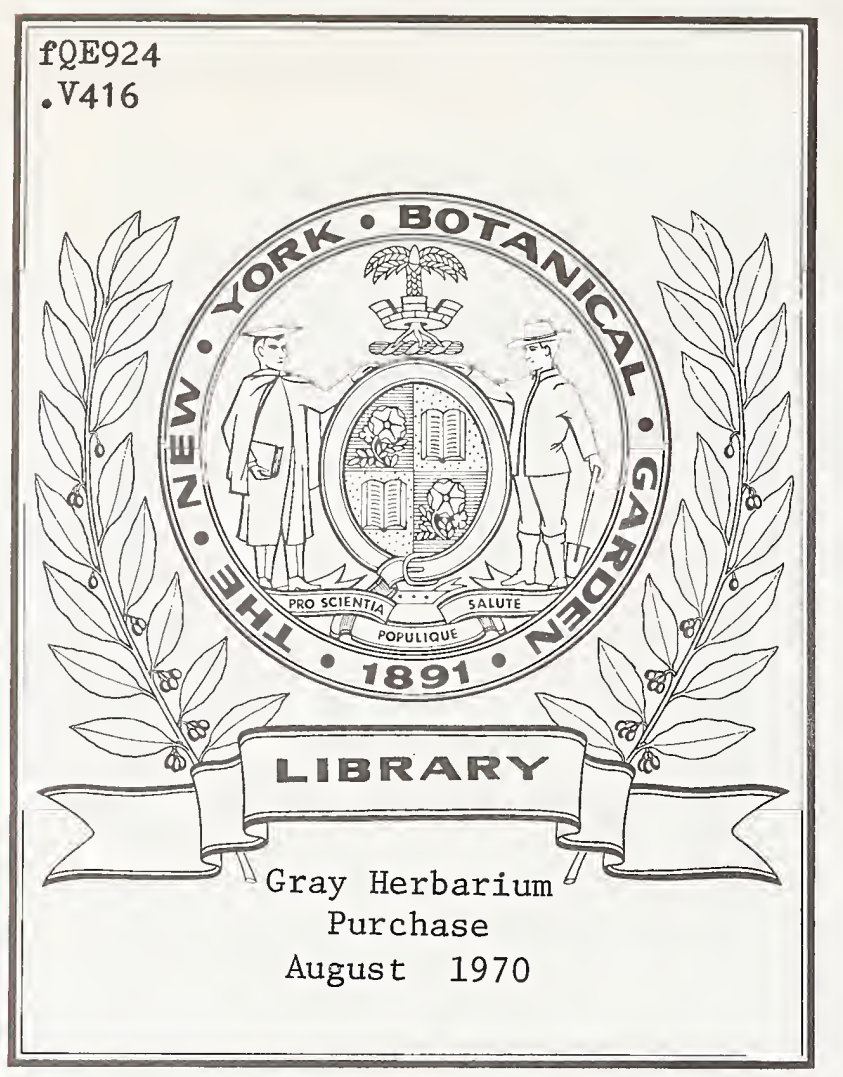





\section{DIE GYMNOSPERMEN}

DER

\section{BÖHMISCHEN KREIDEFORMATION.}

$\mathrm{VON}$

D尽 JOSEF VELENOVSKÝ;

DOCENTEN DER BOTANIK AN DER KAIS. KÖNIGL. BÖHMISCHEN UNIVERSITÄT IN PRAG.

MIT 13 TAFELN.

VERÖFFENTLICHT MIT SUBVENTION DES COMITÉ FÜR DIE NATURWISSENSCHAFTL. DURCHFORSCHUNG BÖHMENS.

PRAG.

DRUCK VON Dr. ED. GRÉGR. - IN COMMISSION BEI F. ŘIVNÁČ.

1885. 


$$
\begin{gathered}
\text { AQE924 } \\
\text { V416 }
\end{gathered}
$$




\section{VORWORT.}

Seit einer Reihe von Jahren mit dem Studium der Flora der böhmischen Kreideformation beschäftigt veröffentlichte ich bereits in den „Beiträgen zur Palaeontologie Oesterreich-Ungarns" von E. von Mojsisovies und Neumayr in Wien einen Theil meines Werkes „Die Flora der böhmischen Kreideformation", welcher in vier Heften die Dicotyledonen mit 25 Familien und 80 beschriebenen und abgebildeten Arten enthält.

Nachdem ich dann die Gymnospermen bearbeitet habe, sah ich, dass ich in Hinsicht auf den Umfang und die Unkosten, mit welchen die Veröffentlichung dieser Arbeit verbunden sein würde, auf die Publication in den oben genannten Beiträgen zur Palaeontologie lange warten müsste, aus welchem Grunde ich mich entschloss diese Partie meines Werkes selbständig zu veröffentlichen.

Da die allgemeinen Resultate sowie die vergleichenden Beziehungen der einzelnen Pflanzenarten der böhmischen Kreideformation erst im letzten Theile meiner Flora behandelt werden sollen, beschränkte ich mich auch in dieser Partie nur auf den beschreibenden Theil der darin enthaltenen Arten.

Der erste, welcher über die Kreide-Gymnospermen Böhmens geschrieben hat, war der berühmte Gelehrte Graf Kaspar von Sternberg, welcher einige Coniferen beschrieben hat, dieselben aber zumeist für Meeresalgen hielt.

Etwa 10 Arten hat C orda in Reuss' "Versteinerungen der böhmischen Kreideformation“ veröffentlicht, von welchen aber einige schlecht erhalten und im Sinne der beschreibenden Botanik werthlos sind.

Ein Verzeichniss der Namen der Gymnospermen der böhmischen Kreideformation hat auch Dr. O. F e istmant el zusammengestellt (Sitzungsber. der k. böhm. Ges. der Wiss. J. 1872) und K. Renger in seiner Abhandlung über die Kreidepflanzen Böhmens in "Živa" J. 1866. besonders die Krannera mirabilis Corda ausführlich besprochen hat. Kleinere Nachrichten über die böhmischen Kreidegymıspermen findet man in Geinitz' „Das Quadersandsteingebirge oder Kreidegebirge in Deutschland".

In der vorliegenden Arbeit sind 40 Gymnospermen beschrieben, von welchen 2 Arten incertae sedis sind, 10 Arten die Cycadeen und 28 die Coniferen enthalten.

Während des Druckes dieser Arbeit wurden in den Kreideschichten Böhmens noch 10 neue Coniferen entdeckt; welche hier nicht berücksichtigt werden konnten, welche aber gleichzeitig mit 
einer Reihe neuer Dicotylen in dem siebenten Theile meiner Flora noch beschrieben werden. Die folgende (sechste) Abtheilung ist den Farnen gewidmet, welche in den „Beiträgen zur Paläontologie Österreich-Ungarns" noch am Ende dieses Jahres zur Publicirung gelangen dürften.

Die Abbildungen dieses Theiles sind lithographisch ausgeführt. Hie und da, wo es sich für die bessere Veranschaulichung der Zapfen oder Zweigtheile vortheilhaft zeigte, habe ich möglichst treue oder wenigstens der Wirklichkeit ziemlich gut entsprechende Restaurationen hinzugefügt.

Die Veröffentlichung dieser Arbeit war nur durch die Subvention des löblichen Comité für die naturwissenschaftliche Durchforschung Böhmens ermöglicht, welchem ich an dieser Stelle meinen verbindlichsten Dank ausspreche.

Mit dem herzlichsten Danke bin ich auch im grössten Masse dem Herrn Prof. Dr. Ant. Frič verpflichtet, welcher nicht nur die Veröffentlichung der vorhandenen Arbeit förderte, sondern mir auch überall bei dem Studium des grösstentheils von ihm zusammengebrachten Materiales mit seinem werthen Rath zur Hand stand.

PRAG, den 1. Juli 1885. 


\section{N H A L T.}

Vorwort.

Seite

Taxodineae.

\section{Gymnospermae.}

Species incertae sedis.

Krannera mirabilis Corda . . . . . . . . . . 1

Thinnfeldia variabilis Vel. . . . . . . . . 6

\section{Cycadeae.}

Microzamia gibba Corda . . . . . . . 6

Fričia nobilis Vel. . . . . . . . . . 8

Podozamites obtusus Vel. . . . . . . . . . . 9

" striatus Vel. . . . . . . . . 10

" latipennis Heer. . . . . . . . . . -

" longipennis Vel. . . . . . . . . .

" Eichwaldi Heer. . . . . . . . . . 11

" lanceolatus Heer. . . . . . . . . . . -

pusillus Vel. .............

Nilssonia bohemica Vel. . . . . . . . . . -

\section{Coniferae.}

\section{Taxaceae.}

Dacrydium densifolium Vel. . . . . . . . . 12

Podocarpus cretacea Vel. . . . . . . . . 13

\section{Arancarieae.}

Cunninghamia elegans Corda . . . . . . . . . 14 stenophylla Vel. . . . . . . 15
Geinitzia cretacea Ung. . . . . . . . . . 15

Echinostrobus squammosus Vel. . . . . . . 16

Cyparissidium gracile Heer. . . . . . . . . . . 17

" pulchellum Vel. . . . . . . . . 18

" minimum Vel. . . . . . . . . . . 19

Sequoia Reichenbachi Gein sp............

"fastigiata Sternb. sp. .........21

" crispa Vel. ............... 22

, heterophylla Vel. . . . . . . . . . . . -

rigida Heer. . . . . . . . . . . . 23

" microcarpa Vel. . . . . . . . . . . 24

Ceratostrobus sequoiaephyllus Vel.......... " echinatus Vel. ......... 25

Glyptostrobus europaeus Heer. . . . . . . . . . 26

\section{Cupressineae.}

Widdringtonia Reichii Ett. . . . . . . . . . 27

Libocedrus salicornioides Heer . . . . . . 28 " Veneris Vel. . . . . . . . . . . . -

Juniperus macilenta Heer. . . . . . . . . . . . . . 29

\section{Abietineae.}

Pinus longissima Vel.. . . . . . . . . . . . 29

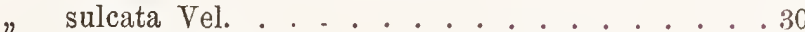

" protopicea Vel. . . . . . . . . . . . 31

"Quenstedti Heer ............ . 32

Abies calcaria Vel. . . . . . . . . . . . . 33

" minor Vel. . . . . . . . . . . . . .

" chuchlensis Vel. . . . . . . . . . 34 



\title{
Gymnospermae.
}

\author{
Species incertae sedis.
}

Taf. I. Fig. 1-7, 10-13. Taf. IV. Fig. 1, 2, 4, 7, 8, 9.

Krannera mirabilis Corda in lit.

Palaeostrobus mirabilis Renger, Živa 1866. Předvěké rostlinstvo.

Palaeostrobus crassipes Renger 1. c.

Flabellaria chamaeropifolia Göpp. Renger 1. c.

Dammara albens Presl im Sternberg's Versuch der Flora der Vorwelt.

Dammarites crassipes Göpp. Flora der Quadersand. in Schlesien. Časop. „Květy“ r. 1871, str. 268.

Lepidocaryopsis Westphaleni Stur. Verhandlungen der geolog. Reichsanst. Wien 1873.

Der cylindrische, dicke, mit breiten Blattnarben bedeckte Stengel ist gerade, oben mit einem zapfenförmigen Gebilde beendet, welches aus dicht stehenden, spiralig angeordneten dicken, holzigen Schuppen zusammengesetzt ist. Diese Schuppen sind am Ende verdickt, auf der Aussenseite gewölbt, auf der Innenseite mit einer Querrinne versehen, in welcher grosse, bis $40 \mathrm{~cm}$. lange, steife, gerade, lineale, ganzrandige, vorne stumpf abgerundete, gegen die Basis zu verschmälerte, derb lederartige Blätter sitzen. Die Nerven der Blätter sind zahlreich, gleich dick, parallel verlaufend; die Blattfläche zwischen den Nerven mit 1-4 sehr feinen parallelen Nervillen gestreift. Das Blatt wird am Grunde dick, wo zugleich die Nervation ụnkennbar ist. Die Früchte kugelig, aussen fleischig, im Inneren hornartig, gestielt.

Eine zur Zeit der Quadersandsteinbildung in Böhmen allgemein verbreitete Pflanzenform. Es liegen uns Überreste derselben von Nehvizd, Kaunic, Vyšerovic, Vysočan, Mšeno, Vojice bei Jič́n und Hořic vor.

Bei Kaunic und. Nehvizd werden in den grossen Sandsteinbrüchen von Arbeitern nicht selten kugelige oder ein wenig verlängerte Zapfen gefunden, welche als sonderbare versteinerte Kieferzapfen in verschiedenen Schulsammlungen anzutreffen sind. Dieselben waren schon den ältesten Paläontologen bekannt, aber unter verschiedenen Namen angeführt und so auch verschiedenartig bestimmt.

Im böhmischen Museum befindet sich eine ganze Sammlung dieser Zapfen, so dass man hier über dieselben die beste Belehrung schöpfen kann. Auf der Tafel IV. sind einige Exemplare als Beispiele abgebildet. Ihre Form ist am meisten kugelig, nicht selten von oben mässig zusammengedrückt, vorne abgerundet, am Grunde vertieft. In der Vertiefung mündẹt ein dicker, gerader Stengel (Fig. 2, 9). Nicht selten ist der Zapfen bedeutend verlängert wie Fig. 7. Die Grösse variirt bei einzelnen Exemplaren; man findet noch kleinere Stücke wie dasjenige Fig. 9 und wieder viel grössere als dasjenige Fig 1; die Grösse des Exemplars Fig. 1 und 4 ist jedoch die gewöhnlichste.

Aussen auf den vermeintlichen Zapfen bemerkt man vor allem zahlreiche in regelmässigen Parastichen angeordnete höckerartige Schuppen. Diese heben sich aus einer querrhombischen Unterlage auf, sind aber 
sehr massiv, dick, auf der Aussenseite gleichmässig gewölbt, glatt oder grob runzelig längs-genervt (Fig. 7), auf der Innenseite kürzer abgeschnitten und hier mit einer tiefen Querrinne versehen. Diese Querrinne charakterisirt alle Zapfen, welche mir überhaupt in die Hand kamen. Freilich findet man auch Zapfenstücke, deren Schuppen von aussen durch den Druck an einander gedrückt sind und in Folge dessen die Querrinne unkennbar wird, oder sind die Schuppen im groben Sandsteine schlecht erhalten, so dass wieder die Rinne im selben verschwindet. Auf dieser Stelle muss ich auch bemerken, dass die Dammara albens Presl im Sternberg's Werke (l. c.) sowie in Schimpers Palaeontologie vegetale und in Schenk's Handbuch der Palaeontologie nach einem schlecht erhaltenen Exemplare abgebildet oder überhaupt die Zeichnung nur oberflächlich ausgeführt ist. Ähnliche Zapfen mit undeutlichen Querrinnen und zusammengedrückten Schuppen stellen uns auch Fig. 2 und 9 dar. Stellenweise lassen sich jedoch alle Charaktere dieser Zapfen verfolgen.

Auf einigen Zapfen stehen die massiven Schuppen ziemlich weit auseinander und sind bedeutend verlängert, so dass sie eine verschiedene Art zu repräsentiren scheinen (siehe Fig. 7). Ob es zweie oder mehrere Arten sind, überlassen wir den weiteren Nachforschungen der böhmischen Paläontologen, hier handelt sich vor allem um die Bedeutung und die Verwandtschaft dieser Pflanzenüberreste.

Beobachtet man den gemeinschaftlichen Boden, aus dem die dicken, höckerigen Schuppen austreten, näher, so scheint derselbe compact, nicht geborsten, durch keine Lücken getheilt, nur oberhalb jeder Schuppe findet sich ein kleines, aber sehr tiefes Loch, von welchem noch später die Rede sein wird.

Die Schuppen sind bis zur Centralspindel von einander getrennt; die scheinbare compacte Oberfläche der Zapfen kann daher nur darin seine Erklärung finden, dass hier die Schuppen sehr dicht aneinander gelegt sind. Dass die Schuppen untereinander frei sind, ist sehr gut an mehreren Exemplaren wahrzunehmen, so z. B. an jenem in Fig. 2, 4. Ich konnte einzelne Schuppen von den übrigen gut entfernen, irgend welche Samen oder was anderes zwischen den Schuppen fand ich nirgends. Die Schuppen laufen in abnehmender Dicke bis zur Centralspindel. Diese ist holzig, gerade und geht in einen gleich dicken, geraden Stengel über, wie bei Fig. 9. Dieser vorher als Zapfenstiel erklärte Stengel lässt auf seiner Oberfläche spiralig stehende Schuppenspuren erkennen (Fig. 9). Auf dem Zapfen Fig. 4 (auf der Rückseite unserer Abbildung) und 9 ist sehr gut zu sehen, dass die holzigen Schuppen auf dem Stengel diese Spuren zurückliessen. Experimentell kann. man diese Spuren erhalten, wenn man einzelne Schuppen abbricht.

Die bereits beschriebenen Eigenschaften der Kaunicer und Vyšerovicer Zapfen können mit keinem Fruchtzapfentypus der sämmtlichen Gymnospermen verglichen werden, und daraus ist auch leicht zu begreifen, warum sie so verschiedenartig als solche bis jetzt bestimmt waren. Presl hielt sie für einen verwandten Typus der. Gattung Dammara, wesshalb seine Bennenung Dammarites albens. Dieselbe Bestimmung hat auch Göppert angenommen (Dammarites crassipes). Renger (l. c.) hat sie für zweifellose PinusZapfen erklärt und zwar für einen ausgestorbenen Typus, dem er den Namen Pala o strobus gegeben hat. Neuerdings hat Stur (l. c.) in den böhmischen Zapfen die beschuppten Früchte einer Palme aus der Gruppe L e pid o caryina e gefunden.

Alle diese Bestimmungen sind unzulässlich, wenn man die Zusammensetzung der fraglichen Zapfen näher betrachtet. Es können dieselben überhaupt keine Fruchtorgane sein. Die Schuppen sind sehr dick, holzig, am Ende noch mehr verdickt und von solcher Form, dass für dieselbe kein Analogon weder bei Cycadeen noch bei Coniferen angeführt werden kann. So gewölbte, dicke und mit einer Rinne auf der Innenseite versehene Schuppen hat keine Pinus noch Dammara der Jetztwelt. Der dicke Stiel war schon Göppert auffallend, darum seine Benennung Dammarites crassipes. Dieser muthmassliche Stiel ist, wirklich ungewöhnlich stark (siehe z. B. Fig. 2, 9), gerade, sehr lang (es war wenigstens seine Beendung noch nicht nachgewiesen), auf der Oberfläche Blattspuren tragend. Solche Stiele hat wieder keine Pinus-, keine Dammaranoch eine Palmenfrucht in der lebenden Pflanzenwelt. Der vermeintliche Zapfenstiel hat vielmehr die Form einer Achse (eines Stengels), welche am Ende ein zapfenähnliches Gebilde trägt.

Zwischen den einzelnen Schuppen befindet sich kein Same noch irgend ein bracteenartiger Gegenstand, woraus auf eine Verwandtschaft mit der Gattung Pinus zu schliessen wäre.

Unsere Zapfen sind nur vegetative Beendung eines Stengels und werden als solche in der Abbildung Fig. 8 dargestellt. Nicht selten sind mit den vermeintlichen Zapfen cylindrische, mehr oder weniger lange Stengelstücke zu finden (Tafel III. Figur 1), auf denen man spiralig stehende, quer verlängerte Blattspuren sieht. Diese Stengelstücke sind nichts anderes, als die dicken, geraden Stiele der Zapfen wie bei Figur 9. Auch auf diesen sieht man dieselben Blattspuren. Wir haben also einen cylindrischen Stengel vor uns, welcher Blätter trägt; diese Blätter stehen am Ende des Stengels sehr dicht und spiralig nebeneinander, sind sehr massiv und holzig. Die Schuppen der scheinbaren Zapfen sind nur Blattbasen, welchen die eigentlichen Blätter als den Ansätzen aufsitzen und endlich gliederig abfallen. Einen direkten Beweis für diese Deutung der vermeintlichen Schuppen findet man auf mehreren Zapfen, wo sich den einzelnen Schuppen in der oben erwähnten 
Rinne breite, lange Blätter anlegen (die Bracteen Rengers). Einen ähnlichen Fall bietet uns das Exemplar Figur 4 dar. Hier sieht man ein deutliches rechts und links vollkommen erhaltenes, oben abgebrochenes Blatt, das mit seiner Basis in der Schuppen-Rinne sitzt. Rechts vom letzteren legen sich mehrere Blätter aneinander und alle sitzen an den einzelnen Schuppen, welche bis zur Centralspindel untereinander frei sind, was besonders auf der Rückenșeite dieses Stückes, wo auch die Centralspindel hervortritt, deutlich ist. Diese Blätter sind auf dem Schema Fig. 8 bei d) angedeutet. Das tiefe Loch hinter jeder Schuppe wäre dann am wahrscheinlichsten ein Gefässbündelstrang, der in das aufsitzende Blatt eintritt.

Es ist also eine nachgewiesene Thatsache, dass jene zapfenförmigen Gebilde nur vegetative blättertragende Axen sind, es bleibt uns aber die Art des Wachsthums der Pflanze, welcher sie angehören, zu erklären. An allen Exemplaren, welche noch im Sandsteine liegen, sind noch die Blätter vorhanden, ebenso alle Lager, aus welchen die vermeintlichen Zapfen weggenommen sind. Gewöhnlich waren nur die Zapfen untersucht, ihre Lager waren aber unbeachtet geblieben und so wurden die ersteren leicht für Coniferenzapfen gehalten. Die ganze Pflanze war entweder einfach, nicht verzweigt, dann aber sehr niedrig, oder war dieselbe gross, dann aber verzweigt. Die verhältnissmässig dünnen Stengel, wären sie einfach und hoch, könnten niemals so zahlreiche und grosse Blätter tragen, weil sie sehr leicht brechen möchten. Sie waren wahrscheinlich niedrig etwa, wie die jetztlebenden Zamien. Übrigens haben die lebenden Zamien annähernd ähnliche kugelige oder ellipsoidische, mit dicken Blattstielen besetzte Stengel. Fossil sind ähnliche Cycadeen- und Zamieenstämme in verschiedenartigen Formen bekannt. Sap orta beschreibt aus den Juraschichten Frankreichs (Palaeontologie Française) auch einen Cycadeenstamm (Bolbopodium), der neben der ähnlichen Form auch dichstehende Blattbasen besitzt, von denen auch regelmässig gliederig die Blätter abfielen. Es bleibt also eine Krannera nicht ohne Analogon im Pflanzenreiche.

Corda hat in seinem Manuscripte die betreffenden Zapfen als selbstständige Gattung Krannera beschrieben und einer neuen Familie Kranneriaceae eingereiht. Er hielt ebenso die vermeintlichen Zapfen für Fruchtzapfen und zwar aus der Verwandtschaft der Cycadeen. Diese Deutung der Zapfen ist freilich falsch, ihre Stellung aber zufällig ziemlich wahrscheinlich. Es liegt daher kein Grund vorhanden, warum diese Pflanze die Benennung Krannera nicht beibehalten könnte. (Siehe Renger 1. c.)

Wir kennen auch die Blätter, welche den Krannera-Zapfen aufsassen, sehr gut. Auf diesen Zapfen sind sie nicht lang, sondern gewöhnlich abgebrochen, in dem Kaunicer, Nehwizder, Charvatecer Sandsteine kommen aber dieselben mehr oder weniger vollkommen erhalten sehr häufig vor. Die Abbildungen Taf. I., Fig. 1-7 stellen sie in natürlicher Grösse dar.

Diese Blätter waren von meinen Vorgängern im Studium der böhmischen Kreideflora grösstentheils als Flabellaria chamaeropifolia Göpp. bestimmt und als solche sind sie auch in einigen Büchern erschienen. Diese Blätter-sind einfach. Die Flabellaria chamaeropifolia Göppert rührt aus den jüngsten Kreideschichten her; im Cenoman (Perucer Schichten) scheinen die Palmen zu fehlen, sind wenigstens bis jetzt nicht vollkommen nachgewiesen.

Die Blätter sind im Sandstein braun abgedrückt und zeigen eine derbe, feste Beschaffenheit. Höclist gut erhalten ist das Exemplar Fig. 1, dessen Blattspitze in Folge von Bruch im Sandsteine gespalten ist. Die Basis des Blattes ist mässig verschmälert und endet mit einer schiefen Narbe. Besonders im negativen Abdrucke ist diese Blattbasis derjenigen Taf. IV. 4 a) ganz ähnlich. Die Blattnarbe deutet wohl die Stelle, wo sich das Blatt oberhalb der Schuppenrinne abgetheilt hat. Die Blattbasis (Figur I. 1) ist etwas grösser als diejenige Figur 4 a) Tafel IV., die Krannera-Zapfen und ihre Schuppen sind aber auch ungleich gross. Wir finden zwischen den langen Blättern auch bedeutend schmale Formen wie z. B. Fig. 7, welche den kleineren Zapfen angehören müssten. Die Blattresten auf den Zapfen sind übrigens ebenso dick-lederartig und ganz ähnlich dicht längs gestreift. Zwischen einzelnen Nerven sind ebenso feine, parallel laufende Nervillen erkennbar, wie auf den grossen Blättern, welche mit den Zapfen vorkommen.

Diese Blattform ist uns aber völlig fremd. Wir finden weder zwischen den Cycadeen noch zwischen den Coniferen ein ähnliches Analagon. Eine Monocotyle kann es ebenso nicht sein, wie wir noch im Folgenden sehen werden.

Sonderbarer Weise können wir dagegen diese Blätter sehr gut mit Blättern der paläozoischen Gattung Cordaites vergleichen. Ich habe zu diesem Behufe viele Abbildungen und Beschreibungen dieser Gattung mit unseren Blättern verglichen und nirgends wesentliche Merkmale gefunden, durch welche sich die letzteren von den Cordaitesblättern unterscheiden möchten.

Unsere Blätter waren wie die der Cordaiten sehr dick, derb lederartig. Für diese Eigenschaft spricht schon der Umstand, dass sie im Gesteine in geraden, nicht gefalteten oder gebogenen Stücken vorkommen. Das Blatt Fig. 1 gibt uns in dieser Hinsicht das beste Zeugniss. Auf einigen Blattstücken sieht man Stellen, wo die ehemalige Blattsubstanz in Form eines dicken, dicht gestreiften Überzuges hervortritt, so z. B. auf 
den Blattfragmenten Fig. 5, 7. Ebenfalls zeigen die quergebrochenen Blätter auf den Krannera-Zapfen eine mächtige Schicht der ehemaligen Blattsubstanz. Die steife, lederartige Form des Blattes lässt vermuthen, dass die Blattsubstanz mit einer festen aus sclerenchymatischen Zellen bestehenden Epidermisschicht überzogen war, wie es für die Cordaitesblätter nachgewiesen ist (siehe $\mathrm{Schenk}$, Handbuch der Palaeontologie II. Bd. S. 245), welchen auch stärkere Mittelrippen fehlen. Die Basis des Blattes Fig. 1, auf dem die Blattsubstanz überall erhalten ist, ist beinahe glatt, unten flach genervt und etwas dicker als der obere Theil des Blattes also wieder analog den Cordaiten.

Die Blattspitze ist ebenso rundlich beendet wie diejenige der Cordaiten (siehe Fig. 1, 4, 5).

Die Nervation besteht aus vielen parallelen, nicht starken Nerven. Die Fläche zwischen den einzelnen Nerven ist etwas gewölbt und mit anderen 2-4 höchst feinen Nerven durchgezogen (eine vergrösserte Partie bei Fig. 2, 3). Dieselbe Nervation fand ich z. B. auf den schön erhaltenen Exemplaren der Cordaites borassifolius aus der böhmischen Permformation.

Die Blattbasis ist breit, gestutzt, wie bei allen Cordaites-Arten, siehe z. B. Schimper, Palaeontologie vegetale, Taf. CX. Fig. 25 Pycnophyllum (Cordaites) borassifolium Brngt.)

In den älteren Formationen finden wir auch ähnliche Blätter, welche aber mannigfaltig von Autoren bestimmt sind. Sehr nahe verwandt scheint mir zu sein das Blattfragment Yuccites tenuinervis Nathorst (Floran vid Bjuf Taf. XI. Figur 3) und die prachtvollen beblätterten Zweigbruchstücke, welche Schenk Eolirion benannt hatte (die fossilen Pflanzen der Wernsdorfer Schichten in den Nordkarpaten).* Schenk vergleicht seine Blätter mit den monocotylen Gattungen Dracaena, Yucca, Lomatophyllum und Cordyline. Ich habe viele Arten aus diesen lebenden Gattungen untersucht, bin aber zu dem Resultate gekommen, dass sie mit unseren Perucer Blättern gar nichts gemeinschaftlich haben. Man findet vor allem bei allen diesen Pflanzen Blätter, welche mit einem Mittelnerven versehen sind, und wenn auch dieses nicht vorhanden ist, so ist derselbe durch eine mittlere dicke Partie am Blattgrunde ersetzt, welcher dann auf der Oberseite des Blattes eine vertiefte Rinne entspricht. Die Länge der Blätter dieser Pflanzentypen erfordert es, dass sie eine mechanische Unterstützungsachse besitzen müssen, welche entweder durch den Mittelnerv oder durch die verdickte Mittelpartie am Blattgrunde dargestellt ist. Bei unserer Art sind aber die Blätter steif, rigid, man bemerkt auf denselben jedoch keinen Mittelnerv, noch eine verdickte Grundrippe, welche die sclerenchymatische Zellenschicht der Oberfläche und die festen zahlreichen Nerven ersetzen.

Die Nerven der verglichenen monocotylen Blätter treten scharf aus der Blattoberfläche hervor, die stärkeren wechseln mit den schwächeren in einem völlig verschiedenen Verhältnisse als bei den KranneraBlättern. Am nächsten könnten die Blätter der Yucca noch in Anbetracht genommen werden. Die Nervation derselben ist doch viel verschieden, die Lederartigkeit der Blätter ist eine andere und alle Blätter dieser Gattung enden mit einer feinen, nicht selten zusammengerollten Spitze. Die Blätter der meisten Bromeliaceen sind zwar auch dick, sie sind aber zum grössten Theile am Rande gezähnt und ungewöhnlich breit massiv.

Unter den Monocotylen ist also für die Krannera-Blätter kein Analogon zu finden, ebenso wenig unter den Dicotylen. Ähnlichen Blättern begegnet man aber neben den erwähnten Cordaiten in der Gruppe der Gymnospermen und zwar am häufigsten bei den ausgestorbenen Formen. Es sei schon darauf hingewiesen, dass die Form unserer Krannera- und der oben erwähnten Schenks und Nathorsts Blätter im Wesentlichen an die Blattform der Gattungen Podozamites, Feildenia, Phoenicopsis erinnert (Schenk hat neuerdings seine Eolirion mit der Gattung Phoenicopsis verbunden. Handbuch der Palaeont. S. 269). Die Blätter dieser fossilen Gattungen sind ebenso derb lederartig und mit ähnlicher Nervation ausgezeichnet. Die Blattspitze ist ebenso stumpf abgerundet und die Blattbasis in einen kurzen, festen, breiten Stiel verschmälert. In dieser Hinsicht nenne ich z. B. Podozamites Agardhianus Brgn. und P. poaeformis Nath. (Floran vid Höganös och Helsingborg). Schmalhausen's Rhiptozamites Göpperti (Beiträge zur Juraflora Russlands) hat Blätter, welche neben anderen Merkmalen auch durch die Grösse unseren Blättern des Quadersandsteins nahestehen. Einige Arten der Gattung No eggerathia können hier auch mit Recht erwähnt werden. Die meisten der bereits genannten Blattarten gehören grösseren gefiederten Blättern, es ist aber möglich, dass viele von denselben selbstständige einfache Blätter sind.

Die Möglichkeit, dass viele ausgestorbenen Gattungen der Jura- und Kreideperiode, die theilweise zu den Taxaceen, theilweise zu den Cycadeen gerechnet werden, die Nachkommen oder die Überreste der Familie Cordaiteae sind, ist daher nicht ausgeschlossen. Die Cordaiteen möchten in der Mitte zwischen den Cycadeen, Gnetaceen und Coniferen stehen. Es fehlen uns freilich direkte Beweise für diese Vermuthung, es gibt aber ebenso wenig negative Gründe gegen dieselbe.

\footnotetext{
* Es ist möglich, dass die Palaeozamia megaphylla Phill. aus Stonesfield in England, welche Nothorst für eine
} Yuccites erklärt, auch hieher gehört. (Nathorst, Über eine wis. Reise nach England 1879). 
In den Perucer Sandsteinen bei Nehvizdy, Charvatec, Vys očany kommen sehr häufig kugelige Gebilde vor (Tafel I., 10-13, 18), welche in der grössten Breite 3 bis $4 \mathrm{~cm}$. im Durchmesser erreichen. Von oben sind sie ein wenig zusammengedrückt, an der oberen Seite gewölbt, an der unteren in der Mitte eingedrückt und hier mit einer kreisförmigen Contour versehen, welche einem abgebrochenen Stiele entspricht. Im Durchschnitte stellt uns diese Fossilien die Abbildung Fig. 12 vor. Auf den ersten Blick können diese Eichen, wie sie die Steinmetzer getauft hatten, für irgend ein Fruchtgebilde gehalten werden. Sie sind auf der Oberfläche glatt, keine Skulptur, Streifen oder Erhabenheiten sind auf selben warzunehmen.

Hielten wir diese Versteinerungen für Früchte, was nicht unwahrscheinlich ist, so müssten sie im lebenden Zustande mehr kugelig sein, da sie durch Druck im Làufe der Fossilification eine grössere oder kleinere Zusammendrückung erleiden müssen. Ihre vollkommene, nicht veränderte Form stellt uns das schöne Stück Fig. 18 dar. Der kugelige Kern musste sehr massiv und hart sein, und da keine Börstungen oder Näthe vorhanden sind, so kann es keine aufspringende Frucht sein. Am wahrscheinlichsten repraesentiren uns diese Früchte aus hartem Endosperm entstandene Kerne, welche noch mit einer fleischigen Aussenschicht umgeben waren. Diese letztere wird im Sandsteine durch einen hohlen braunen Lagerraum angedeutet, in dem die Steinkerne liegen.

Schon längst sind diese Früchte den böhmischen Palaeontologen bekannt, aber bis jetzt war kaum die Vermuthung angedeutet, welcher Pflanze sie angehören könnten. Ich kann freilich für dieselben keine definitive Bestimmung aufstellen, ich will nur auf ihre auffallende Ähnlichkeit mit den meisten CordaitesFrüchten hinweisen.

Die Früchte der Cordaiten waren fleischige Steinfrüchte mit einem inneren hornartigen Endospermkerne, welcher aussen mit einem fleischigen Überzuge umgeben war. In Erdschichten ist nur der harte Kern erhalten, während der fleischige Überzug am meisten verwesen ist oder es stellt uns denselben ein Hohlraum, in dem der Kern liegt, vor. Ihre Form ist mannigfaltig, zuweilen sind sie aber kugelig, herz-kugelig, keine Struktur auf der Oberfläche zeigend. Der Fruchtstiel, wie Schenk bemerkt (Handbuch der Palaeontologie), längte lange Zeit mit der Frucht zusammen, so dass man dieselbe nicht selten auf den versteinerten Arten vorfindet.

Eine ähnliche Steinfrucht mussten nun auch unsere Perucer Früchte gewesen sein. Sie sind ebenso durch einen Stiel ausgezeichnet, welcher häufig in bedeutender Länge mit dem Steinkern zusammenhängt, wird aber regelmässig mit dẹm Sandsteine abgebrochen, so dass nach demselben nur die kreisförmige Contour' zurückbleibt.

Ich habe verschiedene Formen der Cordaiten-Früchte mit unserigen verglichen, und da fand ich in der Steinkohlensammlung des böhm. Museums Corda's Originale von Carpolithes discus und C. placenta (Corda, Beiträge. Taf. II. Fig. 20. Taf. I. Fig. 1.), welche eigentlich dasselbe Objekt wie unsere Kreidefrüchte nur in wenig geringerer Grösse vorstellen. Sie sind etwa um ein Drittel kleiner, aber ebenso linsenförmig zusammengedrückt, ebenso auf der vertieften Seite mit einer kreisförmigen Contour in der Mitte versehen, so dass wir, wenn dieselben zur Vergleichung abgebildet werden sollten, die Abbildungen Figur 10 und 11 copiren könnten.

Auch folgender Umstand ist bei den verglichenen Früchten ebenso interessant wie übereinstimmend: auf den Früchten der Carpolithes discus Corda (Taf. II. Fig. 20) liegt herum der kreisförmigen Stielspur ein rindenartiger, am Rande unregelmässig abgebrochener, schwarzer Überzug, vielleicht ein Überrest der ehemaligen fleischigen Aussenschicht. Dasselbe finden wir auf der Frucht Fig. 18, aber im umgekehrten Verhältnisse; die Aussenrinde bedeckt nämlich die ganze Frucht, nur bei der Stielspur ist sie abgebrochen.

Noch ein anderes Merkmal unserer und Corda's Früchte deutet auffallender Weise auf ihren gleichen Ursprung. Zerschlagen wir den Sandstein, in welchem die kugeligen Früchte eingebettet sind, so theilt sich der Sandstein so, dass die Seite der Frucht, wo sich der Stiel befindet, frei erscheint, die andere abgerundete Seite bleibt immer mit dem Sandstein in Verbindung. Und ähnlich findet man es auf den Steinkohlenfrüchten Corda's. Den Grund dieser Erscheinung suche ich in der ungleich starken fleischigen Aussenschicht der Frucht; auf der Seite, wo der Stiel sich findet, war sie mächtiger und darum ein grösserer Zwischenraum zwischen dem Kern und den Wänden der Höhlung, in der das letztere liegt, und darum löst sich der Kern so leicht vom Sandsteine ab. Auf der entgegengesetzten Seite war oben die fleischige Aussenschicht der Frucht dünn, weshalb eine festere Verbindung des Steinkernes mit dem Sandsteine. Diesen Verhältnissen gemäss habe ich eine ähnliche Frucht im Durchschnitt bei Fig. 13 abgebildet.

Als ich im Jahre 1885 die Sandsteinbrüche bei Nehvizd besucht habe, fand ich auf allen Sandsteinstücken, welche man im ersten Steinbruche am Wege ausgebrochen hat, eine Menge von Krannera-Blätternn und Krannera-Früchten beisammen. Die Arbeiter erzählten mir nebstdem, dass sie sehr häufig in diesen Schichten die „Weintrauben" (Krannera-Zapfen) antreffen. 
Übersieht man nun alle Merkmale und Umstände, unter welchen die bereits beschriebenen Früchte in Erdschichten vorkommen, und erwägt man weiter, dass die Krannera-Blätter so auffallend an die CordaitesBlätter erinnern, so kann die Vermuthung, dass sie derselben Pflanze, und zwar einer Pflanze aus der Verwandtschaft der Cordaiten angehören könnten, ziemlich wahrscheinlich sein. Sicher kann ich aber behaupten, dass ' die beschriebenen Früchte, die Krannera-Zapfen und Krannera-Blätter keiner monocotylen noch dicotylen Pflanze zugezählt werden können.*

Thinnfeldia variabilis n. sp.

Taf. II. Fig. 1-5. Taf. III. Fig. 12.

Blätter stark ungleichseitig dreieckig bis rundlich, ganzrandig, vorne abgerundet, am Grunde in einen kurzen, dicken Stiel verschmälert. Die zahlreichen dünnen, strahlförmigen Nerven laufen in eine gemeinschaftliche Linie zusammen, welche bald in der Mitte liegt, bald rechts oder links in der Blattspreite gerückt ist. Die Nerven sind reichlich, netzaderig verzweigt.

In den Perucer Thonen bei Kuchelbad nicht selten (im Jahre 1881).

Die Form dieser Blätter ist sehr unbeständig. Die gewöhnlichste Form ist diejenige Fig. 1 oder 2, man findet aber nicht selten elliptische oder beinahe rundliche Exemplare, wie bei Fig. 5. Der Blattstiel ist immer gut deutlich und endet mit scharfer Ansatzlinie. Die Blattspreite war von derber, lederartiger Natur. Der Mittelnerv ist dünn und sehr selten in der Mitte der Blattspreite verlaufend. Die übrigen Nerven laufen ziemlich parallel untereinander, sind fein, alle gleich stark und stellenweise gabelig getheilt oder durch Quernerven verbunden.

Das Blatt Fig. 4 hat keinen Mittelnerv, die feinen Seitennerven laufen in der Richtung zur rechten Seite des Blattes. Dieses Blatt hat besonders einen gut erhaltenen Stiel, der am Grunde gerade abgestutzt ist. Das Blattstück Fig. 12 zeigt ebenso einen deutlichen Stiel, auf dem die gliederig abfallende Basis kennbar ist. Der keilförmige Umriss der Blattspreite ist hie und da gefaltet und zerrissen.

Die variirende Form und die Nervation dieser Blätter entspricht sehr gut den Blättern, welche Heer als Thinnfeldia Lesquereuxiana benannt hatte (Fl. grönl. 1. Th. S. 38. Taf. XLIV. Fig. 9, 10. Taf. XLVI. Fig. 1-12). Der Rand ist bei unseren Blättern freilich ungetheilt und die Nerven vielleicht mehrmals verzweigt und nebstdem stellenweise untereinander verbunden, was bei den Heer's Blättern nicht vorkommt.

Die unsymetrische Form der Kuchelbader Blätter scheint mir auf ein grösseres, gefiedertes Blatt hinzuweisen; die Verwandtschaft derselben mit der Gattung Zamia oder Podozamites wäre demnach nicht unwahrscheinlich.

Eine entfernte Ähnlichkeit haben diese Blätter mit einigen Farnen, welcher aber die Lederartigkeit der Blattspreite und besonders der dicke, gliederig sich abtheilende Blattstiel widerspricht.

\section{Cycadeae.}

\section{Microzamia gibba Corda.}

Taf. III. Fig. 5-16. Taf. IV. Fig. 6. Taf. V. Fig. 8.

Corda in Reuss, Versteinerungen der böhmischen Kreideformation Taf. 46. Fig. 1-10.

Conites gibbus Reuss, Geogn. Skiz. 2. pag. 169.

Fruchtzapfen länglich, cylindrisch, vorne kurz zugespitzt, am Grunde verschmälert, auf langen, dicken, verzweigten Stielen. Fruchtschuppen dünn, flach, am Ende in ein sechseckiges, mit rauhen Haaren bedecktes und mit zwei Höckerchen versehenes Schildchen verbreitet. Samen ellipsoidisch, aus einer äusseren fleischigen Testa und einem körnig punktirten, hornartigen Kerne bestehend.

In den grauen Perucer Schieferthonen bei Vyšerovic ziemlich häufig. Im Pläner beim Weiss en Berg nächst Prag und nach Corda auch bei Tř̀iblic und Laun.

* In der Zeitung „Květy“ S. 268. findet man einen restaurirten Zweig der Nehvizder Krannera. Derselbe ist falsch gezeichnet, weil der Krannera-Zapfen als Fruchtzapfen einer Dammara den Zweig beendet, und dass die Blätter dem Zweige selbst aufsitzen; die Blätter sind zu klein und nicht steif lederartig sondern schlaff, hin- und hergebogen wie bei einer Phragmites-Art gezeichnet. 
Aus dem Vyšerovicer Fundorte 'besitzt das böhmische Museum eine ganze Collection dieser so interessanten Fruchtzapfen. Diejenigen aus dem Weissenberger Pläner sind besonders schön erhalten, wenig zusammengedrückt und voll von Samen.

Die grössten Individuen stellt das Exemplar Fig. 7 dar. Die Weissenberger Zapfen (Fig. 9) sind immer viel kleiner als die von Vyšerovic, es ist daher möglich, dass hier zwei Arten zu unterscheiden sind, welche aber jedenfalls derselben Gattung angehören müssen. Die Zapfen sitzen auf langen, dicken, auf der Oberfläche fein narbig gestreiften Stielen, welche, wie Figur 6 Tafel IV. zeigt, zu mehreren in grössere Fruchtzweige verbunden waren. Die Zapfen sind oben und unten mässig verschmälert. Auf dem Abdrucke der Oberfläche eines Zapfens (Fig. 8) sieht man rhombische oder sechseckige Feldchen, die in der Mitte mit zwei tiefen Grübchen versehen sind. Diese Grübchen entsprechen den zwei Höckerchen auf einzelnen Schildchen.

Auf dem schönen, vollkommen im Umrisse erhaltenen Zapfenstücke Fig. 7 sind vor allem in der grösseren oberen Partie dieselben rhombisch-sechseckigen Feldchen warzunehmen, welche aber überall diclit und scharf punktirt sind. Die Punktirung rührt von den senkrecht auf den Schildchen stehenden dichten Haaren her, welche man auf den in der Mitte gebrochenen Zapfentheilen gut im Profile als eine dichte den Zapfen überziehende Haardecke sehen kann. Der untere Theil des Zapfens Fig. 7 ist in der Mitte gebrochen, so dass beiderseits der Centralspindel die zahlreichen Samen unterhalb der Schildchen zu sehen sind; die äusserste Schicht (a) bilden aber die dichten Haare. Hie und da (Fig. 7 b) sind auch dünne, genervte, kleine Schuppen zu finden, welche den samentragenden und mit Schildchen beendeten Schuppen entsprechen.

Auf dem Zapfenbruchstücke Fig. 5 sind oben wieder die punktirten Schildchen von der Oberfläche des Zapfens abgedrückt, am Grunde liegt aber eine Gruppe von Samen, wèlche auf einer Schicht von senkrecht stehenden Haaren beruhen (a). Die Samen liegen sämmtlich zu zweien nebeneinander. Untersucht man nun die Spalte zwischen je zwei Samen, so erscheint zwischen denselben eine dünne Schuppe, welche die Samen theilt und jener bei Fig. 7 b) entspricht.

Auf dem Fragmente Fig. 14, welches die obere Hälfte eines Zapfens darstellt, sind der ganzen Länge nach Samen erhalten. Diese sind wieder zu zweien im Zapfen zusammengestellt, sind aber durch den Druck ein wenig zusammengedrückt. Ihre Oberfläche ist mit feinen netzartigen Feldchen bezeichnet. Es sind dieselben Felderchen, welche Corda (l. c.) auf einem vergrösserten und theilweise restaurirten Samen abbildet.

Auf dem kleinen Zapfen Fig. 9 vom Weissen Berg sind besonders die Samen schön erhalten; sie sind nicht zusammengedrückt, von ellipsoidischer Form und stehen wieder zu zweien beisammen. Die Centralspindel ist im unteren Zapfentheile noch vorhanden. Die netzartigen Feldchen auf der Oberfläche der Samen sind auch wahrnehmbar. Die Oberfläche des Zapfens ist mit deutlicher Haardecke überzogen.

Die Samengruppe Figur 15 stellt ein Zapfenfragment mit reifen Samen dar, welche noch dieselbe Zusammenstellung wie diejenigen der oben beschriebenen Zapfenexemplare haben, so dass sie ganz gewiss einem Zapfen derselben Art gehören und nicht zufällig hieher aufgehäuft worden sind. Diese Samen sind etwas grösser als die vorhergehenden, sind auf der Oberfläche körnig punktirt, stehen aber wieder zu zweien nebeneinander. Ich halte die letzteren für reife Samen, welche von den Zapfen abfielen, so dass man sie nicht selten in Gesellschaft der Zapfen in den Vyšerovicer Schiefern vorfindet. Zuweilen spalten wir ganze Platten aus, welche reichlich mit diesen Samen bedeckt sind (Fig. 8 Taf. V.). Es liegen uns noch mehrere Zapfenfragmente welche wie bei Figur 15 beinahe reife Samen enthalten, die aber mit jenen im Gesteine isolirt zerstreuten Samen, wie Fig. 8 Taf. V. identisch sind.

Solche einzeln vorkommende Samen liegen häufig noch zu zweien in einer Höhlung (Figur 8, Tafel V.), deren Wände mit netzaderigen Feldchen gestreift sind. Die Kerne selbst zeigen auf ihrer Oberfläche eine körnige Sculptur (Figur 10, 16, Tafel III.) und wenn zwei beisammen liegen, so findet man zwischen denselben noch die dünne Schuppe, wie bei a) Figur 8. Liegt ein Same einzeln, so sieht man denselben auf einer Seite mit Höhlungswänden zusammenzuhängen und die Stelle, wo die beiden Samen verbunden waren, wie bei b) und c).

Diese Umstände, unter welchen sich diese reifen Samen vorfinden, müssen uns zur Vermuthung führen, dass die beiden Samen im reifen Zustande mit dem Schildchen und dessen Schuppe oder wenigstens mit einer Partie des Schildchens, auf dem sie befestigt waren, abfielen. Die Höhlung, in welcher die Samen liegen, entspricht der fleischigen Aussenschicht.

Die Samen der Zapfen Fig. 7, 9, 14 sind vielleicht noch jung, nicht reif, da sie zu klein sind und dicht beisammen halten. Die äussere fleischige Testa war noch zu schwach und nicht entwickelt; ich konnte dieselbe in Form einer dünnen Rinde stellenweise vom Samen ablösen; unter dieser Rinde erschien dann die körnige Oberfläche des inneren hornartigen Kernes. 
Was nun die Bedeutung aller dieser Überreste betrifft, so ist ausser allen Zweifel festgestellt, dass sie dasselbe sind, was Corda (l. c) als Microzamia gibba beschrieben hat. Die schönen Zapfenexemplare aus dem Weissenberger Pläner sehen ganz ähnlich aus wie Corda's Zapfen von Třiblic. Ich bin aber in zwei Sachen mit Corda's Angaben nicht einverstanden. Corda sagt, dass die Haare auf den Schuppenschildchen weich sind; sie waren freilich nicht derb borstenförmig, jedoch aber von einer festeren Beschaffenheit als diejenigen auf lebenden Zamienzapfen. Eine so scharfe und tiefe Punktirung, welche man auf den Schildchenabdrücken der Microzamia findet, kann niemals von so weichen, feinen Haaren herrühren, welche als dichter Pelzüberzug die lebenden Zamienzapfen umkleiden.

Weiter sagt Corda, dass er drei und mehrere Samen unterhalb eines Schildchens gefunden hat. Unsere ganze Sammlung weist sämmtlich zweisamige Schuppen auf und die abgebildeten Beispiele beweisen dasselbe in der besten Weise. Corda's Beschreibung muss daher auf irgend einem Übersehen beruhen, die Microzamia der Kreidezeit besitzt nur zweisamige Schuppen wie alle Arten der lebenden Familie der Zamieen.

Vergleichen wir jetzt unsere Kreide-Zamia mit den lebenden verwandten Typen der Zamieen, so sprechen alle wesentliche Merkmale für diese Verwandtschaft, man findet jedoch bei der ersteren manche Charactere, welche sie zu einer selbstständigen, jetzt schon untergangenen Gattung berechtigen.

Die zwei Höckerchen auf den Schildchen der Microzamia sind analog den zwei hornartigen Erhabenheiten auf den Zapfenschuppen der lebenden Gattung Ceratozamia.

Die Diagnose der Microzamia wäre demnach etwa folgende: Schildchen mit einer Schicht grober senkrecht stehender Haare überzogen und in der Mitte mit zwei Höckerchen versehen. Früchte mit ihrer Schuppe im reifen Zustande abfallend. Zapfentragende Äste verzweigt.

\section{Fričia nobilis $m$.}

Tafel III. Figur 1-3, 11, 6 .

Männliche Zapfen etwa viermal so lang als breit, vorne und unten abgerundet, cylindrisch. Schuppen gross, holzig, oben mit einer sechseckigen Fläche, welche unten in ein starkes, undeutlich sechskantiges, zur Basis verdünntes Säulchen übergeht. Die ganze Oberfläche des Säulchens mit Sporangiengrübchen bedeckt. Centralspindel sehr dick, von einem Gefässbündelcylinder durchzogen, welches einzelne Seitenzweige in die Schuppensäulchen absendet.

In den Plänerschichten beim Weissen Berg nächst Prag.

Wir haben mehrere Stücke von diesen Zapfen zur Verfügung. Die grösste Zahl von denselben hat Frau Marie Barthelmus im Jahre 1873 dem böhmischen Museum gewidmet. Die drei schönsten und lehrreichsten Exemplare sind bei Figur 1, 3,6 Tafel III. abgebildet. Der ganze Zapfen musste von einer sehr festen, holzigen Consistenz gewesen sein, da er im Gesteine nur sehr wenig zusammengedrückt ist und die einzelnen Schuppensäulchen untereinander frei wie im lebenden Zustande von der Centralspindel abstehen und ihre ehemalige Form unberührt behalten. Der Raum zwischen einzelnen Schuppensäulchen ist leer, mit der Gesteinsmasse nicht erfüllt.

Der Zapfen Fig. 3 scheint der ganzen Länge nach. erhalten zu sein; die Lage und die verminderte Grösse der oben und unten stehenden Schuppen spricht dafür. Die übrigen zwei Exemplare Fig. 1, 6 sind nur Fragmente, von denen es schwer zu sagen ist, um wie viel sie zu ergänzen sind. Die Spitze des Zapfens war abgerundet, wie es bei Fig. 6 gut zu sehen ist.

Das Bruchstück Fig. 3 ist etwa in der Mitte gebrochen. Die Centralspindel ist sehr stark und von einem braunen Gefässbündelcylinder durchzogen, von welchem einzelne Äste in die senkrecht abstehenden Säulchen abgehen. Das Gefässcylinder ist im Verhältnisse zur Rindenschicht ziemlich dünn. Die Säulchen sind sehr dick, holzig, am Rande des Zapfens durch scharfe, sechseckige Contouren vom Gesteine abgetheilt und von da zur Basis allmälig verschmälert. Die Kanten der Säulchen sind zwar deutlich, jedoch nicht scharf angedeutet.

Auf dem Zapfenfragmente Fig. 6 sieht man die starke Centralspindel, von welcher ähnliche säulenförmige Schuppen in senkrechter Richtung abstehen. Die abgebrochenen Säulchen lassen auf der Spindel kreisförmige Bruchstellen zurück, in deren Mitte der braune Gefässbündel sich findet. Zur linken Seite ist ein Schuppensäulchen vom Gesteine so glücklich abgelöst, dass seine obere sechseckige Fläche vollkommen sichtbar ist.

Auf diesen Schuppensäulchen ist gut zu sehen, wie das Säulchen gleich von den Kanten der sechseckigen Fläche in gleicher Dicke beginnt, so dass unter den Rändern der Fläche keine Vertiefung oder irgend eine Rinne sich findet. Die sechseckige Fläche selbst ist etwas rauh, irgend eine Behaarung ist jedoch nicht kennbar. 
Auf dem Zapfenbruchstücke Fig. 1 ist auch der vordere abgerundete Theil des Zapfens gut erhalten. Die Centralspindel ist gänzlich abgebrochen, so dass die einzelnen Säulchen etwa im unteren Drittel gebrochen sind. Dieselben sind untereinander frei und in verschiedenen Lagen gestellt, so dass hier am besten ihre Form hervortritt. Wir sehen auf den ersten Blick ihren starken, dicken Umriss sowie ihre feste Consistenz. Es ist hier besonders aus den rundlichen Bruchstellen der Säulchen ersichtlich, dass sie nicht flach, schuppenförmig waren. Links oben findet sich wieder ein Schuppensäulchen, welches mit einer sechseckigen, etwas gewölbten Fläche endigt.

Alle Säulchen dieser drei Fragmente sind auf der ganzen Oberfläche mit Grübchen, welche scharfe, erhabene Leisten umsäumen, bedeckt.

Die Erscheinung dieser Zapfen erinnert uns leb̉haft an die Zapfen der lebenden Zamien. Die Abbildung Fig. 2 stellt sie in restaurirter Form dar; die Dimensionen sind vom Zapfen Fig. 3 genommen. Dem festen, holzigen Bau nach ähneln sie den männlichen Zapfen der Cycadeen überhaupt. Bei den letzteren begegnet man ebenso festen, dicken und holzigen Schuppen, während die Schuppen der weiblichen Zapfen dümn und subtil sind. Die sechseckige Fläche, welche die Säulchen der Fri či a beendet, ist freilich auf den männlichen Schuppen der jetzt lebenden Zamien nur schwach bei einigen Arten angedeutet, auf den weiblichen wiederholt sie sich aber häufiger. Der beste Beweis, dass diese Säulchen den männlichen Schuppen der Zamien entsprechen, sind die zahlreichen Grübchen auf ihrer Oberfläche, welche mit erhabenen Leisten in derselben Weise umsäumt sind, wie man es auf männlichen, sporangientragenden Schuppen der lebenden Cycadeen vorfindet. Die Ähnlichkeit in dieser Hinsicht ist hier sehr auffallend.

Es lässt sich also nicht zweifeln, dass die vorliegenden Zapfen einer Zamiee angehören; der Typus, welchen sie aber repräsentiren, ist ein gänzlich fremder. Bei keiner jetzt lebenden Cycadee sind solche säulenförmige Schuppen vorhanden; die männlichen Schuppen derselben sind mehr oder weniger platt gedrückt, oben mit einem spitzigen Anhängsel beendet, seltener ist ihre Spitze etwas verdickt und in einem solchen Falle annähernd sechseckige Form annehmend. Die oben beschriebenen Sporangiengrübchen [finden wir auf der ganzen Oberfläche der Säulchen, so dass in dieser Beziehung wieder ein grosser Unterschied von den lebenden Zamien ausgesprochen ist. Auf den männlichen Zapfen der lebenden Zamien befinden sich die Sporangien nur auf der Unterseite der Schuppen und zwar in zwei getrennten Partien. Ob die Kreidezapfen der Fričia mit einer Haarschicht bedeckt waren, ist nicht entschieden; auf den Fragmenten, welche uns zur Disposition stehen, ist sie nirgends erkennbar. Eine Auffindung der Zapfen dieser Art, wo noch die Sporangien erhalten wären, kann ihre Stellung zwischen den Zamieen noch besser begründen.

Ich habe mir diese höchst eigenthümliche Cycadeenform nach meinem geliebten Lehrer, Herrn Prof. Dr. Ant. Frič zu benennen erlaubt.

Sehr möglich ist es, dass diese Zapfen als männliche Organe zu derselben Art angehören, wie die Microzamia gibba, welche in denselben Plänerschichten vorkommt. Ein umgekehrtes Urtheil ist aber ebenso berechtigt, weil in den böhmischen Kreideschichten so verschiedenartige Cycadeen-Blätter vorkommen.

\section{Podozamites obtusus m.}

Taf. I. Fig. 8, 9.

Das Blatt aus verkehrt eiförmiger Spitze allmälig in einen langen Stiel verschmälert, ganzrandig, derb lederartig. Die Blattspreite grob und ziemlich locker genervt.

In dem Perucer Sandsteine bei Nehvizd.

Wir besitzen nur das einzige abgebildete Blatt von dieser Art, dasselbe ist aber gut erhalten. Der lange Blattstiel ist am Ende abgebrochen, derselbe war vielleicht kaum grösser als er erhalten ist. Das Aussehen des Blattes zeigt eine feste, derb lederartige Consistenz, die Blattränder sind im Sandsteine dick und scharf abgedrückt. Die Streifen auf der Blattfläche sind grob und locker nebeneinander verlaufend; auf der Abbildung sind sie treu auch bezüglich der Anzahl angedeutet. Sie laufen untereinander parallel und münden im Rande der Blattspitze ohne sich zu biegen. Im Blattstiele verwandeln sie sich in feine, scharfe Längsrunzeln. Die ganze Blattfläche, die Nerven sowie ihre Zwischenräume sind unter der Luppe sehr fein gestreift. (Siehe die vergrösserte Partie Fig. 9.)

Das Aussehen des Blattes erinnert uns auf einige Zamien-Arten, wo ähnlich geformte, derb lederartige und grob gestreifte Blätter vorkommen. Die Blätter der lebenden Zamien sind aber gefiedert, was für unseres Blatt sehr unwahrscheinlich ist, da der Blattstiel so lang und verhältnissmässig dünn ist. Einigen Arten der 
Gattung Podozamites kann unser Blatt ebenso sehr nahe gestellt werden, denn auch hier findet sich eine ähnliche Nervation und eine ähnliche Blattform. Podozamites latipennis Heer, Podozamites Agardhianus Brgn. (l. c.) oder die verwandte Rhiptozamites Göpperti Schm. (l. c.) sind analoge Blattformen Ja selbst die Krannera-Blätter zeigen eine nicht geringe Verwandtschaft mit unserem Blatte.

Rührt dieses Blatt in der That von keinem gefiederten grösseren Blatte her, so kann es wirklich entweder der Krannera oder den Heerischen Gattungen Baiera oder Feildenia nahegestellt werden. Die letzteren werden aber zu Taxaceen gezählt.

\section{Podozamites striatus $\mathrm{m}$.}

Taf. II. Fig. 8.

Das Blatt elliptisch, vorne und an der Basis abgerundet, mit einem sehr kurzen, undeutlichen, dicken Stiele. Die Blattfläche mit zahlreichen parallel verlaufenden Nerven, welche. mit anderen viel feineren abwechseln, gestreift. Das Blatt von fester, lederartiger Natur.

In den Perucer Schieferthonen bei Lieben a nur in einem Exemplare.

Dieses Blatt ist nicht nur durch die breite, vorne und unten stumpf abgerundete Form, sondern auch durch die Tracht der Nervation ausgezeichnet. Die Blattspitze ist zur rechten Seite theilweise abgebrochen, die linke Seite zeigt jedoch die rundliche Beendung derselben. Der Blattstiel ist sehr kurz und kaum angedeutet. Die Nerven verlaufen mit dem Blattrande parallel, sind von einander gleich entfernt und etwa in der Anzahl, wie sie auf der Abbildung angedeutet ist. Zwischen je zwei Nerven ist noch ein anderer paralleler aber sehr schwacher Nerv wahrzunehmen. Die Nerven treten nur seicht hervor.

Dieses Blatt gehört entschieden dem Podozamites-Typus an. Sehr ähnliche, jedoch viel kleinere Blätter hat Heer in den Juraschichten der arctischen Länder gefunden und als Podozamites pulchellus beschrieben. (Die Jura-Flora des Cap Boheman S. 38. Taf. IX. Fig. 10-14.) Die Tracht der Nervation stimmt mit derjenigen unseres Blattes auffallend überein.

\section{Podozamites latipennis Heer.}

Taf. II. Fig. 6.

Das Blatt länglich, am Grunde kaum verschmälert, der Mittelspindel mit einer breiten Basis aufsitzend. Die parallelen Nerven dicht, fein.

In den rothen Perucer Schieferthonen bei Liebena u nur in dem abgebildeten Exemplare.

Durch die bedeutende Grösse und die nicht verschmälerte, breit aufsitzende Basis ist dieses Blatt besonders charakterisirt. Heer's Pod. latipennis (Fil. grönl. S. 42. Taf. XIV.) stimmt mit dem letzteren gut überein.

Ob auch die westphalische Art Zamites nervosus Hosius u. M. (Fl. Westf. Taf. XXVI. 203) mit der Pod. latipennis specifisch gleich ist, kann ich nicht entscheiden. Verwandt sind sie sicher.

\section{Podozamites longipennis $\mathrm{m}$.}

Taf. II. Fig. 7.

Das Blatt lineal, mit parallelen Rändern, am Grunde mässig verschmälert, jedoch nicht mit einem deutlichen Stiele beendet, lederartig. Die Blattfläche mit groben, seicht hervortretenden, lockeren Nerven gestreift.

In den rothen Perucer Schieferthonen bei Li e b e $\mathrm{n}$ a u nur in dem abgebildeten Exemplare.

Diese Blattart zeigt wieder alle Merkmale einer Podozamites, durch die lang verschmälerte Basis ist sie von der vorhergehenden Art, durch die bedeutende Grösse und grobe, locker stehende Nerven von den folgenden Arten gleich verschieden. Am Blattrande scheinen die Nerven viel feiner zu sein.

Diese sowie die vorhergehende Art könnte vielmehr der Gattung Z a mites als P o d o z a mites hinzugefügt werden. 
Podozamites Eichwaldi (Schimp.) Heer.

Taf. II. Fig, 9, 10, 23.

Blätter lanzettlich, in der Mitte am breitesten, vorne stumpf, am Grunde in einen dicken, kurzen Stiel verschmälert, lederartig. Die Blattfläche fein, dicht und gleichmässig genervt.

In den weisslichen Perucer Thonen bei $\mathrm{K}$ u ch elbad ziemlich häufig.

Diese Blätter sind der folgenden Art dem ganzen Aussehen nach ziemlich ähnlich, sie sind aber viel grösser und in der Mitte sehr breit. Der Blattstiel ist undeutlich abgetheilt. Die Streifung der Blattspreite ist dieselbe, wie bei der folgenden Art.

Von der Pod. Eichwaldi (Schimp.) Heer kann ich unsere Blätter nicht unterscheiden, sollen sie aber als Species oder Abart der folgenden Pod. lanceolatus angesehen werden, das lässt sich auf dem Kuchelbader Fundorte nicht so leicht ermitteln. (Siehe G e y le r, Jura-Pflanzen Japan's S. 229, oder H e e r', Fl. Spitzb. S. 36.)

\section{Podozamites lanceolatus Heer.}

Taf. II. Fig. 11-19, 24.

Blätter lineal, vorne und an der Basis allmälig verschmälert und hier in einen kurzen, geraden Blattstiel abgetheilt, stumpflich, ganzrandig, lederartig. Die parallelen Nerven dicht, gleichmässig dick.

In den grauen Perucer Thonen bei Kuchelbad und in den röthlichen Schieferthonen bei Liebena u gemein. Bei Kuchelbad giebt es Schichten, wo diese Blätter in Menge ganze Platten bedecken (Fig. 24).

Die gewöhnliche Grösse und Form dieser Blätter stellt uns Fig. 13 dar; häufig sind sie aber viel länger, nur selten dagegen sehr klein und kurz, so wie z. B. bei Fig. 11. Die Streifung der Blattfläche ist fein und dicht, der Blattstiel ist überall deutlich abgetheilt und nicht selten seitwärts gedreht, was durch das Aufsitzen einem grösseren gefiederten Blatte wohl zu erklären ist. Ähnlich gedrehte Blattstiele haben auch die Blattfieder der lebenden Zamien.

Podozam. lanceolatus Heer aus den mesozoischen Schichten (Nathorst, Fl. v. Bjuf Taf. XVI. 2-7) unterscheidet sich von unseren Blättern nicht. Sie sind in demselben Grade veränderlich wie die böhmischen Kreideblätter (Geyler, Foss. Pflanzen aus der Juraform. Japans). Von den Heer's Blättern in Flora arctica weichen unsere Blätter dadurch ab, dass sie etwas kleiner, schmäler und länger sind. In dieser Hinsicht wären sie auf die Pod. minor Heer passender. Die letztere Art ist aber vom Heer nur in einem einzigen Blatte beschrieben und sonach für eine Vergleichung ungenügend.

\section{Pod ozamites pusillus m.}

Taf. II. Fig. 20, 21, 22, 24a.

Blätter klein, rundlich-elliptisch, vorne und unten abgerundet, nicht selten im unteren Drittel am breitesten, mit einem kurzen aber immer deutlichen Stiele der gemeinsamen Spindel aufsitzend, fein gleichmässig parallel genervt.

In den weisslichen Perucer Thonen bei Ku chelbad häufig.

In denselben weissen oder grauen Thonen des Kuchelbader Fundortes, wo die vorhergehende Art so häufig vorkommt, sind auch nicht selten kleine Blättchen zu finden, die viel mehr einer kurzen Schuppe als einem Blatte ähnlich sind. Bei einer näheren Untersuchung finden wir, dass sie auf dieselbe Weise gestreift, ebenso gestielt sind und dass sie dieselbe lederartige Beschaffenheit zeigen wie die Pod. lance olatus und P. Eichwaldi, so dass man leicht alle diese drei Formen unter einer Art zusammenfassen könnte. Das Fragment Fig. 22 zeigt drei Blättchen, welche noch der gemeinsamen Spindel aufsitzen, so dass nicht zu zweifeln ist, dass alle bereits genannten Blattformen nur Blattfieder eines grösseren Blattes sind. Pod. pusillus wäre die geringste Art unter allen bis jetzt bekannten Arten von ihrer Verwandtschaft. Pod. Reinii Geyler (l. c.) aus Japan gleicht der P. pusillus vollkommen, sie ist nur grösser als diese.

\section{Nilssonia boh emica m.}

Taf. II. Fig. 25-28.

Blätter lang-lineal, mit parallelen Rändern, vorne stumpf abgerundet, an der Basis verschmälert, ganzrandig oder seicht eingeschnitten bis lappig getheilt, derb, lederartig. Der Mittelnerv gerade, sehr stark, in der 
Blattspitze merklich verdünnt und hier kurz auslaufend, stark hervortretend. Die Secundärnerven einfach, parallel und sehr dicht verlaufend.

In den Perucer Thonen bei $\mathrm{Ku}$ chelbad nicht selten.

Die abgebildeten Blätter zeigen eine sehr feste, lederartige Natur; die Blattränder sind ein wenig umgerollt. Ganzrandige Exemplare scheinen viel häufiger vorzukommen; die Segmentirung der Blattspreite geschieht besonders an der Blattspitze, wie bei Fig. 28. Bei Fig. 27 sieht man dagegen eine ganzrandige, nicht gelappte Blattspitze. Das Blatt Fig. 26 ist am Grunde vollständig erhalten, der Blattstiel ist jedoch abgebrochen. Der Primärnerv ist ungewöhnlich stark und tritt auf der Rückseite des Blattes scharf hervor. Besonders auf dem Blatte Fig. 28 ist zu sehen, wie der Mittelnerv aus der Blattspitze ausläuft. Die Secundärnerven stehen sehr dicht nebeneinander und zwischen je zweien von denselben ist noch ein sehr feiner Mittelnerv wahrzunehmen.

Nilssonia Johnstrupi Heer aus der Kreide Grönlands (Fl. grönl. 2. Th. S. 44. Taf. VII. 1-6) ist unserer $\mathrm{Nil}$. bohemica am nächsten verwandt, doch sind unsere Blätter viel länger und schmäler.

Nils. polymorpha Schenk. aus den mesozoischen Schichten scheint mir von der böhmischen KreideNilssonia specifisch nicht verschieden zu sein. Die mesozoische Art kommt nur häufiger in segmentirten Formen vor, ist aber zweifellos ein direkter Vorgänger der Kreide-Art.

Zamites familiaris Corda's (Reuss, Versteiner. der böhm. Kreideform. 1845) ist eine sehr zweifelhafte Cycadee. Das Original Corda's (Taf. 49. Fig. 10, 11) zeigt einen quergebrochenen Zapfen, auf welchem von einer dicken Centralspindel spärliche, zur Basis verschmälerte, oben abgerundete Schuppen abstehen. Die Schuppen sind aber so ungünstig abgedrückt, dass man die Form ihrer Schildchen nirgends sehen kann. Dieses Zapfenfragment kann so gut eine Zamiee wie eine Sequoia sein; nur besser erhaltene Exemplare köonnen hier noch entscheidend sein.

\title{
Coniferae.
}

\section{Taxaceae.}

\section{Dacrydium densifolium m.}

\author{
Taf. XII. Fig. $1-4$.
}

Einfache Ästchen mit s ehr dichten, spiralig angeordneten, langen, dem ganzen Verlaufe nach gleich dicken, vorne kurz zugespitzten, einnervigen, geraden oder nur am Grunde gekrümmten, steifen Blättern.

In den Teplitzer Schichten bei Raudnic (H. Zahálka) und Choceñ (H. Barvír) nicht selten.

Im weissen oder grauen Kalksteine der bereits genannten Schichten bei Kaudnic kommen nicht selten ziemlich lange, beblätterte Ästchen vor, welche sich sogleich von allen Sequoien dadurch unterscheiden, dass ihre Blätter auffallend dicht und beinahe gerade vorwärts gerichtet sind. Das Ästchen Figur 2 gibt uns über die Beschaffenheit dieser Überreste die beste Belehrung. Dasselbe ist oben und unten in der Mitte gebrochen, wodurch einige Blätter so quergebrochen sind, dass ihr viereckiger Durchschnitt ihre ehemalige vierseitige Form am besten veräth. Dem zufolge entspricht die Mittelfurche der meisten Blattabdrücke einer Seitenkante des Blattes. Oben und unten auf unserem Ästchen sind die Blätter bedeutend kleiner als diejenigen der Mittelpartie und sind anch mehr gebogen. Die scharfen Contouren und die plastisch vertiefte Mittelfurche der Blätter weist auf ihre feste Consistenz hin. Die mittlere Partie der Abbildung Fig. 2 ist ein Abdruck der Aussenseite eines Ästchens; hier sieht man sehr deutlich, wie die Blätter dicht in regelmässigen Parastichen angeordnet sind. Die Blätter selbst sind im ganzen Verlaufe gleich dick, vorne sehr kurz zugespitzt und vom nicht verbreiteten Grunde kurz herablaufend.

Das Ästchen Fig. 3 stammt auch von Raudnic her. Dasselbe ist wieder einfach und gerade, hat aber am Grunde bedeutend verkleinerte und mehr gekrümmte Blätter als die höher stehenden. Dieses Ästchen ist vielleicht ein Seitenästchen eines anderen Zweiges, mit welchem es mit der verschmälerten Basis in Verbindung stand. Die höher stehenden Blätter sind wieder sehr dicht, beinahe gerade und ein wenig von der Achse abstehend. In der Abbildung Fig. 4 ist eine Partie des letzteren Abdruckes vergrössert dargestellt. 
Das Ästchen Fig. 1 von Choceň ist auch von der Oberfläche abgedrückt und zeigt demnach schön die regelmässige parastychische Anordnung der Blätter.

Diese Conifere kann der äusseren Ähnlichkeit nach am ehesten mit einer Sequoia verglichen werden, doch sind bei keiner bis jetzt bekannten Sequoia die Blätter so dicht, lang und nirgends so gerade vorwärts gerichtet. Auch sind überdies alle Blätter der Sequoien am Grunde bedeutend verbreitet.

Mit dem besten Erfolge konnte ich die beschriebenen Ästchen mit einigen Arten der Gattung Dacrydiu m vergleichen.

D. elatum aus O. Indien hat zwar etwas kleinere, schmälere aber ganz ähnlich geformte und beblätterte Ästchen. Die Blätter sind ebenso dicht in Parastichen geordnet, sind gleich dick, vierseitig, kurz, scharf zugespitzt und schief abstehend. Die unten und oben stehenden Blätter sind gleichfalls kleiner und merklich gekrümmt. Die Seitenästchen sind lang beblättert und nicht verzweigt wie bei unseren Ästchen.

Verzweigte Äste des D. densifolium könnten seine Stellung unter der Gattung Dacrydium noch bestätigen, da die dickeren Zweigtheile der meisten Dacrydium-Arten, speciell aber des D. elatum nur mit kleinen schuppenförmigen Blättern bekleidet sind.

\section{Podocarpus cretacea m.}

Taf. XII. Fig. 5-11.

Blätter lineal, gegen die Spitze hin allmälig verschmälert, im unteren Drittel am breitesten, ganzrandig, lederartig, am Rande mässig umgerollt, am Grunde kurz verschmälert, nicht gestielt. Der Mittelnerv gerade, nicht stark, der ganzen Länge nach gleich dick, nicht hervortretend. Die Blattspreite sehr dicht und fein längsgestreift.

In den Perucer Schieferthonen bei Melník an der Sázava häufig.

In den hellgrauen Schieferthonen dieses Fundortes, welche voll und voll von verschiedenen Dicotylenblättern sind (am häufigsten jedoch die Myrica serrata Vel. Fl. d. böhm. Kreidef. II), findet man nicht selten schmale, lange Blattabdrücke, deren Tracht auf ihre ehemalig lederartige Beschaffenheit hinweist. Sie sind von einem nicht starken, aber der ganzen Länge nach gleich dicken Mittelnerv durchzogen, welcher sich hie und da in einem dunkel gefärbten und so von der übrigen Blattfläche auffallend abgegrenzten, breiten Streifen dahinzieht. Man kann auf einigen Exemplaren sehr deutlich wahrnehmen, wie die beiden Blatthälften ein wenig gewölbt sind, so dass die Blattränder scharf in den Schiefer eindringen. Unter der Luppe sind auf der Blattoberfläche sehr zahlreiche, parallele, aber höchst feine Längsstreifen wahrzunehmen (siehe die Vergrösserung Fig. 5). Die Grösse variirt bedeutend; das grösste Blattstück zeigt die Fig. 10. Das Blatt Fig. 6 ist in der gewöhnlichsten Grösse und Form restaurirt.

Die Blättchen haben auf einigen Exemplaren gut erhaltene Basis, welche eiförmig abgerundet ist, aber niemals in einen Blattstiel übergeht. Die grösste Breite erreichen die Blätter im unteren Drittel, von wo sie sich gegen die Spitze hin allmälig verschmälern.

Die Gattung Podocarpus hat so ähnliche Blätter, dass die unserigen gut zu derselben hingezogen werden können. In dieser Beziehung nenne ich vor allem P. elongata Her. aus Cap der G. Hoffnung und P. sinensis aus China, von welchen die erstere besonders durch die Blattform und Blattstructur, die letztere durch die Blattgrösse der P. cretacea nahesteht. Bei P. elongata sind die Blätter ebenso am Grunde am breitesten und von da gegen die Spitze hin allmälig verschmälert. Der Primärnerv ist auch gleichmässig dünn; zu beiden Seiten desselben laufen ähnliche, sehr zahlreiche, aber höchst feine Parallelstreifen, welche bei anderen Podocarpus-Arten entweder unregelmässig verlaufend oder unḍeutlich sind. Diese Streifen entsprechen den Stomatenreihen in der Epidermis. Die Blätter der P. elongata sind ebenfalls ungestielt wie die der P. cretacea.

Charakteristisch für die meisten Podocarpus-Blätter und in unserem Falle auch für die P. cretacea ist der Mittelnerv, welcher ziemlich dünn, in gleicher Dicke verlaufend, wenig hervortretend und auf der Unterseite durch eine anders gefärbte, im trockenen Zustande aus mehreren stärkeren Nerven zusammengesetzte Längszone läuft. Auf der Oberseite ist das Blatt in der Mitte mässig vertieft und in den beiden Seitenhälften gewölbt, an Rändern mehr oder weniger umgerollt.

Diese alle Merkmale finden sich bei keiner anderen Conifere so ausgezeichnet entwickelt wie bei der Gattung Podocarpus. Demnach wären aber unsere Blätter die erste ziemlich verlässlich bestimmte Art dieser Gattung zur Kreidezeit. 


\section{Araucarieae.}

\section{Cunninghamia elegans Corda.}

Taf. V. Fig. 1, 7. VI, 5. IV. Fig. 5.

Dicke, gerade, einfache oder wenig verzweigte Äste mit schief abstehenden, linealen, an der Basis kurz, gegen die Spitze allmälig und fein verschmälerten, ganzrandigen, flachen, lederartigen Blättern. Durch die Mitte der Blattspreite laufen dicht nebeneinander 5 deutliche, parallele Nerven, von denen der mittlere etwas stärker ist. Die Blattspreite zuweilen seitwärts gebogen. Blattpolster der jüngeren Zweige länglich oder rundlich-rhombisch, vorne stumpf abgerundet, oben mit einem Grübchen, unterhalb dessen durch die Mitte des Polsters eine Rinne herabläuft.

In den Perucer Schieferthonen bei Mšeno und Peruc gemein, bei Jinonic, Lidic und in einer Conifëren-Schicht im Dorfe Vyšerovic mit Widdringtonia Reichii nicht selten.

Schön erhalten und nicht selten in grösseren Ästen kommt diese typische Conifere in den Schieferthonen bei Peruc und Mšeno vor, welche Fundorte übrigens von einander nicht besonders weit entfernt sind. Von hier rührt auch Corda's Original (Reuss, Versteiner. S. 93. Taf. 40. Fig. 29-31) her. Eine sehr gemeine Pflanze ist sie auch in den bröckeligen, gelbgrauen Schieferthonen auf Vydovle bei Jinonic, wo ihre Zweige eine ganze Schicht erfüllen. In den Schiefern bei Vyšerovic, besonders im letzten Steinbruche vom Dorfe, wo eine so reichliche Flora eingebettet ist, fehlt sie vollkommen, während sie im ersten Steinbruche und im Dorfe selbst zu den häufigsten Pflanzenabdrücken gehört; auch in den Kuchelbader Thonen findet man sie nicht.

Mit einer anderen Conifere kann diese Art niemals verwechselt werden. Ihre Zweige sind verhältnissmässig dick, so dass z. B. dünnere Exemplare als dasjenige der Fig. 5 kaum zu finden wären. Diese Äste haben stets deutlich hervortretende Blattpolster, die in den meisten Fällen, wie bereits Fig. 5 zeigt, sehr verlängert, vorne abgerundet und vertieft erscheinen. Die Mitte eines jeden Polsters ist von einer Rinne durchzogen, welche dem Polsterkiele entspricht. Höchst schön ausgebildet und besonders stark verlängert sind diese Blattpolster auf Corda's Originale (l. c.) erhalten. Die Polster des Zweiges Fig. 1 sind fast rundlich und dicht nebeneinander in Parastichen geordnet. Da dieselben in ähnlicher Form auch auf jüngeren, noch beblätterten Ästen vorkommen, so ist nicht anzunehmen, dass sie nur den älteren Zweigtheilen eigen sind. Es ist umgekehrt vielmehr wahrscheinlich, dass sie auf älteren Zweigen spärlicher und mehr verlängert sind, wie es am besten Corda's Zweig beweist. Ich halte deshalb dafür, dass diese rundlichen Polster den Zweigen angehören, welche seitlich auf anderen entstanden und von einem langsamen Wachsthume waren, während diejenigen mit verlängerten Blattpolstern den üppigen, zu meist endständigen Sprossen gehören. Ähnliche Verhältnisse kommen bei den meisten Coniferen vor.

Die Blätter sind lineal, bald ziemlich schmal, bald wieder breiter; ihre Form in treuer Ausführung sieht man vergrössert bei Fig. 7. Sie sind etwa in der Mitte oder im unteren Drittel am breitesten, allmälig. in eine feine, mehr oder weniger lange Spitze auslaufend, am Grunde beinahe abgerundet. Sehr häufig findet man die Blattspitzen seitwärts gerichtet, so besonders auf Cordas's Cunninghamia planifolia l. c. Taf. 50, Fig. 1-3. Dieser Erscheinung nach zu urtheilen, waren die Blätter der Cenomaner C. elegans auf dieselbe Weise zweizeilig geordnet und einseitig gerichtet, wie dies noch bei der Chinesischen Cunningh. sinensis der Fall ist.

Die Blätter der C. elegans waren fest und lederartig, was aus ihren scharfen und starren Abdrücken hervorgeht. Auf einigen gut erhaltenen Stücken ist auch ihre Nervation wahrzunehmen, so z. B. auf der beblätterten Zweigspitze Figur 5, Tafel IV. In der Mitte der Blattspreite finden wir zumeist 5 dicht und parallel verlaufende, dünne Nerven, von denen der mittlere der stärkste ist (Figur 7, Tafel V.). Beiderseits der äussersten Nerven 'bleibt aber noch eine breite Zone zurück, welche bis zum Rande ungestreift ist. Diesen Verhältnissen entspricht in der besten Weise auch die lebende C. sinensis. Die Blätter derselben sind ebenfalls in drei gleiche Zonen getheilt, von denen die mittlere genervt und von einem starken Mittelnerv durchzogen ist, während die beiden seitlichen glatt und mit einer starken, harten Epidermis-Schicht versehen sind.

Die Zähnunng des Blattrandes bei C. sinensis ist so fein, dass dieselbe, wenn sie selbst an den Blättern der C. elegans vorhanden wäre, im groben Schiefer unkennbar sein müsste.

Cunninghamia oxycedros Presl (Sternberg, Vers. II. p. 203. Taf. 49, Fig. 1) unterscheidet sich 
von C. elegans gar nicht, als ich nach dem Originale urtheilen kann. Alle Merkmale der Blätter stimmen mit jenen der letzteren überein. Das männliche Zäpfchen, in welches das Ästchen endet, ist scharf von den unten stehenden Blättern abgetheilt und zeigt besonders am Rande die breiten Schuppen, welche uns an jene der männlichen Zapfen der C. sinensis sofort erinnern. Die Übereinstimmung dieses Zäpfchens und der Blätter der C. elegans mit entsprechenden Theilen der lebenden C. sinensis berechtigt uns die provisorische Benennung Cunninghamites in den Gattungsnamen Cunninghamia umzuwandeln.

Cunninghamites elegans in Heer's Flora von Moletein und Grönland, Cunninghamia planifolia Corda's (l. c.) und vielleicht auch Cun ninghamites squammosus Hosius, aus den Kreideschichten Westfalens, von Aachen und Quedlinburg (Heer) gehören wahrscheinlich derselben Art an. Die Länge und Breite der Blätter variirt ins Unendliche, was am besten auf der böhmischen Pflanze zu sehen ist.

Die übrige Synonymik siehe in Schenk's Palaeontologie S. 283.

\section{Cunninghamia stenophylla $\mathrm{m}$.}

Taf. V. Fig. 2, 4, 10, 16.

Dicke, gerade, ziemlich reichlich verzweigte Äste, mit schmal-linealen, schief abstehenden, f ein und allmälig zug.espitzten, lederartigen, halb so grossen und noch kleineren Blättern als bei der vorhergehenden Art. Der Primärnerv deutlich hervortretend, nicht stark, gerade; beiderseits derselben eine vertiefte mittlere Partie, welche von den randläufigen glatten, breiten Längszonen abgegrenzt ist. Die Blattpolster sind zwar kleiner aber von derselben Form wie jene der vorhergehenden Art.

In den Perucer schwarzgrauen Schieferthonen bei Landsberg, spärlich bei Vyšerovic, Lipenec und im Pläner am Weis s en Berg.

Einen sehr schönen Zweig dieser Art aus der Umgebung von Landsberg stellt uns die Fig. 16 dar. Andere Stücke aus dieser Localität besitzen wir nicht. Der Zweig ist rechts in zwei Seitenäste getheilt, von denen der untere herabgebogen, jedoch nicht gebrochen ist. Der Zweig ist von der Oberfläche abgedrückt, so dass die Blattpolster des Zweiges nur am Grunde in geringer Anzahl vorhanden sind. Die Blätter sind dicht, schief abstehend, schmal pfriemlich, fein zugespitzt.

Die zwei Exemplare Fig. 2, 10 rühren aus den weichen, grauen Schieferthonen bei Lipenec her. Einzelne Ästchen der beiden Bruchstücke gehören einem vollständig zusammenhängenden Zweige an, was aus der Richtung derselben, sowie aus den abgebrochenen Blättern zu schliessen ist. Die Ästchen sind in der Mitte gebrochen, so dass die Blattpolster überall sehr deutlich hervortreten. Die Blätter sind von derselben Form, wie die der Landsberger Pflanze.

Diese Pflanzenüberreste müssen jedenfalls zu derselben Gattung gezogen werden, wie die vorhergehende Art, welcher sie in allen Merkmalen, jedoch in Miniatur gleich kommen. Die Blattpolster sind dieselben, diejenigen der Fig. 10 sehen besonders Corda's Zweige von C. elegans ähnlich. Die Blätter sind ebenfalls gleich gestaltet, sind aber viel schmäler und zweimal und mehr kleiner, so dass der beblätterte Zweig vom Aussen gesehen eine andere Tracht zeigt als C. elegans. Der Mittelnerv liegt in einer vertieften Mittelzone in derselben Weise wie bei C. elegans. Bei Fig. $4_{a}$ sind zwei Blättchen in natürlicher Grösse, bei Fig. 4 ein Blatt vergrössert dargestellt.

Es ist möglich, dass die C. stenophylla nur eine gracile, kleinblätterige Form der vorhergehenden ist, da sie aber so extrem entwickelt ist, so muss sie so lange für eine eigene Art angesehen werden, bis zwischen beiden deutliche Uebergangsformen entdeckt werden.

\section{Taxodineae.}

\section{Geinitzia cretacea Ung.}

Taf. VIII. Fig. 3, 11, 12. Taf. IX. Fig. 1, 2.

Schlanke, ziemlich dicke, wenig verzweigte Aeste, welche entweder mit spiralig stehenden, dünnen, sichelförmig gekrümmten, vierkantigen, fein zugespitzten Blättern oder mit eingedrückten, rhombischen, vorn abgerundeten Blattpolstern umkleidet sind.

In dem Weissenberger Pläner eine ziemlich verbreitete Conifere, bis jetzt aber nur in Zweigen bekannt; so an Weissen Berg, bei Hrádek und Citor bei U. Beřkovic. 
Die Zweige (Fig. 1, 2) sind schlank und lang, verhältnissmässig spärlich getheilt, die Seitenäste stehen unter spitzen Winkeln ab. Das Zweigstück Fig. 1. gehört einem älteren Zweige an, dasselbe hat vier Seitenäste, von denen nur der zur rechten Seite stehende länger erhalten ist, die übrigen aber gleich am Grunde abgebrochen erscheinen. Die ganze Oberfläche des Zweiges ist mit schönen, in spiraliger Stellung angeordneten Blattpolstern bedeckt, die ziemlich tief im Gesteine eingesenkt sind. Dieselben sind im Umrisse rhombisch, vorn abgerundet und daselbst durch einen tiefen Eindruck (siehe die vergrösserte Partie Fig. 12.a), welcher der abgegliederten Basis des Blattes entspricht, ausgezeichnet, oder es ist das Innere des Polsters noch mit Blattsubstanz ausgefühlt und ist in deren Mitte eine Gefässbündelspur bemerkbar (Fig. 12.). Diese Blattsubstanz lässt sich leicht mittelst einer Messerspitze aus der Polsterhöhlung entfernen. Diese Erscheinung ist nämlich so zu erklären, dass die Reste der Blattbasis lange Zeit am Zweige - wiewohl schon verwest - stehen bleiben; in Folge dessen findet man auch auf dem alten und anders blattlosen Zweige Fig. 1. hie und da noch Blattreste. Noch auffallender ist es auf dem Zweige Fig. 2. Diese Eigenschaft der Geinitzia, auf welche schon He er (Fl. von Kvedlinburg) hingewiesen hat, ist auch für einige lebenden Coniferen charakteristisch, so besonders für die Araucaria excelsa, welche übrigens der G. cretacea habituell ähnlich ist. Die Blattpolster stehen sehr dicht beisammen, woraus zu schliessen ist, dass die Aeste reichlich und dicht beblättert waren. Die Fläche eines Blattpolsters ist gewöhnlich glatt, gewölbt, sehr selten ist der Mittelkiel durch eine seichte Rinne angedeutet. Dieses Merkmal ist beachtenswerth, weil es für die Unterscheidung des Blattpolsters von Sequoia Reichenbachi wohl geeignet ist. Heer (l. c.) erwähnt dagegen eine Mittelrinne bei ähnlichen Blattpolstern seiner G. formosa. Die Blattpolster sind durch hervortretende Grenzleisten von einander getrennt (F. 12). Ihre Form variirt wenig, sie ist nur auf jüngeren Aesten mehr verlängert, was z. B. bei dem Zweige Fig. 2 auf den oben stehenden zwei Seitenästen zu sehen ist. Die Rinde ist zwischen den Polstern auf ältern Zweigen (Fig. 1) hie und da grob quergerunzelt.

Die Blätter stehen beinahe rechtwinkelig ab (Fig. 3), sind auffallend dünn und starr, woraus auf ihre ehemalige derbe Beschaffenheit zu schliessen ist. Sie sind stark sichelförmig gekrümmt, gleich lang, so dass sie sich in gleicher Linie mit ihren Spitzen untereinander berühren und dadurch den beblätterten Zweigen eine sonderbare Tracht darbieten, durch welche sogleich eine Geinitzia von einer Sequoia unterschieden werden kann:

Die Blätter waren vierkantig, die Mittelfurche eines Blattabdruckes entspricht demnach einer Seitenkante des Blattes. Die Blattbasis ist sehr wenig herablaufend, was schon aus der beinahe rundlichen Form der Blattpolster hervorgeht. Dieses Merkmal widerspricht der Beschreibung und den Abbildungen der G. formos a Heer (1. c.). Ich habe ein beblättertes Zweigbruchstück (Fig. 11) auf Grundlage des Aestchens Fig. 3. vergrössert und theilweise restaurirt abgebildet.

Auf dem Zweigbruchstücke Fig. 3 sind neben den zahlreichen sichelförmigen Blättern, welche theils dem Zweige aufsitzen, theils abgebrochen sind, noch tiefe, rhombische, Höhlungen wahrzunehmen, welche im Durchschnitt die vierseitigen ins Gestein eindringenden Blätter darstellen.

Alle hervorgehobenen Merkmale der beschriebenen Zweigüberreste stimmen mit einer Geinitzia überein. Es sind dieselben, welche schon längst aus Böhmen als G. cretacea Unger angegeben wurden (siehe noch Schenk's Handbuch der Pal.). Wie viel diese Art von der Heerischen G. form os a verschieden ist, kann ich nicht feststellen.

Corda's Pinus exogyra (l. c. Taf. 48. Fig. 16-18) ist nur die Geinitzia cretacea.

\section{Echinostrobus squammosus $m$.}

Taf. VI. Fig. $3,6,7,8$.

Zweige mit wechselständigen, stumpf beendeten Seitenzweigen. Die schuppigen Blätter dicht angedrückt, rhombisch, kurz bespitzt, sich deckend, auf der Oberseite fein gestreift, auf dünnen Zweigen decussirt, auf den dickeren spiralig geordnet.

In den Perucer Schieferthonen bei Vyš erovic nicht häufig. Diese sonderbare Pflanze liegt uns in den drei abgebildeten Fragmenten vor.

Fig. 6 ist ein Zweigfragment, welches mit drei jüngeren, stumpf abgerundeten Zweigsprossen endet. Die Oberfläche des Fragmentes ist beinahe glatt, die Schuppen stehen gar nicht ab. Die letzteren treten in ihren Contouren scharf hervor, am unteren, dickeren Theile des Zweiges sind sie spiralig gestellt, auf den jungen Zweigen geht aber diese Stellung in eine decussirte über. Dieses Zweigstück sowie die Fig. 7, 8 ist nur ein Abdruck der Oberfläche eines Zweiges. Das Fragment Fig. 3 scheint aber ein wirklicher Zweig zu sein, indem er tief im Gesteine eingesenkt ist und deutliche Überreste des ehemaligen Holzes enthält. 
Dasselbe Zweigfragment (Fig. 3) stellt ein älteres Stadium dieser Art vor. Die Schuppen haben wieder auf dem dickeren Theile des Zweiges eine spiralige, auf den abgebrochenen dünneren Seitenästen eine decussirte Stellung.

Besonders gut erhalten sind die Schuppen auf dem Fragmente Fig. 8. Dieses besteht aus einem dicken Zweigtheile, welcher aber in der Mitte gebrochen ist; rechts theilt sich von demselben ein kurzes, links ein längeres und dünneres Seitenästchen, beide sind aber an ihren Enden abgebrochen. Die Schuppen auf dem dicken Mittelfragmente sind gross, rhombisch, fein zugespitzt, in einer deutlichen, spiraligen Anordnung. Die Schuppen der Seitenästchen sind wieder paarweise decussirt. Alle diese Schuppen sind dicht angedrückt, ein wenig gewölbt und auf der ganzen Oberfläche höchst fein und dicht gestreift; die Streifen sind in der Schuppenspitze zusammenlaufend.

Das Fragment Fig. 7 besteht aus einem Zweigstücke, welches oben und unten abgebrochen ist und links ein seitliches Ästchen trägt. Die oberen abgebrochenen Zweigtheile zeigen freie, fein zugespitzte Schuppen, welche wie die übrigen unten stehenden wieder fein, dicht gestreift und ziemlich gewölbt sind.

Stellen wir uns aus den vorliegenden Fragmenten einen ganzen Zweig restaurirt vor, so erhalten wil ein Pflanzenbild von ganz eigenthümlichem Aussehen. Die Hauptzweige wären dick, die seitlichen unregelmässig verzweigt, mehr oder weniger lang und stumpf an Enden abgerundet. Die Zweige wären cylindrisch und da die breiten Schuppen dicht an einander liegen, beinahe glatt.

Unter den lebenden Coniferen ist freilich keine Analogie für unsere Pflanze zu finden, im fossilen Pflanzenreiche begegnet man aber ziemlich ähnlichen Typen. Ich nenne z. B. die Echinostrobus Sternbergi Schimp. (Traité pal. veg.), welche ebenso rundliche, wechselständige, dicke, stumpf beendete und schuppige Zweige besitzt. Das vergrösserte Ästchen Schimpers Fig. 23 Pl. LXXV. hat dieselbe Form wie die Seitenästchen unserer Fragmente; auffallender Weise sind auf demselben die Schuppen auch decussirt abgebildet.

Solange zu unseren Fragmenten nicht ein Zapfen gefunden wird, können dieselben wohl nur zur Gattung Echinostrobus gezählt werden.

Annähernd ähnliche Form haben auch einige Arten der Gattung Brachyphyllum, z. B. Br. mammilare Brongn.

Die spiralige Stellung der Schuppen, welche auf jungen Zweigen in eine decussirte übergeht, erinnert an Saporta's Gattung Palaeocyparis, welche sämmtlich decussirte, anders aber ähnliche Schuppen besitzt. Unger, Schimper, Brongniart verbinden die Gattung Palaeocyparis mit Echinostrobus und Arthrotaxites. Meiner Meinung nach steht jedenfalls Saporta's Palaeocyparis den Gattungen Brachyphyllum und Echinostrobus sehr nahe. Unsere Echinostrobus squammosus kann, was die Anordnung der Schuppen betrifft, einen Übergang zwischen den Taxodineen und Cupressineen bilden. Saporta's Palaeocyparis hat aber einen Cupressineen-Zapfen.

Die erwähnten Gattungen gehören-der Jura-Zeit an, wodurch unser cenomaner Echinostrobus s quammosus um so interessanter wird.

\section{Cyparissidium gracile Heer.}

Taf. VIII. Fig. 7, 14, 15, 17.

Ruthenförmige, mehrmals getheilte, cylindrische Äste. Schuppen rhombisch lanzettlich, kurz, stumpf beendet, mässig gewölbt, nicht gestielt, nervenlos, spiralig angeordnet und dem Zweige angedrückt.

In den Plänerschichten bei Slavětín und am Weissen Berg.

Besonders belehrend und gut erhalten sind die Zweigfragmente Fig. 7, 14 vom Weissen Berg. Auf denselben sieht man vor allem den mittleren, ziemlich dicken Zweigtheil, welcher theilweise noch mit Holz erfüllt ist, theilweise aber mehrere viereckige, mit einem erhabenen Rande umgebene Felder zeigt, welche nach den Schuppen zurückgeblieben sind. Von diesem centralen Zweige entspringen 11. Seitenäste, welche leider grösstentheils abgebrochen sind. Einige von diesen Ästen sind jung, dünn, kurz, andere stärker und älter. Die Art der Verzweigung ist zwar sehr unregelmässig, man sieht aber, dass immer mehrere Zweige einander genähert sind, wodurch der Zweig eine besondere Tracht bekommt. Dieselbe Verzweigung zeigt der Zweig He er's in Fl. grönl. 2. Th. Taf. I. Fig. 2.

Das Bruchstück Fig. 7 stellt einen jüngeren, ruthenförmig getheilten Zweig dar. Die Schuppen der älteren Zweigtheile sind breiter, beinahe rhombisch, die der jüngeren lanzettlich, etwa in der Mitte am breitesten, vorne stumpflich oder sehr kurz zugespitzt. Besonders deutlich ist ihre Form auf dem kleinen Bruchstücke von Slavětín Fig. $15 \mathrm{zu}$ sehen. Auf jungen; dünnen Seitenästen stehen sie immer viel dichter beisammen, wie es auch Heer auf seinen Abbildungen (l. c.) andeutet. Die Schuppenspitze ist sehr wenig abstehend, die 
Schuppenfläche glatt, nicht gestreift und mässig gewölbt, der Mittelkiel nur schwach angedeutet. Bei Fig. 17 ist eine Partie des Bruchstückes Fig. 7 nach einem Wachsabdrucke vergrössert ausgeführt.

Die ruthenförmige, unregelmässige Verzweigung der langen und allseitig auseinanderstehenden Äste dieser Conifere ist sehr charakteristisch und nicht wenig an jene der lebenden Arthrotaxis cupress o id es erinnernd.

Auf dem rechts stehenden Zweige Fig. 7 bei a) sieht man neben der obersten Verzweigung ein verdicktes, am kurzen, geneigten Stiele sitzendes Gebilde, in dem noch einige Schuppen wahrzunehmen sind, übrigens ist aber dasselbe schlecht erhalten und in der Mitte abgebrochen. Wahrscheinlich gehört dasselbe einem weiblichen Zapfen an. Die Form der Schuppen, so weit sie erkennbar ist, stimmt mit jener der von Heer beschriebenen Zäpfchen dieser Art ziemlich gut überein.

Unsere Fragmente entsprechen dem Cyparissidium gracile Heer (l. c. und Fl. arct. (I.) Tafel XLIII. (III.) Taf. XIX.) sehr gut. Die typische Verzweigung der Äste und die Form der Schuppen stimmen überein.

Bei dieser Conifere lässt sich nicht annehmen, dass die Schuppen nach Art der meisten Taxodineen auf jüngeren Ästchen in lange, abstehende Blätter umgestaltet sind, weil sie auch auf den jüngeren Zweigtheilen nur in schuppenförmiger Gestalt erscheinen. Habituell sind die Zweige des Cyparissidium gracile der Gattung Echinostrobus nicht unähnlich. Von den verwandten lebenden Coniferen muss vor allem die schon erwähnte Arthrotaxis cupressoides genannt werden.

\section{Cyparissidium pulchellum $\mathrm{m}$.}

Taf. V. Fig. 3, 5, 6, 9.

Zapfen etwa $3^{1 / 1} \mathrm{~cm}$. lang, in der Mitte am breitesten, gegen die Basis und die Spitze hin verschmälert. Schuppen nicht dick, vorne elliptisch, fein zugespitzt, ganzrandig, gewölbt, mit einem hervortretenden Mittelkiele und einigen parallelen Längsstreifen, gegen die Basis stielartig verschmälert, mit 1-2 kleinen Samen.

Im feinkörnigen Sandsteine der Korycaner Schichten bei Kněživka nur in einem Exemplare.

Dieser interessante Zapfen, wiewohl nur in einem Exemplare vorhanden, ist so instruktiv erhalten, dass man auf Grundlage desselben den ganzen Zapfen verlässlich restauriren kann, wie es auch in Figur 5 geschehen ist. Der Zapfen ist in der Mitte der Länge nach gebrochen und zwar in so günstiger Weise, dass auf der einen Hälfte desselben (Fig. 3) die Schuppen in ihrem oberen Umrisse, auf der anderen (Fig. 9) die Basen derselben sammt den Samen zu sehen sind. Die geneigte Lage der oberen Schuppen und das Fehlen der weiteren Schuppen beweist, dass hier der Vordertheil des Zapfens beendet ist, die kurzen und stark abstehenden unteren Schuppen sowie der Stiel auf der Zapfenhälfte Fig. 9 deuten dagegen darauf hin, dass sich hier der Zapfengrund befindet und der Zapfen wohl nicht abgebrochen ist.

Auf der Zapfenhälfte Fig. 3. sind oben zwei Schuppen beinahe vollständig erhalten, die zwei anderen, eine links, die andere rechts habe ich aus dem Gesteine herausgearbeitet; sie sind von gleicher Form, auf der Abbildung mussten sie aber von der Seite gezeichnet werden. Die übrigen Schuppen sind ebenfalls im Gesteine gänzlich vorhanden, auf dem Steinstücke erscheinen sie aber in Folge von Bruch als dunkle, gebogenen Linien. Der obere löffelförmige Theil der Schuppen ist auf der Rückseite gewölbt und neben dem erhabenen Mittelkiele mit einigen Längsstreifen versehen. Die Schuppen sind fein zugespitzt und nicht zu dick, wie nach den seitlichen, quergebrochenen Schuppen Fig. 3 zu schliessen ist.

Auf der anderen Zapfenhälfte Fig. 9 findet man oben matte, negative Abdrücke von vier Schuppen, welche aber grösstentheils am Rande abgebrochen sind. Sehr wichtig und belehrend ist aber die untere Partie dieses Fragmentes. Vor allem befinden sich auf der Stelle a) verschmälerte Basen der Schuppen, welche schmal und mit einer Mittellrinne versehen sind. Unterhalb der letzteren sieht man eine Gruppe von rhombischen Höhlungen, welche den Schuppenbasen entsprechen und hier mit der Centralspindel, die auf der Hälfte Fig. 3 sich findet, in Verbindung waren. In diesen Höhlungen liegt nun hie und da ein recht deutlicher Same von kleiner, verlängerter Form. Ich bin aber nicht im Stande zu entscheiden, ob nur ein Same oder zwei nebeneinander in je einer Höhlung vorhanden waren, da neben dem deutlichen, scharf begrenzten Samen noch etwas in matten Contouren als ein zweiter Same liegt. Es ist möglich, dass hier wirklich zwei Samen hinter je einer Schuppe sich vorfanden, dass aber nur einer von beiden zur Entwickelung gelangte.

Die Form der Schuppen, ihre derbe Beschaffenheit, ihre Anordnung in einem ellipsoidischen Zapfen, die rhombischen Höhlungen nach den Schuppenbasen und die Samen hinter den Schuppen lassen keinen Zweifel 
zu, dass man es hier mit einer Conifere zu thun hat. Der Zapfen und seine Schuppen, welche uns die Fig. 5 , 6 restaurirt darstellt, findet aber kein Analogon in der lebenden Natur. Wäre in der That nur ein Same hinter einer Schuppe, so wäre dieses Merkmal für die systematische Stellung nnseres Zapfens sehr befremdend; wahrscheinlich waren doch zwei Samen vorhanden, da der deutliche Same in der Höhlung immer etwas zur Seite geschoben ist.

Die zahlreichen in spiraliger Ordnung gestellten Schuppen weisen auf die Taxodineen oder Abietineen: besonders auf die Gattung Abies hin. Die Zapfen, welche Heer bei seinem Cyparissidium gracile und Inolepis imbricata (Kreide-Flora der arct. Zone 1884) anfführt, sind im Wesentlichen unserem Zapfen ähnlich und sicher nahe verwandt. Die Schuppen haben annähernd dieselbe vorn rhombische und zugespitzte Form, die Oberfläche der Schuppen ist ebenso gestreift, jedoch nicht gekielt, wie es bei unserem Zapfen der Fall ist. Der einzelne Same hinter je einer Schuppe, welchen Heer nur auf einem ungenügenden Fragmente abbildet, scheint mir in demselben Masse zweifelhaft zu sein wie der einzige Same in den Schuppenhöhlungen nnseres Zapfens. Die schuppenförmigen Blätter auf den Zweigen, mit welchen Heer's Zapfen noch in Verbindung stehen, erklären die Zapfen für eine echte Taxodinee.

Wir haben leider keine Zweige in Verbindung mit dem besprochenen Zapfen gefunden, und so haben wir den letzteren nur auf Grundlage der annähernd gleichen Schuppen mit dem Cyparissidium gracile Heer's der Gattung Cyparissidium untergebracht, indem es immer möglich bleibt, dass es eine selbstständige Gattung ist. Cyparissidium gracile im Weissenberger Pläner spricht theilweise für das Vorkommen dieses Coniferen-Typus in der böhmischen Kreide, welchem vielleicht auch unser Zapfen angelıört. Unmittelbar unter den Weissenberger Schichten liegen die Korycaner Schichten, in welchen das Cyp. pulchellum gefunden wurde.

\section{Cyparissidium minimum $\mathrm{m}$.}

Taf. IX. Fig. 6-7. Taf. X. Fig. 4.

Zweige dünn, reichlich getheilt. Schuppenblätter schmal-länglich, in der Mitte am breitesten, zugespitzt, schwach gewölbt, mit einem dünnen Mittelnerven, spiralig geordnet. Zapfen kugelig, zur Basis verschmälert, kaum $1 \mathrm{~cm}$. im Durchmesser breit. Schuppen breit-eiförmig, vorn in eine kurze Spitze verschmälert, von derber Consistenz, gewölbt und grob längsgestreift, spiralig geordnet.

In den schwarzgrauen Perucer Schieferthonen bei Lan d s berg.

Neben den zwei abgebildeten Überresten von dieser Art liegen in unseren Sammlungen noch mehrere Fragmente kleiner Zweigbruchstücke, welche ähnlich gross und ähnlich gestaltet sind, wie das Exemplar Fig. 4. Dieses stellt uns ein Ästchen dar, welches sich mehrmals unter spitzen Winkeln in dünne, schlanke Seitenäste verzweigt. Die schwarze verkohlte Substanz der Blättchen deutet auf ihre ehemalige feste Beschaffenheit hin. Die Blätter sind länglich, kurz zugespitzt, am Rücken ein wenig gewölbt und einnervig.

Die Schuppen des kugeligen Zapfens sind breit eiförmig, gewölbt, in eine kurze Spitze verschmälert und grob längsgestreift.

Die dünnen Zweige sind einem Widdringtonites (z. B. W. subtilis Heer, Kreidefl. d. arct. Zone) nicht unähnlich, die Blätter sind jedoch zu dicht und laufen nicht so lang herab, wie es bei dem Widdringtonites und bei der echten Widdringtonia der Fall ist. Dass es keine Widdringtonites-artige Pflanze sein kann, beweist deutlich der Zapfen Fig. 7. Derselbe ist zwar oben abgebrochen, die zurückgebliebenen Spitzen der obersten Schuppen ergänzen aber ziemlich treu den äusseren Umriss des Zapfens. Die Schuppen haben dieselbe Form und eine ähnliche Streifung wie die Zapfen, welche nach Heer (l. c.) dem Cyparissidium gracile angehören. Die Vergrösserung Fig. 6 zeigt am besten, wie unser Zapfen Fig. 7 die Zapfen Heer's in Miniatur vorstellen.

Allein die Blätter sind für ein Cyparissidium zu lang und zu dicht dem Ästchen aufsitzend. Ebenfalls die dünnen Zweige und ihre Theilung ähnelt dem Cyparissidium gracile aus dem Weissenberger Pläner sehr wenig.

Ich habe daher diese Conifere mit der Gattung Cyparissidium nur auf Grundlage der gleich gestalteten Zapfen zusammengezogen, die Auffindung anderer Belege dafür muss diese Bestimmung noch bestätigen.

\section{Sequoia Reichenbachi Geinitz sp.}

Taf. VIII. Fig. 9, 8. Taf. IX. Fig. 6a, 12a, 7a, 5a, 14, 13, 12, 10a, 5.

Blätter lang, zur Spitze allmälig verschmälert, sichelförmig gekrümmt, schief vom Zweige abstehend und von einem tiefen Mittelnerven durchzogen, kurz herablaufend. Blattpolster länglich-elliptisch bis rhombisch, 
mit einer deutlichen Mittelrinne. Fruchtzapfen gross, kugelig, Schuppen bis zweimal so lang als die grösste Breite ihrer Schildchen. Sprosse mit geraden, verlängerten, flachen Blättern nicht bekannt.

Eine für die böhmische wie die ausländische Kreideformation sehr charakteristische Pflanze, welche nicht nur in den untersten Etagen dieser Schichten, sondern auch in den obersten überall verbreitet zu sein scheint. In Böhmen fand ich sie in den ältesten Perucer Schichten und in allen jüngeren Ablagerungen, ja noch in den Chlomeker Sandsteinen. Folgende Standorte können für dieselbe mit Sicherheit verzeichnet werden: in den Perucer Sandsteinen bei Mšeno, Charvatec, Nehvizd, im Weissenberger Pläner am Weissen Berg, bei Schlan, im Vehlovicer Pläner bei Vinary, im Malnicer Sandsteine bei Malnic, in jüngeren Ablagerungen bei Vunic, Sovic, Levín, Priesen, Choceň, Voškobrd bei Poděbrad, und endlich in den Chlomeker Sandsteinen bei Kieslingswalde und Tannenberg.

Wiewohl diese Conifere allgemein verbreitet ist, so sind doch grössere Stücke oder beblätterte Zweige derselben eine grosse Seltenheit. Das beste Zweigfragment stellt das Exemplar Fig. 13 von Vinary dar. Dasselbe ist im festen, grauen Pläner zierlich dunkelbraun abgedrückt. Die Blätter sind auffallend lang, vom breiten Grunde gegen die Spitze hin allmälig verschmälert und hier zugespitzt, vom Zweige in schiefer Richtung abstehend. Durch die Länge und die verhältnissmässig grosse Breite und durch die zugespitzten Enden der Blätter unterscheidet sich diese Art schon in kleinen Bruchstücken von anderen Sequoia-Arten.

Das Ästchen Fig. 5 rührt aus den Teplicer Schichten von Voškobrd bei Poděbrad her. Dasselbe hat am Grunde sehr kurze, kaum abstehende Blätter, je höher aber, desto länger werden dieselben, so dass sie am Ende des Fragmentes schon die gewöhnliche Grösse erreichen. Dieses Ästchen ist demnach ein jähriger Spross, welcher bei anderen Arten der Gattung Sequoia zumeist mit langen, geraden, flachen Blättern beendet ist, hier aber wieder nur sichelförmige Blätter trägt. Überdies wurden andere als mit sichelförmigen Blättern bekleidete Ästchen von S. Reichenbachi bis jetzt nicht gefunden.

Das kleine Fragment Fig. 10a). gehört einem mit ungewöhnlich verlängerten aber noch mehr gekrümmten Blättern besetzten Ästchen an.

Fig. 12a) stellt ein im Perucer Sandsteine von Nehvizd ziemlich schlecht erhaltenes Fragment dar. Nach der Dicke des mittleren Zweigtheiles gehört dasselbe einem älteren Stadium an. Die Blattspuren und die Blätter selbst sind im groben Sandsteine nur angedeutet, die Länge und Form der letzteren weist jedoch das Fragment zur S. Reichenbachi hin. In derselben Weise erhalten ist das Ästchen Fig. 14 aus den Chlomeker Sandsteinen von Kieslingswalde, wo diese Art häufig ist.

In den sandigen Ablagerungen bei Malnic kommen mit den zahlreichen Meeres-Mollusken nicht selten kleine Zweigstïcke von S. Reichenbachi vor (Fig. 5a, 7a, 12), welche ebenso lange, gekrümmte Blätter tragen und mit schönen, rhombischen, mit einer Rinne versehenen Blattspuren ausgezeichnet sind. Auf einem ähnlichen Sandsteinstücke findet man einen gebrochenen Zapfen Fig. 7a), mit dem unten noch ein kurzes, mit langen, sichelförmigen Blättern besetztes Ästchen zusammenhängt. Der Zapfen ist rundlich und gross, wie es auch aus der Stellung der Schuppen eines anderen Zapfenüberrestes Fig. 8 Taf. VIII. von demselben Standorte hervorgeht. Die Schuppen sind etwa zweimal so lang als die grösste Breite ihrer Schildchen, in der Mitte mit einer seichten Rinne, gegen die Basis hin allmälig verschmälert und auf der Oberfläche längsgerunzelt. Die Schildchen sind quer-rhombisch, mit einer tiefen Querfurche (oder mit einem negativen Mittelkiele), in der Mitte mit einem Nabel, von welchem in radialer Richtung zum Rande strahlförmige Runzeln auseinander laufen. Besonders gut zeigt diese Verhältnisse der Schildchenabdruck Fig. 7 a) und ein anderer in schiefer Lage bei $b$ ).

Die Grösse und Form des Zapfens der S. Reichenbachi stellt auch der Zapfenüberrest Fig. 6 a) aus dem Perucer Sandsteine von Mšeno dar. Der Zapfen sitzt auch einem beblätterten Ästchen von Seq. Reichenbachi auf; die Schuppen sind matt abgedrückt, die Grösse und Form der Schildchen ist aber ziemlich erkennbar.

Die Zapfen dieser Art sind die grössten von allen bis jetzt bekannten fossilen Sequoia-Arten. Dasselbe beweisen auch die Zapfenabdrücke dieser Art, welche $\mathrm{He} e \mathrm{r}$ in seiner Flora von Moletein beschreibt und die mit den unseren in jeder Hinsicht übereinstimmend sind.

Die Sequoien haben zur Kreidezeit die reichste und mannigfaltigste Entwickelung erreicht, die tertiären Arten sind zweifellos unmittelbare Nachkommen derselben. Die zahlreichen besonders von Heer aus arctischen Ländern beschriebenen Sequoiá-Arten sind jedoch so diagnoscirt, dass ich nicht im Stande bin die böhmischen Kreide-Sequoien nach jenen zu bestimmen, wiewohl ich überzeugt bin, dass sie in den arctischen Arten enthalten sind. Durch weitere Studien wird die Zahl der Kreide- und Tertiär-Sequoien wohl noch vermehrt, in demselben Masse werden aber die specifischen Diagnosen einzelner Arten undeutlicher, so dass sich schon die Nothwendigkeit zeigt alle diese Sequoien einer precisen, vergleichenden Untersuchung auf Grundlage der Originale unterzuziehen. 
Unsere Sequoia Reichenbachi fand ich mit folgenden beschriebenen Sequoien identisch:

Sequoia Reichenbachi Heer, Flora von Moletein S. 7. Taf. I. Fig. 1-9. Die Schichten, aus welchen die Moleteiner S. Reichenbachi herrührt; sind die Perucer Sandsteine Böhmens.

Sequoia Reich enbach i Herr, Fl. v. Quedlinburg. Taf. I. Fig. 11.

Sequoia Reichenbachi Heer, die Kreideflora d. arct. Zone 1874. - Beiträge zur Kreideflora, Schweizer Denkschrift. 1869. Taf. I. Fig. 1-9.

Araucarites Reichenbachi Geinitz, Charakteristik der Schichten und Petrefacten des sächs. böhm. Kreidegeb.

Cryptomeria primaeva Corda in Reuss Verstein. Taf. XLVIII. Fig. 1-11. Hier wird auch ein vergrössertes Zweigstück sehr gut abgebildet.

Araucarites a d p ress a v. Mark. Palaeontograph. XI. Taf. VIII. Fig. 10.

Se qu oi a Reich enbachi Geinitz, Elbthalgeb. in Sachsen. Taf. 67. Fig. 6.

Sequoia Reich en ba chi Hosius u. v. d. M. Fl. v. Westfalen. Paläontogr. XXVI.

Geinitzia cretacea Endl. Synops. Conif.

Sequoia fastigiata Sternb. sp. (non Heer).

Taf. VIII. Fig. 13. Taf. IX. Fig. 3, 4, 9, 10, 11. Taf. XI. Fig. 1, 2. Taf. XII. Fig. 13.

Thuites alienus et Caulerpites fastigiatus Sternb. in Flora d. Vorw.

Widdringtonites fastigiatus Endl., Unger.

Zweige unregelmässig verzweigt, dick, nicht schlank. Blätter kurz herablaufend, mit einer kurze n, wenig abstehenden, kaum gekrümmten, sehr breiten und stumpf abgerundeten Spitze. In der Mitte des Blattes eine deutliche Furche. Fruchtzapfen länger als breit. Schuppen wenig länger als die grösste Breite der Schildchen.

In den Weissenberger Plänerschichten Böhmens eine verbreitete Pflanze. Das Original Sternbergs rührt von Smečno her, unsere vom Weissen Berg und Hrádek (Herr Dr. Čurda). Der grosse Zweig Fig. 1, Taf. XI. aus den Perucer Sandsteinen bei Hospozin wurde vom H. Stodola den geologischen Sammlungen der böhmischen Universität gewidmet.

Diese Art ist durch die oben hervorgehobenen Merkmale sehr ausgezeichnet und leicht von anderen Sequoien zu unterscheiden. Die Zweige sind verhältnissmässig sehr stark, dick und kurz, die Blätter auffallend breit, stumpf abgerundet, kurz und wenig vom Zweige abstehend. Die Mittelfurche ist auf den Blättern wie bei anderen Sequoien immer vorhanden. Die Blattpolster, welche besonders auf dem schönen Zweigstücke Fig. 13, Taf. XII. erhalten sind, sind vorne stumpf beendet und neben der Mittelfurche noch mit einigen sehr feinen Längsstreifen versehen.

Nicht selten kommen im Pläner am Weissen Berg Fruchtzapfen vor. Solche sind bei Fig. 13, Taf. VIII. und Fig. 3, Taf. IX. abgebildet. Dieselben sind aus spiralig angeordneten, gegen die Basis verschmälerten, längs-gerunzelten, in der Mitte mit einer Furche versehenen Schuppen zusammengesetzt. Die Schildchen sind rhombisch, mit einer Querfurche und einem Nabel in der Mitte versehen. Es unterliegt also keinem Zweifel, dass diese Zapfen einer Sequoia angehören, und zwar der S. fastigiata, da man den Zapfen Fig. 13, Taf. VIII. noch in Verbindung mit einem Zweigstück findet, welches dieselben charakteristisch kurzen, stumpfen Blätter wie die oben beschriebenen Zweigreste trägt.

Noch schöner ist der grosse Zweig von Hospozín Fig. 1, Taf. XI, dessen einzelne Ästchen noch 5 quergebrochene Zapfen und bei a) den äusseren Abdruck eines sechsten Zapfens tragen. Die Zapfen haben wieder eine elliptische Form, ihre Schuppen und Schildchen sind in verschiedenartiger Lage gebrochen. Die von der Oberfläche abgedrückte Partie eines Zapfens bei a) zeigt gut die Form und Grösse der Schildchen. Nicht nur die ähnlichen Zapfen, sondern auch die dicken, nicht schlanken Zweige weisen auf dieselbe Art wie die oben beschriebenen Überreste. Nebstem sind in dem groben Sandsteine hie und da spiralig stehende Schuppenblätter wahrnehmbar, welche ebenso stumpf, kurz und breit sind, wie auf den Weissenberger Zweigen.

Dass diese Pflanze eine echte Sequoia und zwar eine selbstständige Art ist, ist wohl nicht zu bezweifeln, schwieriger ist aber zu entscheiden, mit welchen Sequoien der ausländischen Kreideformation sie zu verbinden sei. Die von Sternberg als Thuites alienus und Caulerpites fastigiatus beschriebene Conifere konnte ich in Originalen mit unserer S. fastigiata vergleichen. Unsere Pflanzenüberreste müssen jedenfalls mit jenen Sternberg's zu einer Art untergebracht werden, alle Merkmale derselben sowie die äussere Tracht der in demselben Pläner abgedrückten Pflanzen stimmen sämmtlich überein. Unser Zweigstück Fig. 13 Taf. XII ist besonders jenem Sternberg's Taf. XLV. Fig. 1 ähnlich. 
Die Sequoia fastigiata Heer's (Flora v. Moletein) ist mit aller Sicherheit eine von unserer und Sternberg's Art sehr weit abweichende Pflanze. Die Zapfen der Sternbergischen Sequ oia fastigiata sind zweimal so gross und mehr verlängert als diejenigen, welche Heer für seine S. fastigiata angibt. Die Zweige der S. fastigiata aus der grönländischen Kreide sind im Vergleich mit unserer Pflanze ungemein schlank, dünn, die Blätter lang, schmal, dem Zweige angedrückt und nach Heer's Beschreibung (Die Flora der arct. Zone und Fl. grönl.) in eine feine Spitze auslaufend. Der böhmischen S. fastigiata steht aus den Heerischen Kreide-Sequoien die S. ambigu a am nächsten, welche aber rundliche, kleine Zapfen trägt.

Unsere S. fastigiata kann mit keiner bis jetzt bekannten Sequoia-Art der Kreidezeit verbunden werden, ebenso kann ich nicht ihr Verhältniss zu den tertiären Arten dieser Gattung ermitteln. Sie scheint der S. Reichenbachi am nächsten zu stehen, durch Blätter sowie die ellipsoidischen Zapfen ist sie aber von dieser verschieden (siehe den restaurirten Zapfen mit einem beblätterten Zweigstücke Fig. 11 Taf. IX.)

\section{S e q u o i a c r i s p a m.}

Taf. X. Fig. 5-7, 9, 14, 16.

Ästchen dünn, schlank und lang. Blätter dicht, ziemlich kurz, dünn, fest lederartig, sehr stark sichelförmig einwärts gebogen, kurz herablaufend, stimpflich. Fruchtzapfen rundlich, etwa $3 \mathrm{~cm}$. im Durchmesser.

In den Perucer Schieferthonen bei Lidic nächst Schlan, bei Lipenec und Jinonic.

Eine schöne und immer sehr kennbare Art. In dem Lidicer Schieferthone kommen nicht nur die Äste, sondern auch häufig Fruchtzapfen vor. Bei Jinonic sind am meisten nur Zweigüberreste vorhanden, nur ein Zapfenfragment wurde hier bis jetzt gefunden. Im Lipenecer Standorte sind uns bis jetzt nur Äste bekannt.

Die Äste liegen uns in langen und verhältnissmässig dünnen Bruchstücken vor; der ganze Zweig war demnach von einem schlanken Wachsthum. Die Blätter stehen sehr dicht beisammen, sind ziemlich dünn und auffallend stark sichelförmig einwärtsgebogen, so dass ihre Spitzen den Rücken der nächst folgenden Blätter berühren und auf solche Weise dem Zweige eine sonderbare, krausige Tracht darbieten. Die Consistenz der Blätter musste sehr hart, derb lederartig sein, da dieselben im Schiefer tief und scharf abgedrückt sind.

Wie gesagt, sind die Fruchtzapfen im Schieferthone bei Lidic eine gewöhnliche Erscheinung. Man findet sie häufig quergebrochen (wie Fig. 6), in welchem Falle ausser dem äusseren vollkommen kreisförmigen Umrisse des Zapfens nur die längs-gerunzelten, mit einem centralen Kiele versehenen, verschiedenartig gebrochenen und radial zusammengestellten Schuppen wahrzunehmen sind. Samen konnte ich nirgends finden. Als Beispiele der von der Oberfläche abgedrückten Zapfen sind uns die bei Fig. 5, 7. Die schönen rhombischen Schildchen sind zumeist gut abgedrïckt, und durch eine Querfurche in die obere und untere Hälfte getheilt: In der Mitte sieht man den nicht zu erhabenen Nabel, von dem zahlreiche, narbige Strahlen in radialer Richtung gegen den Rand hin auseinanderlaufen. Diese Schildchen sowie der untere, narbig gestreifte und mit einem Mittelkiele (oder mit einer Mittelfurche) versehene Theil der Schuppe lassen also nicht zweifeln, dass die vorhandene Conifere wirklich eine echte Sequoia ist.

Die Zapfen Fig. 5, 7 stehen noch in Verbindung mit ziemlich langen Zweigstücken, welche mit den Zweigen Fig. 9, 14, 16 identisch sind. Es gehören also die kugeligen Zapfen und die krausigen Äste derselben Art an.

Diese Sequoia-Art ist gewiss von allen bis jetzt bekannten Arten specifisch verschieden; sie muss in allen Fällen nach den krausigen, festen Blättern, den dünnen, langen Ästen und grossen, rundlichen Zapfen überall wieder erkannt werden.

\section{Sequoia heterophylla $\mathrm{m}$.}

Taf. XII. Fig. 2-4, 6-9. Taf. XIII. Fig. 12.

Zweige ruthenförmig, unter spitzen Winkeln getheilt, ziemlich dünn und schlank. Blätter zweierlei: die schuppenförmigen sehr verlängert, mit stumpfen, nicht abstehenden Spitzen, locker dem Zweige a ufsitzend; die der jüngeren Sprosse blattartig, zweireihig am Zweige geordnet, lineal, breit, dick, lederartig, vorne stumpf abgerundet, am Grunde merklich verschmälert, von mehreren Längsstreifen durchzogen. Der Zapfen unbekannt.

In den Perucer Schieferthonen bei Peruc sehr gemein, seltener bei Landsberg, Lipenec und Vyšerovic. 
Eine in Beblätterung sehr variirende Pflanze. Aus dem Perucer Fundorte befindet sich im böhmischen Museum eine Reihe von grösseren und kleineren Zweigfragmenten, von welchen die dickeren Exemplare lang herablaufende, locker stehende Blätter, deren Spitze immer stumpf beendet und dem Zweige angedrückt ist, tragen. Ein solches Fragment stellt der Zweig Fig. 6 dar. Zuweilen findet man auch sehr dünne, reichlich verzweigte Äste, welche ebenso lange, schuppenförmige Blätter tragen, die aber in solchen Fällen noch locker der Achse aufsitzen. Letzterer Umstand beweist, dass nicht alle jährige Sprosse mit Laubblätterm enden müssen; an Enden ähnlicher jungen Sprosse übergehen häufig die angedrückten Schuppen in die abstehende, laubartige Form, wie z. B. auf den zwei Ästchen Fig. 2 a) zu sehen ist.

Die schuppenförmigen Blätter sind dick, an Enden fast rundlich, welches Merkmal auch für die breiten, abstehenden Blätter charakteristisch ist.

Die Schuppen verwandeln sich also auf jungen Sprossen in lineale, zweireihig am Zweige gestellte Blätter, welche sämmtlich vorn sehr stumpf abgerundet sind. Am Grunde sind sie nur schwach verschmälert und kurz herablaufend. In der Mitte der Laubspreite läuft ein starker, nicht selten durch eine dunkle farbe markirter Mittelnerv. Beiderseits desselben ziehen sich noch andere aber höchst feine Längsnerven (siehe die vergrösserte Abbildung der Blätter Fig. 7).

Ob diese beblätterten Sprosse nach Art der tertiären S. Langsdorfi oder des amerikanischen Taxodium distichum jährlich abfielen, ist schwer zu ermitteln. Nicht selten findet man aber solche Ästchen isolirt im Gesteine abgedrückt und am Grunde mit dichten Übergangsblättern bekleidet (Fig. 4), gerade wie es bei ähnlichen Sprossen der S. Langsdorfi der Fall ist.

Die gleichartige Orientirung der drei Ästchen Fig. 3 ist dadurch zu erklären, dass dieselben in einen grösseren Zweig verbunden waren, welche Verbindung abel abgebrochen ist. Ähnliche Sprosse aufsitzen den grösseren beschuppten Zweigen auf der Steinplatte Fig. 9, wo auch zwischen den beiden Zweigen ein dickeres Zweigfragment liegt, welches am Ende noch lange schuppenförmige Blätter trägt. Das Ästchen Fig. 9 Taf. XII. besitzt die längsten Blätter, welche mir von dieser Art zu Gesicht gekommen sind.

Auf dem schuppentragenden Zweige Fig. 8, welcher theilweise durch die Schattirung ergänzt ist, befinden sich an den Enden der Ästchen beiderseits rundliche, knospenartige Gebilde, welche aus breiten und kurzen Schuppen zusammengesetzt sind. Welche Bedeutung aber diesen Knospen beigelegt werden soll, ist freilich schwer zu constatiren. Sind sie nicht die männlichen Blüthenorgane, so sind sie wahrscheinlich Knospen, aus welchen die laubtragenden đ̈stchen hervorsprossen. Ähnliche Knospensprosse kommen auch bei der noch lebenden Sequoia sempervirens vor.

Zapfen fand ich nicht, nach der Ähnlichkeit der vegetativen Zweige mit jenen der S. Langsdorfi zu urtheilen, ist aber diese Conifere sehr wahrscheinlich eine Sequoia. Unsere S. heterophylla kann ich mit keiner von den bis jetzt beschriebenen Sequoia-Arten zusammenstellen. Der tertiären S. Langsdorfi steht sie zwar sehr nahe, dennoch ist sie aber durch das häufige Vorkommen der schuppentragenden Äste bedeutend verschieden, die laubtragenden Ästchen stimmen aber gut überein. Die Laubblätter der S. semper virens zeigen ebenfalls dieselbe Form und eine ähnliche Nervation.

\section{Sequoia rigida Heer.}

Taf. XI. Fig. 5. Taf. XIII. Fig. 10. Taf. IX. Fig. 8. Taf. X. Fig. 10.

Die abgebildeten 4. Zweigfragmente bilden alles, was wir von dieser Art zur Disposition haben. Der Fundort derselben sind die rothen Perucer Schieferthone bei Liebenau. Die Blätter sind schmal-lineal, steif in zwei Reihen abstehend, vorne stumpflich, am Grunde mit verschmälerter Basis herablaufend. Ausser dem ziemlich starken Mittelnerven ist keine andere Nervation kennbar.

Das Ästchen Fig. 5, Taf. XI. kann ein jährlich abfallendes Ästchen der Sequoien sein, da man am Grunde desselben zwei schuppenförmige Blätter findet, ähnlich jenen, mit welchen die Ästchen der Sequoien gewöhnlich beginnen.

Die Möglichkeit, dass diese Ästchen der vorhergehenden Art angehören, von der sie nur durch bedeutend längere Blätter verschieden sind, ist nicht ausgeschlossen. Ähnliche laubtragende Ästchen besitzt auch die Sequoia rigida Heer aus arctischen Ländern (Fl. grönl. und die Flora d. arct. Zone).

Ein reichlicheres Material aus dem Liebenauer Fundorte ist für die definitive Bestimmung dieser für Böhmen provisorischen Art noch sehr nothwendig. 


\section{Sequoia microcarpa m.}

Das Zäpfchen Figur 2, 3, Tafel X. gehört ausgesprochen einer Sequoia-Art an, da wir aber ausser dem einzigen abgebildeten Exemplare dieser Art nichts mehr besitzen, so ist ihre specifische Diagnoscirung sowie das Verhältniss zu anderen Arten dieser Gattung schwer zu ermitteln. Indessen bleibt nur die Thatsache sicher, dass das Zäpfchen eine von den vorhergehenden Arten verschiedene Species repräsentirt.

Das Zäpfchen ist sehr klein, aus zahlreichen, spiralig stehenden Schuppen zusammengesetzt. Diese sind gegen die Basis hin keilförmig verschmälert, längsgerunzelt und mit einer seichten Mittelfurche versehen. Das Schildchen ist rhombisch, mit einer Querfurche und einem Centralnabel. Unter der Schuppe a) sind deutlich zwei ziemlich grosse, plastisch hervortretende, ellipsoidische Samen zu sehen, an welchen aber kein Saumrand vorhanden ist.

Ich habe das Zäpfchen der Quere nach gebrochen und da zeigte sich, dass es unten mit einem kurzen Ästchen zusammenhängt. Dieses Ästchen (Figur 2) trägt lange, sichelförmige Blättchen, welche mit einer schwarzen, verkohlten Substanz ausgefüllt sind. Ihre Form und derbe Consistenz weist also ebenfalls auf die Gattung Sequ oia hin.

Das Zäpfchen wurde vom H. Zahálka in den Teplicer Schichten bei Raudnic gefunden.

Ähnliche kleine Sequola-Zäpfchen fand ich noch in den Perucer Schieferthonen bei Lidic in der Nähe von Schlan; in wie weit aber diese Zäpfchen mit jenen von Raudnic verwandt sind, ist mir des ungenügenden Materiales wegen nicht möglich festzustellen.

\section{Ceratostrobus m.}

Blätter spiralig dem Zweige aufsitzend, pfriemlich; sichelförmig gekrümmt, herablaufend. Fruchtzapfen kugelig, mit spiralig geordneten Schuppen. Schuppen zur Basis keilig verschmälert, längsgerunzelt, mit einem niederen Mittelkiele, oben in ein rhombisches Schildchen verbreitet, welches sich in der Mittellinie in einen langen, mehr oder weniger flachen, festen, geraden Schnabel verlängert.

\section{Ceratostrobus sequoiaephyllus $\mathrm{m}$.}

Taf. XII. Fig. 16, 15, 14.

Zweige unregelmässig getheilt, nicht stark. Blätter pfriemlich, von der Basis gegen das Ende hin allmählig verschmälert und hier fein zugespitzt, fest lederartig, sichelförmig gekrümmt, kurz herablaufend, von einem Mittelnerven durchzogen. Blattpolster länglich-elliptisch, mit einer Mittelfurche. Fruchtzapfen kugelig, etwa $3 \mathrm{~cm}$. im Durchmesser. Schuppen mehr als zweimal so lang als das rhombische, in einen ziemlich flachen, langen Schnabel auslaufende Schildchen.

In den grauen Perucer Schieferthonen bei Lipenec der gewöhnlichste Pflanzenabdruck. orte herrührt.

Die beblätterten Zweige dieser Conifere bedecken eine jede Schieferplatte, welche vom Lipenecer Fund-

Sie sind mehr oder weniger gross und nicht selten findet man ganze grosse Zweigstücke von ziemlicher Grösse, wie z. B. Fig. 16. Die holzige Achse der Zweige ist ziemlich dünn und dicht mit langen, sichelförmigen Blättern bedeckt. Die Blätter weisen eine feste, lederartige Consistenz auf und sind wie die Blätter der Sequoien und der Gattung Cryptomeria von einer Mittelfurche durchzogen; diese entspricht, wie bekannt, der Seitenkante des Blattes. Nach dem Habitus ähneln diese Zweige nicht wenig denen der Sequoia Reichenbachi, doch sind die Blätter etwas kürzer und schmäler.

Glücklicherweise gelang es mir, als ich im Jahre 1884 den Lipenecer Fundort besucht habe, einen Zapfen zu finden, welcher einem kurzen mit Blättern dicht besetzten Ästchen derselben Art, wie der Zweig Fig. 16, aufsitzt. Der Zapfen (Fig. 15) ist etwa in der Mitte gebrochen, ich habe aber die meisten Schuppen entfernt, um die Abdrücke der Schildchen sichtbar zu machen. Dieselben sind bei $a$ ) und b) besonders schön abgedrückt. Sie haben wie alle Sequoien eine rhombische Form, sind jedoch im Verhältnisse zum Zapfen auffallend klein. In der Mitte sieht man eine tiefe Rinne, welche besonders auf dem Schildchen a) tief in den Schiefer eindringt, so dass ihre Beendung nicht mehr zu sehen ist. Diese Rinne ist im Centrum, wo sich bei den Sequoien ein Nabel befindet, in eine kleine, rhombische Öffnung erweitert. Von dieser Öffnung laufen wie bei den Sequoien radiale Streifen gegen den Rand hin. 
Am äusseren Umfange des Zapfens sieht man mehrere, dreieckige, allmälig in eine Spitze auslaufende, gerade oder etwas aufwärts gekrümmte Abdrücke, unterhalb welcher bei c) und e) noch ein anderes Flächchen sich befindet. Anfänglich konnte ich mir diese dreieckigen Abdrücke nicht erkiären, da sie keineswegs vom rhombischen Schildchen wie bei a) herrühren konnten und doch mit den Schuppen des Zapfens zusammenhängten, denn unterhalb des Flächchenabdruckes c) findet man den unteren herablaufenden Theil einer Schuppe. Eine Aufklärung zu. diesen Abdrücken gibt uns das Schildchen e). Dasselbe war ursprünglich auf dieselbe Weise rhombisch abgedrückt wie dasjenige bei a.), nur war es von den Seiten stark zusammengedrückit. Mittelst einer Messerspitze entfernte ich den oberen Theil des Schildchens, so dass nur die Hälfte unterhalb der Querrinne zurückblieb. Die Fortsetzuug der tiefen Querrinne zeigte sich nun als ein verlängerter', zugespitzter Abdruck von derselben Form wie alle übrigen oben erwähnten Flächchen, wie z. B. c).

Wir haben demnach vor uns einen sonderbaren von der Gattung Sequoia verschiedenen Schuppentypus. Die Schuppe besteht aus einem unteren, runzelig gestreiften, keilförmigen Theile (siehe c) d)) und aus einem wie bei der Sequoia rhombischen, gleichfalls radial gestreiften Schildchen. Allein die Querfurche und der Mittelnabel der Sequoia verlängert sich bei dem Ceratostrobus in einen langen, dicken, entweder geraden oder ein wenig gekrümmten Schnabel. Bei Fig. 14 ist eine solche Schuppe des Lipenecer Zapfens vergrössert und restaurirt dargestellt.

Die lebende Cryptomeria trägt einen ähnlichen Fortsatz auf den Schuppen, doch besitzt dieser kein rhombisches Schildchen; der Fortsatz ist übrigens dünn und meist zurückgeschlagen. Wie bei der Cryptomeria entspricht auch bei dem Ceratostrobus dieser Fortsatz der mit der Schuppe zusammengewachsenen Bractee.

Diesen Merkmalen nach steht also die neue Gattung Ceratostrobus in der Mitte zwischen den Gattungen Cryptomeria und Sequoia. Es ist sogar wahrscheinlich, dass einige der fossilen Sequoien, für welche die Zapfen nicht nachgewiesen sind, der Gattung Ceratostrobus angehören. Einige von denselben können auch zur Gattung Cryptomeria gehören, wie dies in neuerer Zeit H. Starkie Gardner in seiner British eocene Flore, Part. II. 1884. für die im Eocen verbreitete Sequoia Sternbergi Heer nachgewiesen hat.

Nach den blossen blatttragenden Zweigen ist freilich die Gattung Ceratostrobus von einer Se$q u$ i a schwer zu unterscheiden, die geschnabelten Schuppen müssen dagegen im jeden Falle dieselbe verrathen.

\section{Ceratostrobus echinatus m.}

Taf. XI. Fig. 7-15. Taf. XIII. Fig. 5.

Äste dünn, unregelmässig verzweigt. Blätter pfriemlich, aus breiter Basis gegen die Spitze hin allmälig verschmälert, fein zugespitzt, beinahe.in senkrechter Richtung abstehend, sichelförmig gekrümmt, von einem Mittelnerven durchzogen. Fruchtzapfen kugelig, höchstens $1 \frac{1}{2} \mathrm{~cm}$. im Durchmesser. Das rhombische Schildchen in einen langen, aufwärts gekrümmten, kaum zusammengedrückten Schnabel verlängert. Männliche Zapfen elliptisch, aus breit-lanzettlichen, kurz zugespitzten Schuppen zusammengesetzt.

In dem Perucer Schieferthone bei Vyšerovic, seltener bei Liebenau.

Es liegt uns zwar kein reichliches Material von dieser Art vor, doch ist dasselbe so instruktiv in so prächtigen Stücken vorhanden, dass man hier über die neue Gattung Ceratostrobus noch besser belehrt werden kann als bei der vorhergehenden Art. Vor allem ist der Zapfen Fig. 12 bemerkenswerth. Der negative Abdruck zeigt die Oberfläche der Zapfenschuppen, der positive die gebrochenen, schwarz verkohlten Schuppen selbst. Auf den ersten Blick müssen uns die spitzen, aus dem Umrisse des Zạpfens heraustretenden Fortsätze auffallen. Das Innere des Zapfens (Fig. 12) selbst füllen rhombische, in Parastichen angeordnete Schildchenabdrücke aus. Diese zeigen alle Merkmale der Schildchen der vorhergehenden Art, und sind auch mit einer ähnlichen tiefen Querrinne, oder besser gesagt, mit einer Querspalte, die im Centrum erweitert ist, versehen. Von der Centralöffnung laufen wieder zahlreiche, radiale Streifen gegen den Rand hin. Hie und da ist noch eine Partie der längsgerunzelten, herablaufenden Schuppe unterhalb des Schildchens erhalten (ein treu vergrössertes Schildchen siehe bei Fig. 9).

Am Rande des Zapfens finden sich die Schildchen so abgedrückt, dass man stellenweise deutlich sehen kann, wie die Querspalte des Schildchens in einen langen, ziemlich schmalen Schnabel verläuft. Bei Fig. 14 ist ein ähnlicher Abdruck vergrössert abgebildet, auf dessen Grundlage rechts eine Schuppe restaurirt und ergänzt ist. Den Abdruck Fig. 14. müssen wir uns als die Hinterseite eines Schildchens vorstellen; auf dem restaurirten Schildchen ist freilich die Vorderseite gegen uns gekehrt. 
Der Schnabel dieses Schildchens ist im Vergleiche mit der vorhergehenden Art länger und nach der Tiefe des Abdruckes zu urtheilen, massiver, dicker und fester als jener des C. sequoiaephyllus. Der andere Zapfen Fig. 11 ist etwas kleiner, aber schlecht erhalten, am Rande gebrochen. Im Ganzen zeigt er dieselben Merkmale wie der in Fig. 12.

Die beiden Zapfen sitzen auf einem kurzen, beblätterten Ästchen. Die Blätter sind spiralig geordnet, ziemlich tief herablaufend, fein allmälig zugespitzt und in einem rechten Winkel vom Zweige abstehend. Neben dem obligaten Mittelnerven sind noch andere, aber sehr feine Längsstreifen wahrzunehmen. Die Blattpolster sind länglich, mit einer deutlichen Mittelfurche und seitlichen Längsstreifen. Diese Verhältnisse sind auf dem vergrösserten Ästchen Fig. 8 dargestellt. Das Ästchen Fig. 7. ist mehrmals getheilt, zeigt aber alle Merkmale des zapfentragenden Ästchens Fig. 12.

Das Ästchen Fig. 5 Taf. XIII. von Liebenau ist ähnlich beblättert wie die Ästchen von Vyšerovic, so dass es zweifellos auch hieher gehört.

Sehr interessant sind die Fragmente Fig. 15 und 13. Das erstere ist ein ähnliches Ästchen wie die bereits beschriebenen, nur steht mit demselben durch einen abgeneigten Stiel ein Zäpfchen in Verbindung, welches elliptisch und aus zahlreichen, kleinen Schuppen zusammengesetzt ist. Die Schuppen sind breit lanzettlich, kurz bespitzt, in Parastichen angeordnet.

Dieselbe Form hat auch das Zäpfchen Fig. 13; dieses ist nur etwas länger. Die Schuppen sind ähnlich geordnet und ähnlich gestaltet wie die des ersteren Zäpfchens, so dass wahrscheinlich beide von derselben Pflanze herrühren. Das Zäpfchen Fig. 13 sitzt aber auf einem dünnen Ästchen, welches mit sehr lang herablaufenden und wenig abstehenden Blättern bekleidet ist, wodurch es von den obigen Ästchen bedeutend abweicht. Die Beblätterung der Zweige der meisten Coniferen variirt aber nicht selten, besonders auf den geschlechtstragenden Theilen. Bei Fig. 10 ist eine Partie dieser Zäpfchen vergrössert dargestellt.

\section{Glyptostrobus europaeus Heer cretaceus m.}

Taf. VI. Fig. 2. Taf. VII. Fig. 2, 3, 9, 10.

Ästchen mit spiraligen, schuppenförmigen, rhombisch-lanzettlichen, kurz zugespitzten und mit einem Rückenkiele versehenen Blättern. Die Blätter der jüngeren Ästchen lineal-verlängert, steif und schief abstehend, in gleicher Breite herablaufend, scharf gestreift.

In den grauen Perucer Schieferthonen bei Lidic unweit von Schlan.

Bei Lidic, dicht neben der Eisenbahn, etwa hundert Schritte von der Strassenbrücke beissen ziemlich mächtige Schichten der grauen Schieferthone aus, welche mit kleinen, zumeist zerfetzten Ästchen dieser Conifere überfüllt sind. Grössere, verkohlte Holzstücke, die in diesen Schichten eingebettet sind, können auch dieser Conifere angehören. Eine andere Pflanzenart fand ich in diesen Schichten nicht.

Eine Schieferplatte, die mit kleinen Ästchen dieser Conifere bedeckt ist, stellt uns die Fig. 2. dar. Die dünnen Ästchen sind theilweise ziemlich lang, theilweise in kleine Stücke zerfetzt.

Die Schuppenblätter sind spiralig gestellt, rhombisch-lanzettlich, mit einer festen, kaum abstehenden Spitze. Auf allen Schuppen sieht man in der Mitte einen scharf hervortretenden Kiel, welcher in die feste Schuppenspitze mündet (Fig. 9).

Auf der. Schieferplatte Fig. 10 liegt ein jüngeres verzweigtes Ästchen neben dickeren, einfachen, mit scharf abgedrückten Schuppen bedeckten Zweigstücken. Die Zweige theilen sich unter ziemlich spitzen Winkeln.

Auf einigen Ästchen übergehen die Schuppenblätter in lange, schmale Blätter, welche sich auf kleinen, häufig mit den übrigen Bruchstücken vorkommenden Ästchen noch mehr verlängert vorfinden. Solche Ästchen sind z. B. auf der Schieferplatte Fig. 2 abgebildet. Die Blätter dieser Ästchen stehen steif und zweireihig von der Achse ab, sind an den Spitzen ein wenig gekrümmt und am Grunde lang herablaufend ohne sich jedoch zu verschmälern. Jedes Blatt ist von einem scharfen Mittelnerven durchzogen, beiderseits derselben sind aber noch andere feine Parallelnerven wahrzunehmen (Fig. 3). Diese langblätterigen Ästchen beginnen am Grunde mit mehreren dicht bei einander stehenden Schuppenblättern auf dieselbe Weise wie bei dem tertiären Gl. Ungeri Heer (siehe d. Fl. der Schweiz S. 52), mit welchem unsere Pflanze für identisch gehalten werden kann. Diese Ästchen sehen auch ganz ähnlich aus, wie diejenigen des Gl. europaeus aus den tertiären Letten bei Laun (die tert. Fl. v. Laun). Alle Merkmale der tertiären und der Lidicer Kreidepflanze sind so übereinstimmend, dass ich die Benennung Gl. europaeus auch für die letztere behielt. Eigentlich ist es der Glypt. Ungeri, welcher aber keine von dem Gl. europaeus verschiedene Art ist.

Ob auch der Gl. grönlandicus Heer (Kreideflora der arct. Zone 1874 S. 76) hieher gehört, ist aus den ungenügenden Fragmenten derselben schwer zu ermitteln. 


\section{Cupressineae.}

Widdringtonia Reichii Ettings. sp.

Taf.- VIII. Fig. 4-6, 16. Taf. X. Fig. 1, 11, 12.

Frenelites Reichii Ettingshausen, Niederschöna, S. 246. Taf. I. 10.

Lycopodites insignis Reich. in Geinitz, Charakt. der Schichten und Petr. sächs. böhm. Geb.

Widdringtonites Reichii Heer, Fl. grönl. I. Theil. S. 51. Taf. XXVIII. 5. II. Theil, S. 13. Taf. LII. 4, 5. Glyptostrobus gracillimus Lesquereux, Cret. Fl. Taf. I. 8, 11.

Zweige in zahlreiche, sehr dünne, ruthenförmige Ästchen getheilt. Schuppenblätter schmal, fest, nur mit einer kurzen Spitze schwach vom Ästchen abstehend, immer mit einer deutlichen Mittelrippe, spiralig und locker dem Ästchen aufsitzend, unter den Zäpfchen genähert und hier beinahe gepaart-decussirt. Männliche Zäpfchen klein, elliptisch und einzeln auf dünnen Ästchen. Fruchtzapfen eiförmig, mit vier beinahe gleichen Schuppen.

Eine für die Perucer Schichten sehr charakteristische Pflanze. In den Schieferthonen bei Vy šerovic, Kaunic und Landsberg sehr häufig, seltener bei Mšeno, Peruc, Liebenau. In den so pflanzenreichen Thonen bei $\mathrm{Ku}$ chelbad kommt sie nicht vor.

Die dünnen, fadenförmigen, geraden Ästchen dieser Art sind schon auf den ersten Blick von allen Coniferen der böhmischen Kreideformation leicht erkennbar. Die Verzweigung ist unregelmässig, doch nie anders als unter sehr spitzen Winkeln vorhanden. Von Vyšerovic und Landsberg besitzen wir schöne, bis $30 \mathrm{~cm}$. lange, reichlich verzweigte Äste; als Beispiel der letzteren sind die Zweige Fig. 11, 12. Die Schuppenblätter sind den Ästchen dicht angedrückt und locker auf denselben zerstreut, so dass sie erst unter der Luppe deutlich hervortreten. Sie sind im Gesteine tief und scharf abgedrückt, mit einer kurzen, wenig abstehenden Spitze beendet und lang am Ästchen herablaufend. Von der Schuppenspitze läuft am Rü̈cken ein Kiel herab, wodurch die Oberfläche des Zweiges tief gefurcht erscheint. Die Abbildung Fig. 16, Taf. VIII. stellt ein solches Ästchen mit treu ausgeführten Blättern dar.

Auf alten, dicken Zweigen sind die Schuppenblätter breiter, mit scharfen, abstehenden Spitzen; die tiefe Streifung der Zweigoberfläche tritt dann nicht so scharf hervor (Fig. 6, Taf. VIII.).

Die Blätter sind spiralig geordnet, unter den Zäpfchen (Fig. 1. Taf. X.) stehen sie aber viel dichter beisammen und nehmen beinahe eine decussirte Stellung ein.

Der Zweig Fig. 1, Taf. X., rührt von Vyšerovic her und zeigt seinen oberen, mit zahlreichen dünnen Ästchen beendeten Theil. Die meisten dieser Ästchen sind mit kugeligen oder ellipsoidischen Zäpfchen beendet, an deren Grunde dichte, genäherte Schuppenblättchen, auf der Oberfläche aber kreisförmige, nebeneinander liegende, kleine Schuppenabdrücke wahrzunehmen sind, die wahrscheinlich den Staubblättern angehören. Wir haben vor uns einen blühenden Zweig, dessen Ästchen sämmtlich mit einzelnen männlichen Zäpfchen beendet sind. Im Zweige Fig. 11 liegt bei a) ein ähnliches Zäpfchen.

Auf der Schieferplatte Fig. 5, Taf. VIII. von Vyšerovic liegen neben den Blattresten von Eucalyptus Geinitzi noch einige dünne Ästchen von W. Reichii, bei deren Ende man einen Abdruck sieht, welcher aus drei breiten Schuppen und aus einer vierten, im Schiefer tief eingesenkten und zusammengedrückten Schuppe besteht. Rechts bei dieser vierten Schuppe ist ein kurzes Stielchen wahrzunehmen, welchem noch einige kleine Schuppenblätter aufsitzen. Dieses Stielchen ist aber nur ein Zweigstück von W. Reichii.

Einen ähnlichen Abdruck fand ich in den röthlichen Schiefern von Liebenau; derselbe ist bei Fig. 4 abgebildet. Der eiförmige Umriss dieses Gebildes ist zwar sehr deutlich, die Oberfläche desselben ist aber körnig punktirt und theilweise verwischt. Nur oben ist eine rhombische, allmälig gegen die Basis sich verschmälerndé Schuppe zu erkennen, welcher beiderseits zwei andere Schuppen sich beilegen. Das ziemlich lange, tief gestreifte Stielchen ist gewiss ein noch mit einigen Schuppenblättern besetztes Ästchen von Wid. Reichii, so dass jener Abdruck derselben Pflanze angehören muss.

Vergleicht man nun diesen Abdruck mit demjenigen Fig. 5, so lässt sich mit ziemlich grosser Wahrscheinlichkeit schliessen, dass beide die Fruchtzapfen der W. Reichii vorstellen. Diesen Umständen nach wäre ein Fruchtzapfen der W. Reichii aus vier Schuppen zusammengesetzt, auf dieselbe Weise wie die Zapfen der lebenden W. cupressoides Endl. und die Zapfen der verwandten tertiären Arten, wie besonders diejenigen der W. helvetica Heer (Fil. d. Schweiz Taf. XVI).

Auf diese Weise wäre der Widdringtonites als eine echte Widdringtonia aufzufassen, für welche Ansicht auch die männlichen, den Widdringtonien so ähnlichen Zäpfchen der [Fig. 1. Taf. X. sprechen. 
Die Blätter sind ebenso gekielt (siehe die umgekehrte Behauptung Heer's l. c.) und von derselben Beschaffenheit wie die lebende W. cupressoides und die tertiäre W. helvetic a (l. c. Taf. XVI. 13, 14). Nur die gegenständige Anordnung der Blätter derselben widerspricht der spiraligen Blattstellung bei W. Reichii. Die Blätter der lebenden W. cupressoides sind aber auf älteren Zweigen ebenso spiralig angeordnet und wie oben erwälnt wurde, stehen die Blätter der W. Reichii unter den männlichen Zäpfchen genähert, beinahe decussirt; es ist also auch in dieser Beziehung zwischen unserer Art und den echten Widdringtonien kein so bedeutender Unterschied.

Mit Sequoia fastigiata (Heer, l. c.) und mit der Gattung Sequoia überhaupt haben die sterilen Äste der W. Reichii schon gar nichts zu thun.

\section{Libocedrus salicornioides Heer cretacea m.}

Taf. VIII. Fig. 2.

Ich habe nur ein kleines Fragment von dieser Conifere in den Perucer Schieferthonen bei Lidic nächst Schlan gefunden. Durch die Form und alle Merkmale, welche sich auf diesem Abdrucke wahrnehmen lassen, stimmt aber derselbe sehr gut mit den einzelnen Zweiggliedern der tertiären Art L. salicorni oi des Heer überein.

Das abgebildete Fragment ist ein grösseres Zweigglied mit zwei seitlichen Schuppenblättern, zwischen welche ein decussirtes Blatt eingeschoben ist. Die Oberfläche der Blätter ist narbig genervt, der Vorderrand der Blättchen gekerbt. Oben schliessen sich dem Zweiggliede kleinere ähnliche Gliedchen an, zu denen noch ein links stehendes zu ergänzen ist. Es ist vielleicht ein Zweigende, wo gewöhnlich die letzten Glieder bedeutend verkleinert sind.

Die Bestimmung dieses Abdruckes kann nur in einer Vergleichung mit der tertiären L. s alic o rnio ides ihre Bestätigung finden.

Es ist bemerkenswerth, dass man sehr viele Pflanzenarten in den Kreideschichten findet, welche noch in der nächst folgenden Tertiärperiode beinahe in derselben Form verbreitet sind.

\section{Libocedrus Veneris m.}

Taf. X. Fig. 13, 15, 17.

Ästchen mit regelmässig decussirten Blattpaaren. Alle Blätter gleich gross, in vier Reihen gestellt, ziemlich lang, unter fast rechten Winkeln abstehend, vorne stumpf abgerundet und nicht gebogen, gegen die Basis hin verbreitet und herablaufend, etwa in der Mitte von einem. Nerven, welcher mit dem des gegenüber stehenden Blattes zusammenläuft, durchzogen.

In den Weissenberger Plänerschichten bei Gr. Černosek und Raudnic (H. Zahálka).

Wir haben zwar nur wenige Fragmente von dieser interessanten Conifere in die Hand bekommen, doch sind sie so charakteristisch beblättert, dass sie für die Bestimmung ziemlich genügen.

Anf den beiden abgebildeten Zweigbruchstücken sind die Blätter stellenweise so abgedrückt, dass zwei Reihen derselben in die Gesteinsebene fallen, die dritte Reihe aber tiefe, mit den ersteren Blättern abwechselnde Löcher bildet (so z. B. bei Fig. 17 a). Fallen zwei Blattreihen in die Gesteinsebene, die zwei anderen aber in das Gestein selbst, so sind die Blattabdrücke abwechselnd, wodurch auch die dritte Reihe verschwindet. Die Blätter stehen in beinahe rechten Winkeln vom Zweige ab, sind fast gerade und mit breiter Basis herablaufend.

Die Verwandtschaft dieser Pflanzenüberreste ist am ehesten zu ermitteln, wenn man sie der Gattung Libocedrus zunächst stellt. Was die Form der Blätter betrifft, so steht unsere Pflanze am nächsten der jetzt lebenden Libocedrus excelsa, nur hat diese wie die meisten Arten dieser Gattung abwechselnd verkümmerte Blattpaare. Die grösseren Blätter sind jedoch von derselben Form, gerade so gegenständig und herablaufend und mit derselben Mittelfurche versehen; sie sind nur mehr nach vorn hin gerichtet.

Unsere Ästchen sind nicht verzweigt, wie es auch bei einigien lebenden Arten der Fall ist. In dieser Beziehung gleicht die L. Veneris auch der Chilischen L. tetragona, mit der sie noch darin übereinstimmend ist, dass alle Blattpare gleich entwickelt sind. L. tetragona hat aber viel kleinere, dichter stehende Blätter.

$\mathrm{Ob}$ auch die von Heer (Die Fl. S. arct. Zone) beschriebene L. cretacea der L. Veneris verwandt ist, muss bis jetzt-dahin gestellt werden, da die Fragmente Heer's zum Vergleiche sehr ungenügend sind. 
Juniperus macilenta Heer (Die foss. Flora Grönl. I. Theil. S. 47. Taf. XXXV. 10, 11).

Taf. IX. Fig. 3, 4, 6. Taf. XII. Fig. 1.

Ästchen dünn, reichlich unregelmässig verzweigt, nicht schlank, moosartig, mit dichten, scharf abgedrückten, geraden, fein zugespitzten, einnervigen, schief abstehenden, gegenständigen Blättern. Lipenec.

In den Perucer Schieferthonen bei Vyšerovic im ersten Steinbruche vom Dorfe, seltener bei

Eine subtile Pflanze, welche auf den ersten Blick mehr einem Moose als einer Conifere älnlich sieht. Dass es eine Holzpflanze und nicht ein Moos ist, beweist vor allem die Schieferplatte Fig. 1., wo man neben den schönen Ästchen, welche hie und da gebrochen umherliegen und die besonders bei c) besser erhalten sind, ein dickeres Zweiglein bei a) sieht, welches scharf längsgestreift ist und undeutliche, scharf zugespitzte, locker stehende Blättchen trägt. Unten bei b) liegen mehrere ähnliche aber viel dickere, holzige Zweigstïcke, welche ebenso gestreift sind. Wahrscheinlich sind die letzteren als ein ganzer Zweig anzusehen, welcher aber bedeutend zerstückelt und verwest in die Gesteinsmasse eingebettet erscheint, da man hier zwischen den dickeren Zweigen zahlreiche, kleine Fragmente von beblätterten Ästchen findet, so besonders bei d).

Bei näherer Untersuchung unter der Luppe finden wir, dass die meisten Blättchen der kleinen Ästchen gegenständig sind; zwischen den einzelnen Blattpaaren befinden sich andere, langgezogene Abdrücke der decussirten Blattpaare. Die Blätter sind scharf abgedrückt und allmälig zugespitzt, schmal, einnervig, nach vorn gerade vorgestreckt und schief abstehend, nicht gekrümmt. Die Seitenästchen sind reichlich aber kur'.

Das Ästchen Fig. 6. liegt isolirt auf einer Schieferplatte und zeigt besonders gut die angedeuteten Details.

Fig. 4. ist ein vergrössertes und treu ausgeführtes Ästchen.

Das schöne Ästchen Fig. 3., welches von Lipenec herstammt, zeigt alle Merkmale der Vyšerovicer Ästchen. Die Blättchen sind besonders scharf abgedrückt, dünu, fein zugespitzt und vorwärts gerichtet, zumeist gegenständig.

Es lässt sich nicht leugnen, dass unsere Pflanze mit Heer's J. macilenta sehr verwandt und wahrscheinlich identisch ist. Alle Merkmale, wie sie Heer angibt (l. c.), stimmen mit denen unserer Pflanze vollkommen überein.

Einige Arten der lebenden Gattung Juniperus gleichen diesem Fossile nicht wenig, sie sind aber grösstentheils robuster, niemals so gracil gebaut, wie es bei J. macilenta vorkommt. Die Auffindung der Früchte muss die Stellung dieser Conifere noch bestätigen.

\title{
Abietineae.
}

\section{P in us I on gis s i m a m.}

\author{
Taf. I. Fig. 14-17.
}

Der Zapfen $31 \mathrm{~cm}$ lang, $3 \mathrm{~cm}$ im Durchmesser, beinahe der ganzen Länge nach gleichmässig dick, cylindrisch, am Grunde abgerundet, mit einem starken etwa $3 \mathrm{~cm}$ langen Stiele. Schuppen mehr als $2 \mathrm{~cm}$ lang, unterhalb des Schildchens etwa $8 \mathrm{~mm}$ breit und von hier gegen die Basis hin allmälig verschmälert, holzig. Schuppenschildchen rhombisch, ein wenig gewölbt, mit einem undeutlichen Grübchen in der Mitte. Samen ellipsoidisch, zu zweien der Schuppenbasis aufsitzend.

Dieser Zapfen wurde bei Kralup vom H. Prof. Ant. Frič in einer Schichte gefunden, welche über den Perucer Sandsteinen liegt und aus einem grobkörnigen, mit grösseren Quarzstücken gemischten Sandsteine besteht, der noch zu den Perucer Schichten gezählt ùnd von den Arbeitern Droždí genannt wird.

Der Zapfen ist in jeder Hinsicht sehr gut erhalten und zeigt auch alle Details, welche sich auf einem Coniferen-Zapfen überhaupt wahrnehmen lassen. Er ist in der Mitte gebrochen und nur auf der Stelle bei i) in Folge des Bruches des Steinstückes theilweise beschädigt. Obwohl die abnehmende Grösse und die Anordnung der Schildchenabdrücke bei der Zapfenspitze das Ende des Zapfens andeuten, so kann doch der Schildchenabdruck $b$ ) nicht für den letzten gehalten werden, sondern wir müssen uns nach der ganzen Configuration der bereits erhaltenen Zapfenspitze den Zapfen noch um etwa $1 \mathrm{~cm}$ verlängert denken. Der Zapfen ist etwa $3 \mathrm{~cm}$ breit, auf der linken Seite im Umrisse überall erhalten, gerade, nur in dem oberen Theile schwach gebogen. Der Zapfenstiel ist ungewöhnlich dick, gebogen und zeigt auf dem Abdrucke eine holzige, feste Beschaffenheit. 
Die Basis des Zapfens ist abgerundet. Ich habe in dieser Partie die aufeinander liegenden Schuppen entfernt, um die Schildchenabdrücke zu sehen. Diese sind rhombisch, scharf und tief im Sandsteine abgedrückt, in Parastichen angeordnet, zur rechten Seite theilweise verwischt. Auf der Abbildung Fig. 15, welche nach einem positiven Abdrucke im Wachse hergestellt wurde, sieht man die Zapfenbasis, wie sie in natürlicher Form ausgesehen hat. Die Schuppenschildchen sind ziemlich gewölbt und mit einer kaum erkennbaren Vertiefung in der Mitte versehen. Eine Sculptur auf ihrer Oberfläche oder ein Centralschnabel, welcher für die meisten Pinus-Arten so charakteristisch ist, ist nirgends zu sehén, obwohl uns diese Schildchen in einem ziemlich guten Zustande erhalten blieben. Es ist demnach anzunehmen, dass die Schuppenschildchen dieser Pinus-Art nur gewölbt und in der Mitte schwach vertieft waren.

Im ganzen folgenden Theile des Zapfens finden wir gebrochene, zur linken Seite schief angeordnete Schuppen, deren Erscheinung ihrer ehemaligen holzigen Natur gut entspricht. Die Schuppe $e$ ) ist zufällig im ganzen oberen Umrisse und theilweise noch mit Schildchen erhalten. In der Partie $d$ ), besonders aber in jener bei c) finden wir die Schuppen nicht so unregelmässig gebrochen, sondern die Oberfläche dieser Partie ist ziemlich flach und tief, regelmässig quergestreift. Unmittelbar oberhalb dieser Querstreifen sieht man zwei ellipsoidische Samenabdrücke. Wir haben vor uns die Schuppenbasen, auf deren Innenseite je zwei Samen sitzen. Dass die betreffenden Samen nur auf diese Weise aufzufassen sind, beweist nicht nur ihre Anordnung und Form, sondern auch die Schuppen a) selbst, welche glücklicherweise der ganzen Länge nach erhalten sind und mit ihrer Basis in derselben Stelle enden. Die flügelartigen Anhängsel der Samen sind auf den Abdrücken nicht zu erkennen. Den zwei Schuppen bei a) gehören die zwei ersten rhombischen Schildchen an, nach denen noch mehrere, ziemlich flach und fein abgedrückte Schildchen anderer Schuppen folgen.

Fig. 16. stellt uns die obere Ansicht einer isolirten Schuppe dar, Fig. 17. die untere Ansicht derselben.

Die bereits erörterten Merkmale dieses Zapfens beweisen ohne Zweifel, dass man es hier mit einer echten Pinus-Art zu thun hat. Ich kann aber keine verwandte Art weder von der lebenden, noch von der ausgestorbenen Flora zur Vergleichung finden. Es ist demnach eine untergegangene Form, zu welcher verwandte Typen in den Erdschichten zu suchen sind.

Der Zapfenstiel ist ungewöhnlich lang und dick, dem robusten Zapfen aber vollkommen angemessen. So lange und starke Zapfenstiele fand ich bei keiner anderen mir bekannten Pinus-Art. Die Krümmung und Länge dieses Zapfenstieles deuten darauf hin, dass diese Zapfen von Ästen herabhingen.

\section{Pinus sulcatam.}

\section{Taf. VII. Fig. 11, 5.}

Der Zapfen lang, cylindrisch, an der Spitze mässig verschmälert. Die Schuppenschildchen anderthalb $\mathrm{cm}$. breit und lang, rundlich-rhombisch, flach, nur schwach gewölbt, auf der Oberfläche mit tiefen Furchen, welche unregelmässige, polygonale Feldchen bilden. Die Schuppe selbst etwa $3 \mathrm{~cm}$. lang, holzig, zur Basis hin verschmälert.

Wurde in dem Weissenberger Pläner bei $\mathrm{S} c h l$ an nur in dem einzigen Exemplare gefunden, welches mir durch die Freundlichkeit des H. Dr. Novák aus den geol. Universitätssammlungen zu Prag zur Untersuchung geborgt wurde.

Vom ganzen Zapfen hat sich etwa nur die obere Hälfte erhalten; am Grunde des Fragmentes finden wir noch Schildchenabdrücke a) b) c), welche gerade so gross sind wie die schönen oberen Schildchen d) e), weshalb hier die Verschmälerung gegen die Basis noch nicht beginnen kann; denken wir uns zu den Schuppen abc) noch den ganzen unteren Theil hinzu, wie er z. B. auf der Schuppe d) zu sehen ist, so müssen wir uns den ganzen Zapfen wenigstens zweimal so lang denken, als er im Abdrucke liegt, da unter den untersten Schuppen $a b c$ ) noch einige andere Schuppen folgen müssen.

Den äusseren Umrissen des vorliegenden Zapfenfragmentes nach war dieser Zapfen schlank-cylindrisch, sehr verlängert, mit verhältnissmässig grossen aber spärlichen Schuppen. Die Schuppenschildchen sind undeutlich rhombisch, mit bogenförmigen Grenzcontouren, auf der Oberfläche flach und durch sonderbare Furchen in unregelmässige, polygonale Feldchen getheilt. Der untere Theil der Schuppe verschmälert sich allmälig zur Basis und ist undeutlich fein runzelig längsgestreift. In der Stelle $f$ ) sehen wir mehrere Schuppen, welche dicke, holzige Beschaffenheit zeigen und auf einander liegen. Samen finden sich auf den Schuppenfragmenten nicht vor. Der obere Theil des Zapfens zeigt sehr schön abgedrückte Schuppenschildchen.

Die Form der Schuppen (F. 5 stellt sie restaurirt dar) beweist uns genau, dass das abgebildete Zapfenfragment der Gattung Pinus angehört, es ist aber schwer eine analoge Art zur Vergleichung herbeizuziehen. Durch die furchige Structur sieht das Schildchen so aus, als wäre es mehrmals geborsten und da 
dies ausnahmslos bei allen Schildchen der Fall ist, so muss man diese Structur für ein specifisches Merkmal gelten lassen. Wahrscheinlich gehört dieser Zapfen in die Verwandtschaft der Pinus Strobus, wo ebenso verlängerte Zapfen mit ähnlich spärlichen aber verhältnissmässig grossen Schuppen vorkommen; die Schuppenschildchen sind gleich gross, von annähernd ähnlichen äusseren Umrissen und ebenso wenig gewölbt und flach. Nur der kleine, fast rudimentäre Schnabel, in welchen die Spitze des Schuppenschildchens der P. Strobus endet, findet sich nicht bei P. sulcata.

Nach der sonderbar gefurchten Oberfläche der Schuppenschildchen habe ich diese Kreideart P. sulcata benannt.

\section{Pinus protopicea $m$.}

Taf. VII., Fig. 1, 4, 6. Taf. III., Fig. 4.

Der Zapfen $16 \mathrm{~cm}$ lang, cylindrisch, durchschnittlich etwa $5^{1 / 2} \mathrm{~cm}$ breit, in dem unteren Drittel etwas breiter, am Grunde und an der Spitze abgerundet. Die Schuppen holzig, in dem oberen Drittel am breitesten, vorn in eine stumpfe Spitze kurz verschmälert, gegen die Basis keilförmig herablaufend, gewölbt.

Das einzige erhaltene Exemplar, welches hier abgebildet ist, wurde von Prof. Dr. A. Fri č in dem Perucer Sandsteine bei Vyšerovi c gefunden.

Der Zapfen ist auf dem Steinstücke so gebrochen, dass die grössere Hälfte mit der Centralspindel auf dem anderen Steinstücke, welches wir leider nicht besitzen, geblieben ist. Aus dieser Ursache können wir auch den Zapfenstiel auf unserer Hälfte nicht sehen, da derselbe auf der anderen Hälfte die Centralspindel geblieben ist.

Auf dem vorliegenden Zapfen sieht man vor allem dicke, flach ausgebreitete Schuppen, welche sich dachziegelartig decken und welche etwa in der Mitte gebrochen sind. Am besten sind sie in dem unteren Theile des Zapfens zu sehen. Die Stelle c) ist beschädigt und deshalb schuppenlos. Bei der Spitze des Zapfens sind diese Schuppen etwas verkleinert, in der Stelle k) gegeneinander geneigt. Die Schuppen d) und e) habe ich vorsichtig in dem Sandsteine von den sie deckenden anderen Schuppen weggelöst, so dass man ihr stumpfes Ende und ihre Breite im oberen Theile gut wahrnehmen kann. Eine andere noch besser im Umrisse und sammt der Spitze erhaltene Schuppe liegt auf demselben Steinstücke links von dem abgebildeten Zapfen auf dem Fragmente eines anderen Zapfens. Sie ist am Ende in eine Spitze zusammengezogen und fein längs-gerunzelt; die Runzeln sind in der Schuppenspitze zusammenlaufend.

Die Schuppen waren etwa von der Grösse, welche uns Fig. 4, Taf. III. darstellt. Auf dem Zapfen sind sie unter spitzen Winkeln abstehend; dieselben waren nicht dick, besonders am Rande dünn und daselbst einwärts gebogen, so dass sie im Ganzen gewölbt erscheinen. Im Querbruche findet man sie mit gebogenen Spitzen zur linken und rechten Seite des abgebildeten Zapfens. Wir müssen daher, um das Bild des Zapfens zu erhalten, seine ganze Breite von den Spitzen der seitlichen Schuppen a) zu den Spitzen der rechts liegenden Schuppen b) messen, da sich hier noch Schuppen vorfinden, welche aber quergebrochen sind. Auf den letzteren sieht man schön ıhre Lage zur Centralaxe, ihre Dicke und die einwärtsgebogenen Spitzen. Figur 6 stellt. eine solche Schuppe in restaurirter Form dar, welche etwa in der Mitte durchgeschnitten ist. Samen konnte ich freilich nicht finden, weil die Basis der Schuppen überall fehlt. Es ist auch nirgends eine Spur nach den Bracteen vorhanden.

Die Form der Schuppen ist also auf Grundlage der oben erwähnten drei Schuppenfragmente leicht zu construiren, ihre Lage ist auf dem bereits beschriebenen Zapfen bestimmt, wir können also ziemlich sicher den ganzen Zapfen restauriren, was auch auf der Abbildung Fig. 1 geschehen ist. Dass diese Abbildung treu der Natur entspricht, beweist die Fig. 12, welche uns den positiven Abdruck der Zapfenbasis Fig. 4 im Wachse darstellt. Hier sei nur bemerkt, dass die Schuppen etwa unter der Mitte ihrer Länge gebrochen sind und in Folge dessen muss die Zapfenbasis viel kleiner sein als dieselbe auf dem restaurirten Zapfen Figur 1 erscheint.

Beobachtet man nun den restaurirten Zapfen, so ist seine Ähnlichkeit mit den Zapfen der lebenden Pi c e a ex.cels a gleich auffallend. Die Schuppen sind nur etwas grösser, und der ganze Zapfen viel robuster. Die Schuppenform ist fast dieselbe; die Schuppenspitze ist ebenso einwärts gebogen, die Schuppenränder ähnlich verdünnt. Der Zapfenstiel ist freilich nicht vorhanden; ich habe ihn aber auf dem restaurirten Zapfen der P. protopicea auf Grundlage der P. excelsa ergänzt.

Zerschneidet man den Zapfen von P. excelsa der Länge nach so, dass der grösseren Hälfte die Centralspindel zurückbleibt, so erhält man in verkleinerter Form dasselbe Bild, welches uns der fossile Zapfen 
der P. protopicea darstellt. Ich halte deshalb dafür, dass die P. protopicea jedenfalls in die nächste Verwandtschaft der P. excels a angehört.

Die Abbildung Figur 3, Tafel IV. gehört einem Zapfenfragmente an, von welchem nur gesagt werden kann, dass es einen endständigen Theil eines Pinus-Zapfens vorstellt. Die obersten Schuppen sind bedeutend verkleinert und beenden bereits den Zapfen. Links sieht man 3 grosse Schuppen, deren Ränder und Schildchen abgebrochen sind. Sehr schön sind die :Samenpaare, die der Basis der einzelnen Schuppen aufsitzen und im Innern des Zapfenfragmentes erhalten sind, so dass man auf Grundlage derselben das Fragment zur Gattung Pinus mit ziemlich grosser Wahrscheinlichheit stellen kann. Die Schildchen sind nur auf den obersten Schuppen und das noch sehr ungenügend angedeutet. Die übrigen Schildchen waren schon vor der Fossilification abgebrochen.

Die Möglichkeit, dass dieses Fragment der Pinus sulcata angehört, ist nicht ausgeschlossen. Die. Schuppen sind ebenso gross, ebenso spärlich und nach der schiefen Richtung, in der sie von der Centralspindel abstehen, zu urtheilen, war der Zapfen, von dem das Fragment herrührt, bedeutend verlängert.

Der Fundort desselben sind auch die Weissenberger Plänerschichten (bei Prag) wie derjenige der Pin. sul cata.

\section{Pinus Quenstedti Heer (Kreide-Flora von Moletein).}

Taf. VI. Fig. 4. Taf. VII. Fig. 7, 8. Taf. VIII. Fig. 10.

Sehr lange, dünne, dreikantige, feste Nadeln je zu 5 in Büscheln verbunden. Die jungen Zweige mit erhabenen, vorne abgerundeten, mit einem Närbchen versehenen, langen Blattpolstern.

In den grauen Perucer Schieferthonen bei Vyš erovic in einer dünnen Schicht massenhaft beisammen. Einzelne Nadeln in den Perucer Schieferthonen bei Landsberg.

Ich habe eine Schieferplatte von dem Vyšerovicer Fundorte bei Fig. 4 abgebildet, auf welcher neben den unzähligen, in allen Richtungen herumliegenden Nadelabdrücken etwa in der Mitte eine Menge von sehr langen, parallel verlaufenden Nadeln zu sehen ist, welche wohl noch einem Zweige aufsassen und deshalb auf der Schieferplatte noch in gleicher Richtung verlaufen.

Die Abdrücke zeigen eine feste, derbe Consistenz, so dass sie von keinen weichen Würzelchen oder weichen Wasserpflanzen herrühren können. Die seitlichen parallelen Contouren sind sehr scharf und zumeist eine gerade, schmale Fläche umgebend. Stellenweise ist aber die letztere durch eine scharfe Rinne vertreten; Fig. 7 stellt sie vergrössert dar. Es waren demnach die abgedrückten Nadeln scharf dreikantig, so wie man es noch bei den verwandten Mexilkanischen Strobus-Arten vorfindet.

Ein weiterer Beweis, dass diese nadelartigen Abdrücke nur Pinus-Nadeln angehören können, ist die Stelle a) Fig. 4, wo 5 Nadeln in einem Punkte zusammenlaufen und so einen Büschel bilden. Dieser Nadelbüschel ist, viel besser auf der negativen Schieferplatte abgedrückt, wo noch ein anderer daneben liegt. Auch der Umstand, dass die linienförmigen Abdrücke sehr häufig zu zweien und mehreren einander genähert verlaufen oder in einer Stelle zusammenlaufen, deutet auf ihre ehemalige büschelartige Verbindung hin.

Zur rechten Seite der abgebildeten Steinplatte habe ich ein Zweigfragment entdeckt, auf dem verlängerte, vorne abgerundete und mit einer Narbe versehene Polster wahrzunehmen sind.

Die seichte Rinne elnes jeden Polsters entspricht dem erhabenen Polsterkiele. Es ist dies also ein junger Pinus-Zweig, dessen Polstern die Nadelbüschel aufsassen. Er gleicht in jeder Hinsicht den jungen Zweigen der allgemein cultivirten Pinus Strobus, und es ist wohl anzunehmen, dass er mit den nebenliegenden Nadeln in eine Art verbunden werden kann. Oberhalb dieses. Zweiges befinden sich noch zwei kleine ähnliche Ästchenabdrücke. Das gleichzeitige Vorhandensein der Pinus-Zweige bestätigt noch mehr die Deutung der Nadelabdrücke auf der abgebildeten Schieferplatte.

$\mathrm{H}$ e e $\mathrm{r}$ hat ganz ähnliche, dünne Nadeln, welche aber noch in Menge einem polstertragenden Zweige aufsitzen, von Moletein in Mähren (l. c.) beschrieben. Der Habitus, sowie alle Mèrkmale der Heer's PinusNadeln gleichen den unserigen vollkommen. Die Länge dieser Nadeln war aber so gross, dass die abgebildete Steinplatte von Vyšerovic einem ganzen Nadelbüschel nicht genügen kann. Die Moleteiner Nadeln sind ebenso in Büscheln verbunden.

Die Ähnlichkeit der Vyšerovicer und Moleteiner Flora, das gleiche Alter der beiden Standorte machen die Annahme, dass unsere Nadelabdrücke der Moleteiner P. Quenstedti angehören, noch wahrscheinlicher. Die zahlreichen in Büscheln verbundenen Nadeln müssten, ihrer Länge gemäss, nach Art der Strobus- 
Arten von Zweigen herabhängen, und da ihre Länge auch die mit den längsten Nadeln versehenen lebenden Arten dieser Gruppe übertrifft, so gehörte die P. Quenstedti den zierlichsten Bäumen der Perucer Wälder an.

Das Zweigfragment Fig. 10 rührt auch von Vyšerovic her. Es ist ein junges Ästchen und zwar nur das innere, nackte Holz, von dem die Rinde abgelöst ist. Die geraden Nadeln laufen gegen das Ästclıen hin in verschiedenen Richtungen zusammen, es ist aber schwer zu ermitteln, wie viele von denselben einen Büschel bilden. Auf der Abbildung sind nur wenige gezeichnet, da die meisten Nadeln im Schiefer in allen Richtungen auseinanderlaufen.

Abies calcaria $\mathrm{m}$.

Taf. V. Fig. 1. Taf. VI. Fig. 17.

Blattnadeln lineal, bis $2 \frac{3}{4} \mathrm{~cm}$. lang, stumpf, etwa von der Mitte gegen die Basis hin allmälig verschmälert, derb lederartig, mit einem dicken Mittelnerven und mehreren parallel verlaufenden, feinen Streifen.

In dem Weissenberger grauen Kalksteine, welcher spärliche Spuren von Glimmer enthält und von schieferartiger Beschaffenheit ist, bei Bezděkov in der Umgebung von Reichenau vom Herrn H. Barvír gefunden.

Blattnadeln dieser Art bilden im genannten Pläner eine dünne Schicht, in welcher sie massenhaft angehäuft sind. Die Abbildung Fig. 1 stellt uns in natürlicher Grösse ein Steinstück aus diesem Fundorte dar, auf dem besonders am oberen Ende eine Menge solcher Nadeln zu sehen ist. Die Nadeln sind scharf abgedrückt, zumeist gebrochen, nur hie und da ist noch die Basis oder die Spitze, seltener die ganze Nadel erhalten. Unten liegt ein Zweigfragment, auf dem aber keine Structur wahrnehmbar ist, so dass es nur wahrscheinlich ist, dass dasselbe zu den Nadeln gehört.

Die Fig. 17 stellt in natürlicher Grösse und in treuer Ausfïhrung diese Nadeln dar. Sie haben dieselbe Form und Grösse wie die Nadeln der gewöhnlichen Tanne (Abies alba Mill.), vorne sind sie stumpf beendet und etwa von der Mitte allmälig gegen die Basis hin verschmälert. Sie zeigen eine feste, derbe Beschaffenheit. Die meisten sind nur blosse Abdrücke mit einem starken Mittelnerven, zwisclien welchem und dem Blattrande noch mehrere aber sehr feine Streifen verlaufen. Stellenweise ist der Nadelabdruck noch mit verkohlter Blattsubstanz erfüllt, auf der der starke Mittelnerv und die feinen Streifen hervortreten. Diese feinen Streifen sind auf den Nadeln lebender Tannenarten äusserlich nicht kennbar, obwohl sie unter der festen Epidermis als feste, aus sclerenchymatischen Zellen zusammengesetzte Streifen vorhanden sind.

Wir können folglich dafürhalten, dass sie im Laufe der Versteinerung durch eine Versenkung der Epidermis aus der Blattsubstanz mehr hervorgetreten und dadurch die Ursache der deutlichen Streifen auf dem Abdrucke geworden sind. Auf den starken Nadeln der P. silvestris, P. nigricans sind diese Streifen schon vom Aussen besonders unter der Luppe zu sehen.

Das Vorhandensein einer Abies-Art in den Weissenberger Schichten bietet uns noch einen weiteren Grund für die Richtigkeit der Bestimmung des Zapfens der Pinus protopicea, welche demnach in die nächste Verwandtschaft mit den Blattnadeln der Ab. calcaria gehört.

\section{Abies minor m.}

Taf. V. Fig. 14, 15. Taf. VIII. Fig. 1.

Nadeln etwa $2 \mathrm{~cm}$. lang, schmal-lineal, am Ende fein zugespitzt, gegen die Basis hin verschmälert mit einem nicht starken Mittelnerven und einigen feinen Längsstreifen.

Im grauen Kalksteine der Teplicer Schichten bei Raudnic vom Hr. Zahálka gefunden.

Die Blattnadeln dieser Art liegen in einer Menge auf einer Steinplatte Fig. 1 verwirrt beisammen. Nur wenige von ihnen lassen die Spitze oder die Basis erkennen, am meisten sind sie gebrochen oder durch unten- und obenliegenden anderen Nadeln in ihren Contouren undeutlich gemacht. Auf einzeln liegenden Nadelstücken tritt noch ihre Form hervor. Die Abdrücke sind tief im Gesteine eingesenkt, woraus nur auf ihre ehemalige feste Beschaffenheit zu schliessen ist. Die Form ist schmal-lineal, schwach zur Basis verschmälert und vorn ziemlich fein zugespitzt. Der Mittelnerv ist nicht stark und selten deutlich hervortretend. Beiderseits desselben sind wieder einige feine Längsstreifen erkennbar, welche die Nadelfläche durchlaufen.

Von den lebenden Abies-Arten steht der Ab. minor die Ab. picea Mill. am nächsten; die geringe Grösse der Nadeln, ihre schmale Form und besonders das fein-zugespitzte Blattende ist beiden gemeinschaftlich. Die Nadeln der Ab. picea sind aber noch kleiner und schmäler und noch dadurch nicht wenig abweichend, dass der Mittelnerv sehr stark und scharf hervortretend ist.

Fig. 14 stellt die Blattnadeln von Ab. minor in natürlicher Grösse und Form, die Fig. 15 dieselben vergrössert dar. 


\section{Abies chuchlensis m.}

Taf. V. Fig. 11-13.

Blätter nadelförmig, oben und unten allmälig verschmälert, mit parallelen Rändern, derb lederartig. Der Mittelnerv ziemlich stark, gerade, nicht hervortretend; zu beiden Seiten desselben noch zwei andere schwach hervortretende parallele Nerven. Der Blattstiel durch eine rundliche Narbe abfallend.

In den Perucer Thonen bei Kuchelbad nur in den zwei abgebildeten Exemplaren.

Die Nadel Fig. 12 ist ganz erhalten und zeigt eine feste, derbe Beschaffenheit. Die parallelen Seitennerven, wiewohl kennbar, sind doch fein hervortretend. Auf der zweiten Nadel Fig. 13, welche vorn abgebrochen ist, ist wie bei der ersteren wohl die Abgliederungsnarbe am Grunde zu sehen. Die Fig. 11 stellt die Nadel Fig. 12 vergrössert dar.

Die meisten Merkmale dieser Blattnadeln sprechen für die Verwandtschaft mit den Blattnadeln der Tanne, besonders lässt die Abgliederungsnarbe am Blattgrunde diese Vergleichung zu. Ich kann jedoch bei keiner lebenden Art der bezeichneten Pinus-Gruppe die zwei Seitennerven auf den Blattnadeln finden. Dieselben lassen sich auf ähnliche Weise wie bei Abies calcaria nicht erklären, und es bleibt daher ihre Stellung unter der Gattung Abies immerhin verdächtig. Diese Nerven fand auch Heer bei seiner Pinus Olafiana (die Kreideflora d. arct. Zone, S. 85, Taf. XX. Fig 10. Taf. XXIII. Fig. 19.). 



\section{TAFEL I.}

Krannera mirabilis Corda. Seite 1.

Aus dem Perucer Sandsteine von Nehvizd.

Fig. 1. Ein vollkommen erhaltenes Blatt in natürl. Grösse; die von der Achse abgegliederte Basis ist bedeutend verdickt; die Streifung der Blattoberfläche überall kennbar; die Blattspitze durch Druck gespalten.

Fig. 2. Eine Partie des vorhergehenden Blattes etwa zweimal vergrössert; die Nervation besteht aus zahlreichen parallelen Nerven.

Fig. 3. Eine Blattpartie mit 4 Nerven noch mehr vergrössert; zwischen den starken Parallelnerven sind noch andere, höchst feine Streifen bemerkbar.

Fig. 4-5. Zwei Blattfragmente mit gut erhaltener Blattspitze; in natürl. Grösse.

Fig. 6-7. Blattfragmente mit deutlicher Nervation und von schmälerer Form als die vorhergehenden Exemplare; in natürl. Grösse.

Podozamites obtusus Vel. Seite 9 .

Aus dem Perucer Sandsteine von Nehvizd.

Fig. 8. Ein vollkommen erhaltenes Blatt, in natürl. Grösse; die Blattoberfläche zeigt zahlreiche grobe Längssitreifen, welche am bedeutend verlängerten Blattstiele in längliche Narben übergehen; der Blattstiel ist vollkommen erhalten.

Fig. 9. Eine etwa zweimal vergrösserte Blattpartie mit starken parallelen Nerven, zwischen welchen sehr feine Streifen verlaufen.

Krannera mirabilis Corda. Seite 5 .

Aus dem Perucer Sandsteine von Nehvizd.

Fig. 10-11. Zwei kugelige, von oben zusammengedrückte Früchte, welche vielleicht zur Krannera mirabilis gehören; die kreisförmige Narbe in der Mitte zeigt die Stelle, wo die Frucht mit dem Stiele zusammenhieng; in natürl. Grösse.

Fig. 12. Durchschnitt einer Frucht in natürl. Grösse und Form.

Fig. 13. Eine auf Grundlage der vorhergehenden versteinerten Fruchtstïcke restaurirte Frucht im Durchschnitt und in natürl. Grösse; den inneren Steinkern, der noch mit dem Stiele zusammenhängt, umhülltt eine fleischige Aussenschicht.

Pinus longissima Vel. Seite 29.

Aus dem Perucer Sandsteine bei Kralup.

Fig. 14. Ein der ganzen Länge nach erhaltener Zapfen in natürl. Grösse; am Grunde befindet sich ein ungewöhnlich starker, gekrümmter Stiel; die untere Partie des Zapfens zeigt die Abdrücke der rhombischen Schildchen, während der ganze obere Theil in verschiedener Lage gebrochene Schuppen

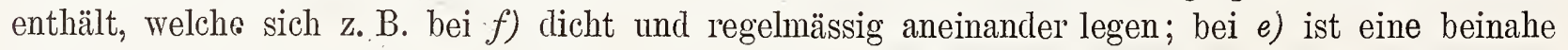
vollkommen erhaltene Schuppe; bei c) und d) sind ellipsoidische Samen zu sehen, welche den Schuppenbasen aufsitzen; bei a) sieht man einige Schuppen, welche oben mit rhombischen Schildchenabdrücken enden; bei $b$ ) die Spuren der letzten Schildchenabdrücke; bei $i$ ) eine verwischte Partie.

Fig. 15. Die Abbildung eines positiven Wachsabdruckes der Zapfenbasis Fig. 14.

Fig. 16. Aussenseite einer in natürl. Grösse restaurirten Zapfenschuppe.

Fig. 17. Dieselbe Zapfenschuppe von der Innenseite mit zwei Samen am Grunde.

Kranuera mirabilis Corda. Seite 5 .

Aus dem Perucer Sandsteine von Nehvizd.

Fig. 18. Eine Frucht, welche noch im Sandsteine liegt; die bei Fig. 13. angedeutete Form ist hier besonders erkennbar. 


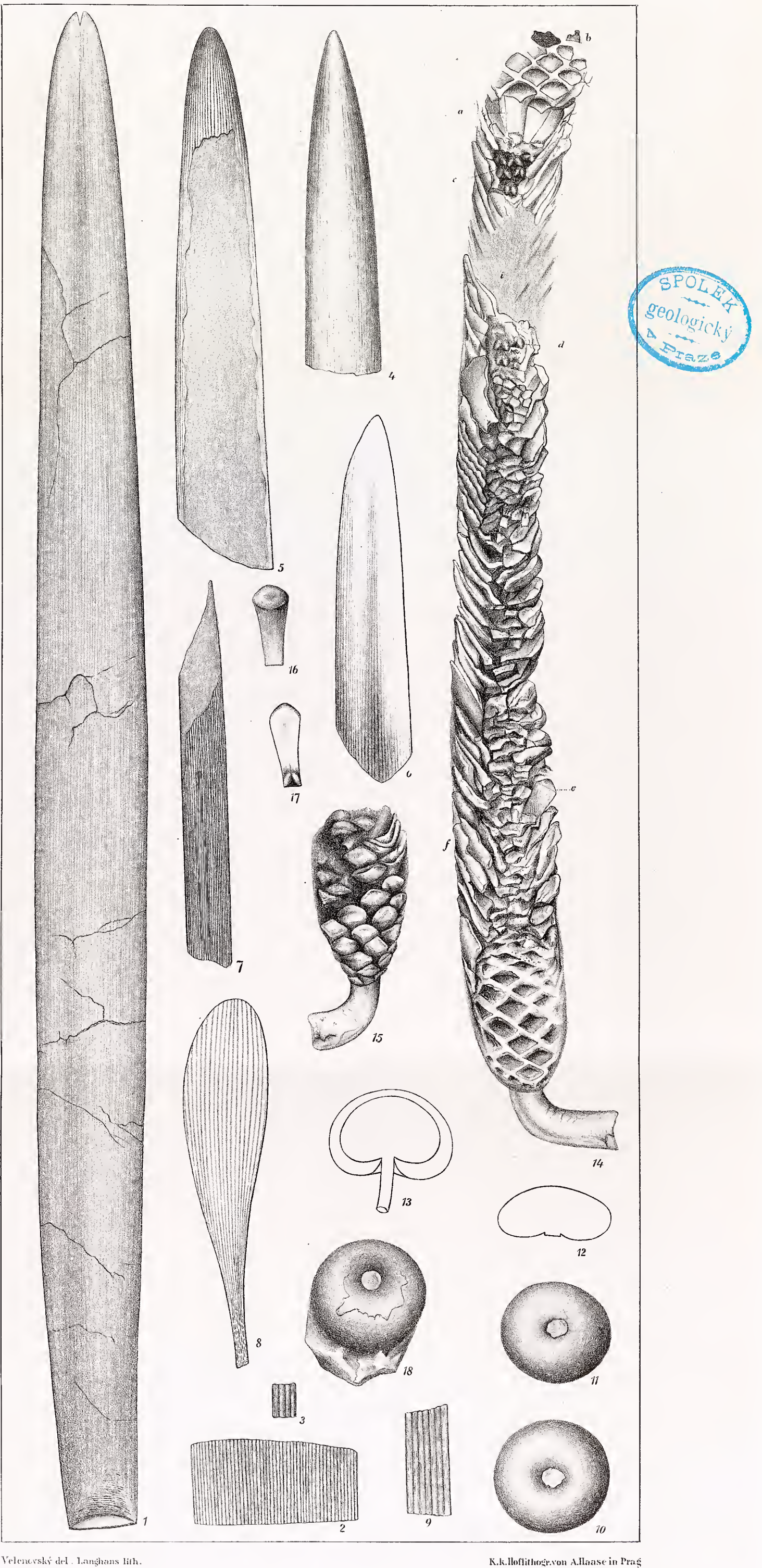


<smiles>c1ccccc1</smiles> 



\section{TAFEL II.}

Thinnfeldia variabilis Vel. Seite 6 .

Aus den plastischen Perucer Thonen von Kuchelbad.

Fig. 1-2. Zwei Blattstücke in natürl. Grösse von sehr unsymmetrischer Form.

Fig. 3. Die untere Partie eines Blattes mit gut erhaltenem Blattstiele; in natürl. Grösse.

Fig. 4. Ein Blatt, auf welchem der Mittelnerv nicht vorhanden ist; in natürl. Grösse; der Blattstiel besonders gut erhalten.

Fig. 5. Eine beinahe vollkommen symmetrische Blattform, in natürl. Grösse.

Podozamites latipennis Heer. Seite 10.

Aus den röthlichen Perucer Schieferthonen von Liebenau.

Fig. 6. Der untere Theil eines Blattes, auf welchem die breit abgestutzte Basis zu sehen ist; in natürl. Grösse.

Podozamites longipennis Vel. Seite 10.

Aus den röthlichen Perucer Schieferthonen von Liebenau.

Fig 7. Die untere Hälfte eines Blattes mit gut erhaltener Basis und mit grober, paralleler Streifung auf. der Oberfläche; in natürl. Grösse.

Podozamites striatus Vel. Seite 10.

Aus den röthlichen Perucer Schieferthonen von Liebenau.

Fig. 8. Ein elliptisches Blatt mit gut erhaltener Basis und theilweise abgebrochener Spitze; die stärkeren Nerven wechseln mit feineren ab; in natürl. Grösse.

Podozamites Eichwaldi Heer. Seite 11.

Aus den plastischen Perucer Thonen von Ku chelbad.

Fig. 9. $\quad$ Ein Blattstück mit erhaltener Spitze; in natürl. Grösse.

Fig. 10. Ein anderes Blattstück mit kurz abgestutzter Basis; in natürl. Grösse.

Podozamites lanceolatus Heer. Seite 11.

Aus den plastischen Perucer Thonen von $\mathrm{Ku}$ chelbad.

Fig. 11-19. Blattformen von verschiedener Grösse; der Blattstiel ist überall deutlich abgetheilt, die Streifung fein, parallel; sämmtlich in natürl. Grösse.

Podozamites pusillus Vel. Seite 11.

Aus den plastischen Perucer Thonen von Kuchel bad.

Fig. 20-21. Zwei Blättchen mit einem deutlichen Stielchen und mit einer sehr feinen, parallelen Streifung; in' natürl. Grösse.

Fig. 22. Bruchstück eines ganzen Wedels, dessen Mittelrippe noch drei schön erhaltene Blättchen aufsitzen; in natürl. Grösse.

Podozamites Eichwaldi Heer. Seite 11.

Aus den plastischen Perucer Thonen von Kuchelbad.

Fig. 23. Ein Blatt mit deutlichem Stiele und ziemlich gut erhaltener. Spitze.

Fig. 24. Eine Thonplatte von Kuchelbad, auf welcher sich zwischen den häufigen, länglichen Blattabdrücken der Podozamites lanceolatus noch ein schönes Blattstück der Podozamites pusillus bei $a$ ) und ein Blattfragment von Diospyros provecta Vel. bei $b$ ) findet. Alles in nat. Grösse.

Nilssonia bohemica Vel. Seite 11.

Aus den Perucer Thonen von $\mathrm{Ku}$ ch el bad.

Fig. 25. Ein Blattstück nur in der mittleren Partie erhalten; der Blattrand nicht eingeschnitten; in natürl. Grösse.

Fig. 26. Ein Blatt, auf welchem die starke Mittelrippe, die seitlichen dichten Nerven und besonders gut erhaltene Basis zu sehen ist; in natürl. Grösse.

Fig. 27. Eine Blattspitze, welche nicht eingeschnitten ist; in natürl. Grösse.

Fig. 28. Ein schönes Blatt, welches die vordere kerbig eingeschnittene Spitze zeigt; in natürl. Grösse. 


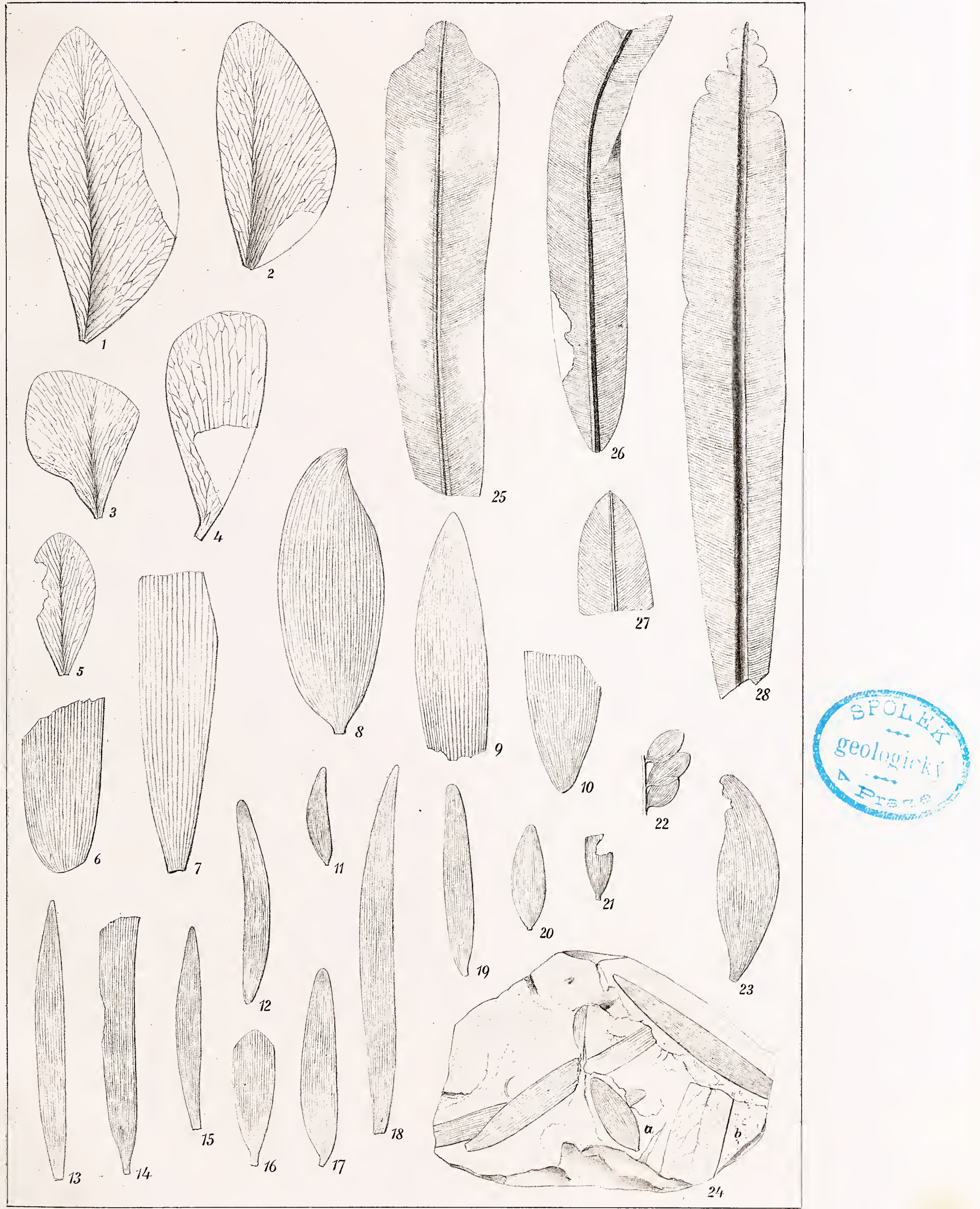

Velenorský del . Langhans lith.

K.k.Iloflithogrevon Allarse in l'mat 


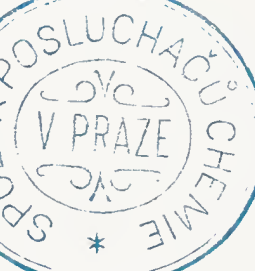




\section{TAFEL III.}

Fričia nobilis Vel. Seite 8 .

Aus den Plänerschichten vom Weissen Berg.

Fig. 1. Eim Zapfenfragment, welches aus zahlreichen, dicken, pyramidalen Schuppen zusammengesetzt ist; die Centralspindel ist abgebrochen, so dass man auf den dicken Schuppen die abgebrochene verschmälerte Basis sieht, in deren Mitte der centrale Gefässbündelstrang erkennbar ist; in nat. Gr.

Fig. 2. Ein auf Grundlage des Zapfenbruchstückes Fig. 3 restaurirter Zapfen in natürl. Grösse: der Stiel am Grunde übergeht im Zapfen in die starke Centralspindel.

Fig. 3. Ein Zapfen, der der ganzen Länge nach in der Mitte gebrochen ist, so dass auch die starke Centralspindel zu sehen ist; durch die starke Centralspindel lüuft ein dicker Gefässbündelstrang, von welchem sich die Seitenäste abzweigen, welche in die Schuppen hinauslaufen; auf den Schuppensäulchen sind gut die seitlichen Kanten und die kleinen Grübchen nach den Sporangien zu sehen; in natürl. Grösse.

Pinus protopicea Vel. Seite 31.

Aus dem Perucer Sandsteine von Ka uni c.

Fig. 4. Eine in natürl. Grösse restaurirte Zapfenschuppe.

Microzamia gibba Corda. Seite 6.

Aus den Perucer Schieferthonen von Vyšerovic.

Fig. 5. Ein gebrochener Zapfen, an dessen Grunde noch zahlreiche Doppelsamen angehäuft sind; bei a) sind die Haare, welche die Oberfläche der Schildchen bekleiden und die Punktirung auf den hexagonalen Schildchenabdrücken des oberen Theiles dieses Zapfenfragmentes verursachen; in der Mitte einzelner Schildchen sind zwei Grübchen zu sehen, welche den zwei Höckerchen auf dem Schildchen entsprechen; in natürl. Grösse.

Fričia nobilis Vel. Seite 8 .

Aus den Plänerschichten vom Weissen Berg.

Fig. 6. Ein Zapfenfragment, welchem der untere Theil fehlt, in natürl. Grösse; in der Mitte befindet sich die Centralspindel, welcher die einzelnen dicken Schuppen aufsitzen; links sieht man eine Schuppe, die mit einem sechseckigen Schildchen endet.

Microzamia gibba Corda. Seite 6.

Aus den Perucer Schieferthonen von Vyšerovic.

Fig. 7. Ein der ganzen Länge nach vollkommen erhaltener Zapfen, in natürl. Grösse; in der oberen Partie sind die zahlreichen, parastichisch angeordneten Schildchen zu sehen, in der unteren die Centralspindel und beiderseits derselben die Doppelsamen, zwischen welchen hie und da (so bei b)) Schuppenfragmente eingemischt sind; der Aussenrand des Zapfens ist von einer Haarschicht umgeben, welche auch bei a) wahrzunehmen ist.

Fig. 8. Ein Abdruck der Oberfläche eines Zapfens, wo besonders gut die Schildchenabdrücke hervortreten; in natürl. Grösse.

Fig. 9. $\quad$ Ein kleiner Zapfen aus dem Weiss enberger Pläner, in natürl. Grösse.

Fig. 10. Etwa zweimal vergrösserte Samen der Fig. 16; siehe die kernige Structur der Oberfläche.

Fričia nobilis Vel. Seite 8.

Fig. 11. Eine restaurirte und ein wenig vergrösserte Zapfenschuppe, auf welcher man die obere sechseckige Fläche und den grübchentragenden, dicken, unteren Theil sieht.

Vilssonia bohemica Vel. Seite 11.

Aus den plastischen Thonen von $\mathrm{Ku}$ chelbad.

Fig. 12. Ein ziemlich gut erhaltenes Blatt in natürl. Grösse.

Krannera mirabilis Corda. Seite 2.

Aus dem Perucer Sandsteine von Ne hviz d.

Fig. 13. Muthmasslicher Stengel, welcher mit den Krannera-Zapfen endet; die Blattnarben auf der Oberfläche; in natürl. Grösse.

Microzamia gibba Corda. Seite 6.

Aus den Perucer Schieferthonen von Vyšerovic.

Fig. 14. Der obere Theil eines Zapfens, welcher noch mit zahlreichen Doppelsamen erfüllt ist; die Samen zeigen stellenweise die kernige Structur der Oberfläche; in natürl. Grösse.

Fig. 15. Ein Zapfenfragment mit vollkommen reifen Samen; in natürl. Grösse.

Fig. 16. Ein isolirt liegender Same von derselben Form wie diejenigen bei Fig. 15.; in natürl. Grösse. 
Velenovský. Die Gymnospermen derböhm. Kreideformation.

Taf. III.

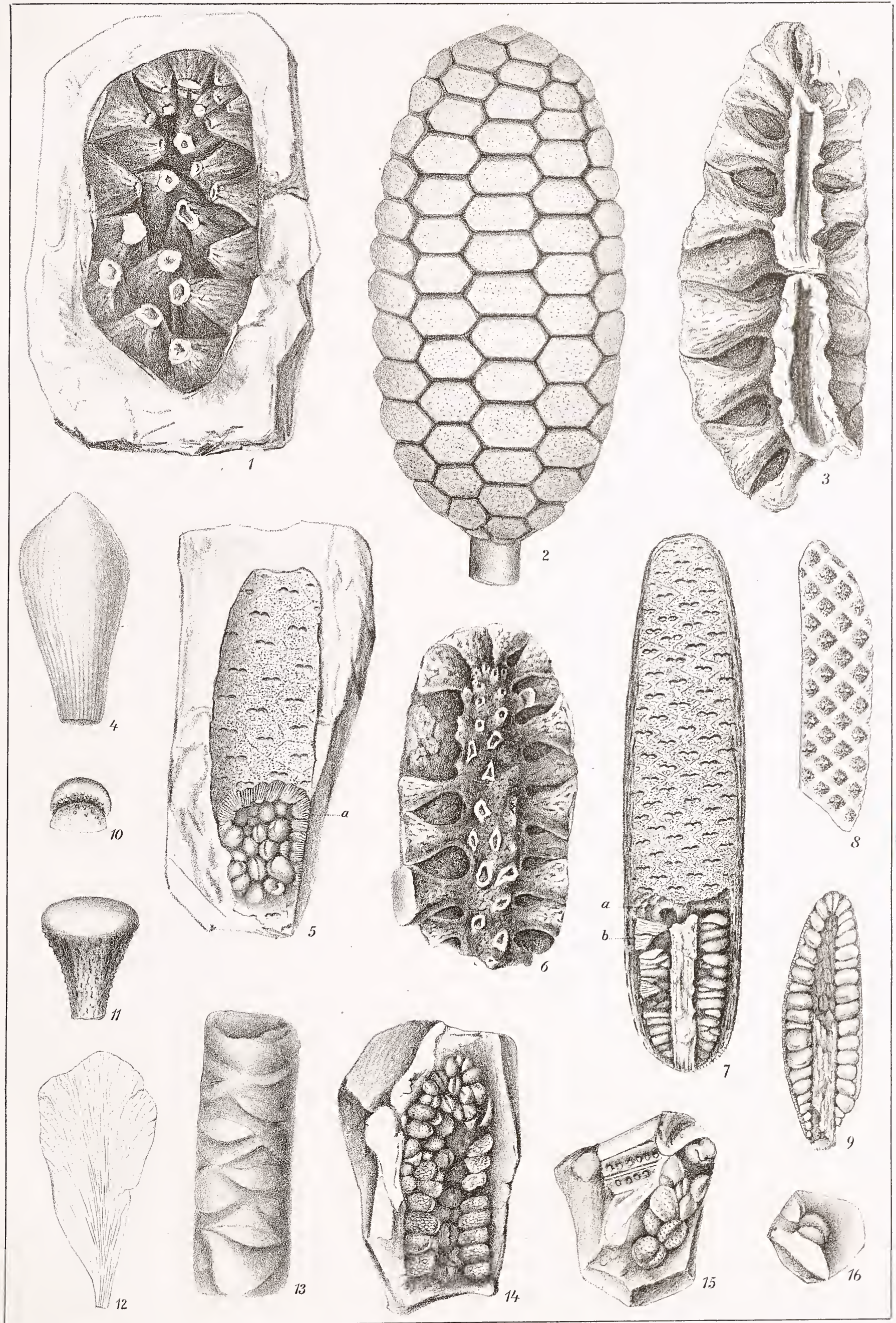






\section{TAFEL IV.}

Krannera mirabilis Corda. Seite 1.

Aus dem Perucer Sandsteine von Nehvizd.

Fig. 1. Ein zapfenartiger Stengel in natürl. Grösse; die parastichisch angeordneten dicken Schuppen zeigen eine tiefe Querrinne.

Fig. 2. Ein ähnlicher Zapfen, in dessen Mitte die ungewöhnlich dicke Centralspindel zu sehen ist; in natürl. Grösse.

Fig. 3. Fragment eines Pinus-Zapfens aus dem Pläner vom Weis sen Berg, auf welchem die Schuppe und am Grunde derselben die Samenpaare deutlich zu sehen sind; in natürl. Grösse; die Art unbestimmbar.

Krannera mirabilis Corda. Seite 1.

Aus dem Perucer Sandsteine von Nehvizd.

Fig. 4. Lin Krannera-Zapfen, wo man rechts mehrere Blätter sieht, die den einzelnen dicken Schuppen aufsitzen; in natürl. Grösse.

Cunninghamia elegans Corda. Seite 14.

Aus dem Schieferthone von Peruc.

Fig. 5. Sehr gut sammt der Nervation erhaltene Blätter; der Mittelnerv und die feinen seitlichen Streifen treten gut hervor; in natürl. Grösse.

Microzamia gibba Corda. Seite 6 .

Aus den Perucer Schieferthonen von Vyšerovic.

Fig. 6. $\quad$ Ein grosser Zweig, dessen einzelne Arme die Zapfen tragen; in natürl. Grösse.

Krannera mirabilis Corda. Seite 1.

Fig. 7. Ein bedeutend verlängerter Krannera-Zapfen, vielleicht eine andere Art als z. B. Fig. 1.; die Löcher oberhalb einer Schuppe entsprechen den Gefässbündeln, welche in die aufsitzenden Blätter eintreten; in natürl. Grösse; Perucer Sandstein von Nehvizd.

Fig. 8. Schematischer Durchschnitt eines Krannera-Zapfens in natürl. Grösse; a) der Stengel mit Blattnarben; b) die Basen der Blätter, welche als Schuppen fungiren; c) die Centralspindel als Fortsetzung des Stengels; d) die Blätter, welche den Schuppen aufsitzen.

Fig. 9. Ein Krannera-Zapfen aus dem Sandsteine von Jičín; der mit Blattnarben bedeckte Stengel steht noch mit dem Zapfen in Verbindung. 
Velenovský. Die Gymnospermen derböhm. Kreideformation.

Taf. IV.

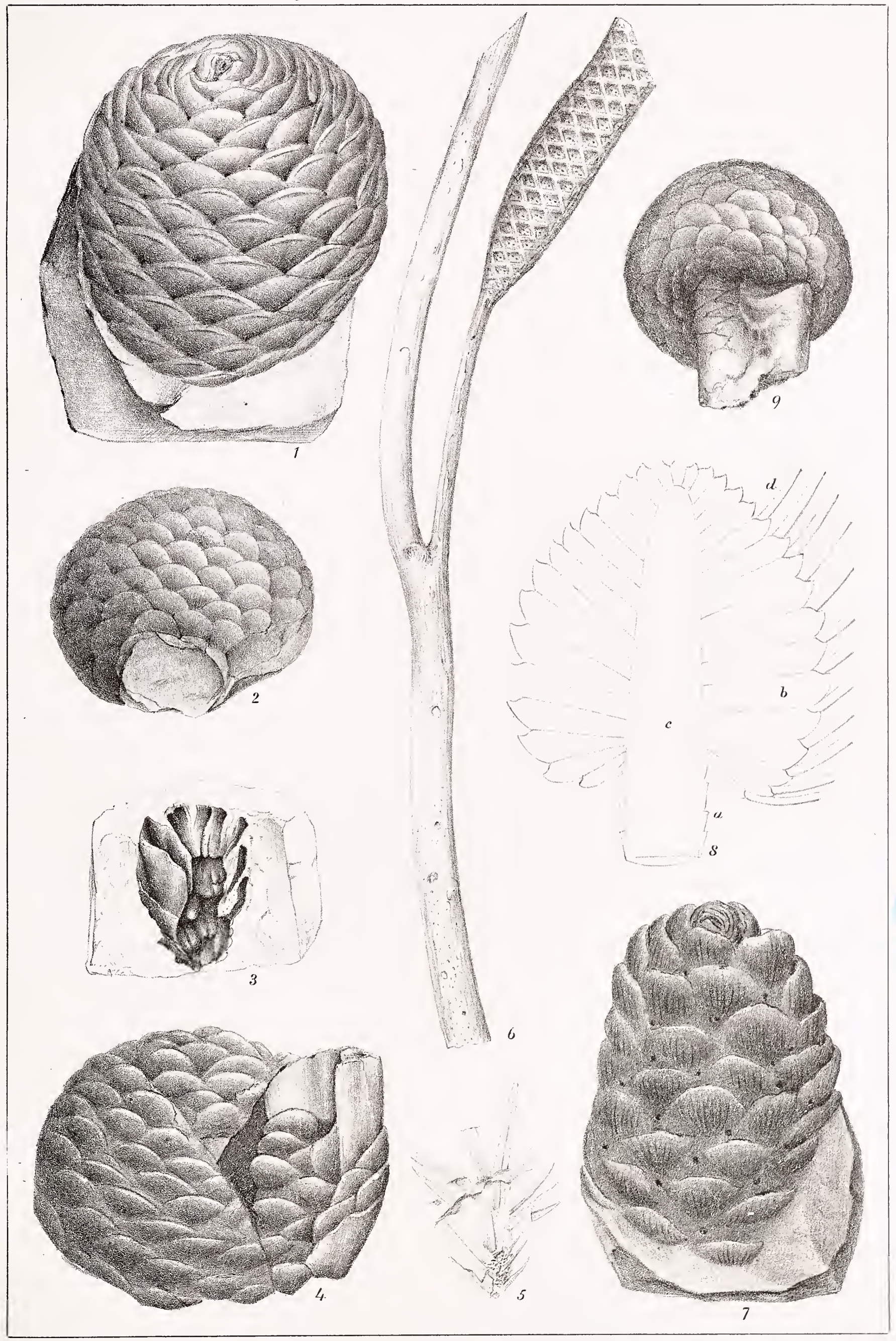

Velenovský del, Lanğhans lith.

K.k.Iloflithogir.von A.Ilaase in Pra 



\section{TAFEL V.}

Cunninghamia elegans Corda. Seite 14.

Aus dem Schieferthone von Peruc.

Fig. 1. Ein Stengelstück mit dicht stehenden, beinahe rundlichen Blattpolstern; in natürl. Grösse.

Cumminghamia stenophylla Vel. Seite 15.

Aus dem Schieferthone von Lip en ec.

Fig. 2. Ein Zweigstück in natürl. Grösse.

Cyparissidium pulchellum Vel. Seite 18.

Aus dem Korycaner Sandsteine von Kněživka.

Fig. 3. Ein Fruchtzapfen mit einigen in verschiedener Lage erhaltenen Schuppen; in natürl. Grösse.

Cumniughamia stenophylla Vel. Seite 15.

Fig. 4. Ein Blatt etwa zweimal vergrössert.

Fig 4a) . Blätter in natürl. Grösse.

Cyparissidium pulchellum Vel. Seite 18.

Fig. 5. $\quad$ Ein in natürl. Grösse restaurirter Zapfen.

Fig. 6. Zwei in natürl. Grösse restaurirte Schuppen, die eine von der Rückseite, die andere von der Unterseite mit Samen am Grunde.

Cunninghamia elegans Corda. Seite 14.

Fig. 7. Etwa zweimal vergrösserte verschiedene Blattformen.

Microzamia gibba Corda. Seite 6.

Aus den Perucer Schieferthonen von Vy š erovic.

Fig. 8. Eine Schieferplatte mit reifen Samen, in natürl. Grösse.

Cyparissidium pulchellum Vel. Seite 18.

Fig. 9. Negativer Abdruck der Fig. 3, auf welchem der kurze Stiel und die samentragenden Schuppenbasen zu sehen sind; in natürl. Grösse.

Cunnimghamia stenophylla Vel. Seite 15.

Aus dem Perucer Schieferthone von Lipenec.

Fig. 10. Ein beblättertes Zweigstück in natürl. Grösse.

Abies chuchlensis Vel. Seite 34 .

Aus dem plastischen Perucer Thone von $\mathrm{Ku}$ chelbad.

Fig. 11. Vergrösserte Abbildung des Blattes Fig. 12.

Fig. 12, 13. Blattnadeln in natürl. Grösse.

Abies minor Vel. Seite 33.

Fig. 14. Blattnadeln in natürl. Grösse.

Fig. 15. Ein Blatt vergrössert.

Cunninghamia stenophylla Vel. Seite 15.

Aus dem Perucer Schieferthone von Landsberg.

Fig. 16. Ein Zweigstück mit schmalen Blattnadeln; das Holz mit Blattpolstern nur am Grunde des Zweiges abgedrückt; in natürl. Grösse.

Abies calcaria Vel. Seite 33 .

Aus dem Pläner von Rei chenau.

Fig. 17. Blattnadeln in natürl. Grösse restaurirt. 


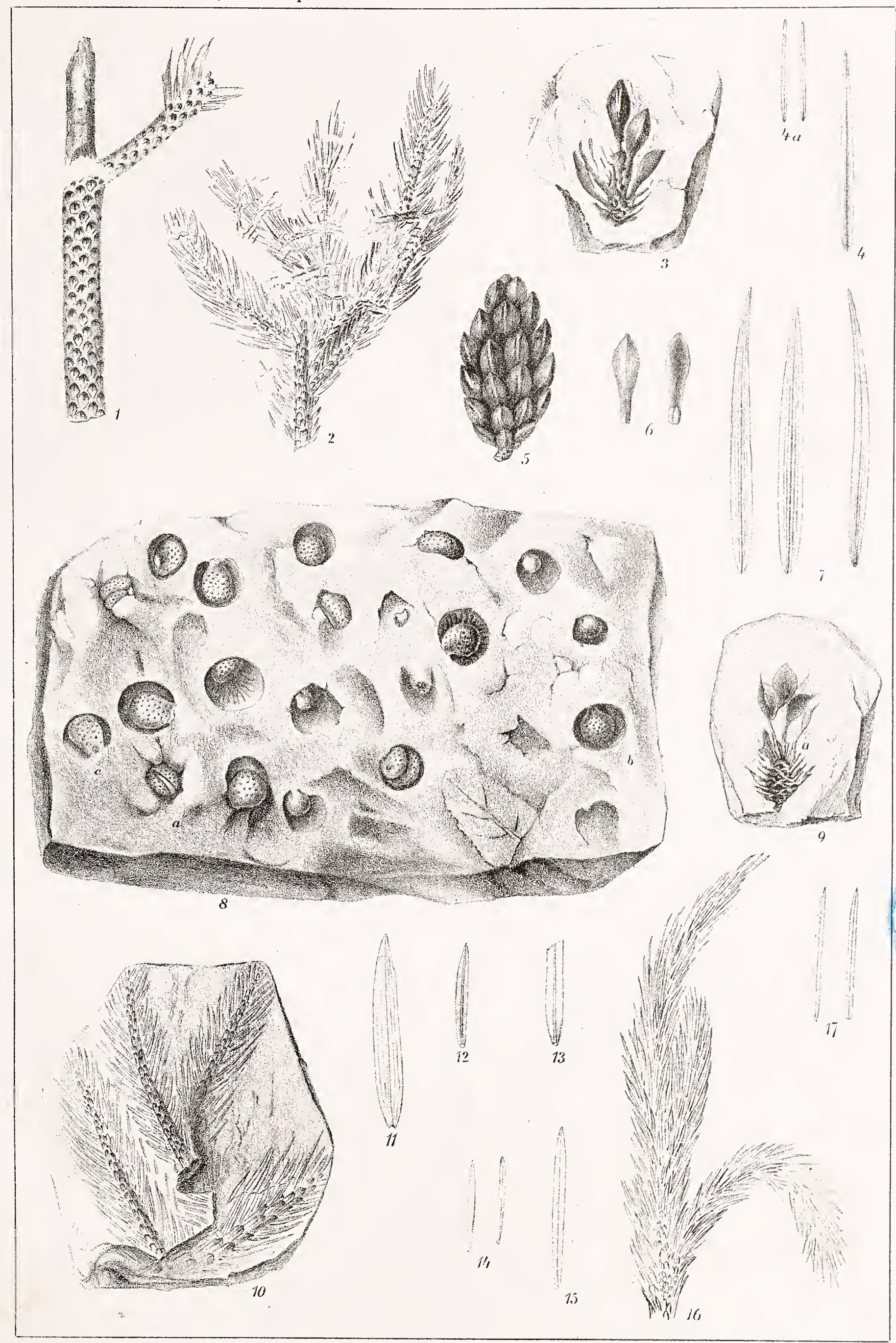






\title{
TAFEL VI.
}

\author{
Abies calcaria Vel. Seite 33. \\ Aus dem Pläner von Reich en au.
}

Fig. 1. Eine Steinplatte mit zahlreichen Blattnadeln, in natürl. Grösse.

Glyptostrobus europaens Heer, cretaceus Vel. Seite 26.

Aus den Perucer Schieferthonen von Lidic.

Fig. 2. Eine Schieferplatte mit beblätterten, jährigen Ästchen, in natürl. Grösse.

Echinostrobus squammosus Vel. Seite 16.

Aus den Perucer Schieferthonen von Vyšerovic.

Fig. 3. $\quad$ Ein altes Zweigfragment mit spiralig angeordneten Schuppen; in natürl. Grösse.

Pinus Quenstedti Heer. Seite 32.

Aus den Perucer Schieferthonen von Vy šerovic.

Fig. 4. Eine Schieferplatte mit einer Menge von langen Blattnadeln; bei a) ein Nadelbüschel; rechts ein Zweigstück mit Blattpolstern von derselben Art; in natürl. Grösse.

Cunninghamia elegans Corda. Seite 14.

Aus dem Schieferthone von Peruc.

Fig. 5. Ein Zweig mit schön abgedrückten Blättern und Blattpolstern; in natürl. Grösse.

Echinostrobus squammosus Vel. Seite 16.

Aus den Perucer Schieferthonen von Vyšer ovi c.

Fig. 6. Das Ende eines jungen Zweiges, wo die Schuppen noch decussirt angeordnet sind; in nat. Gr.

Fig. 7-8. Andere Zweigfragmente mit gut erhaltenen rhombischen Schuppen, welche höchst fein gestreift sind; in natiirl. Grösse. 


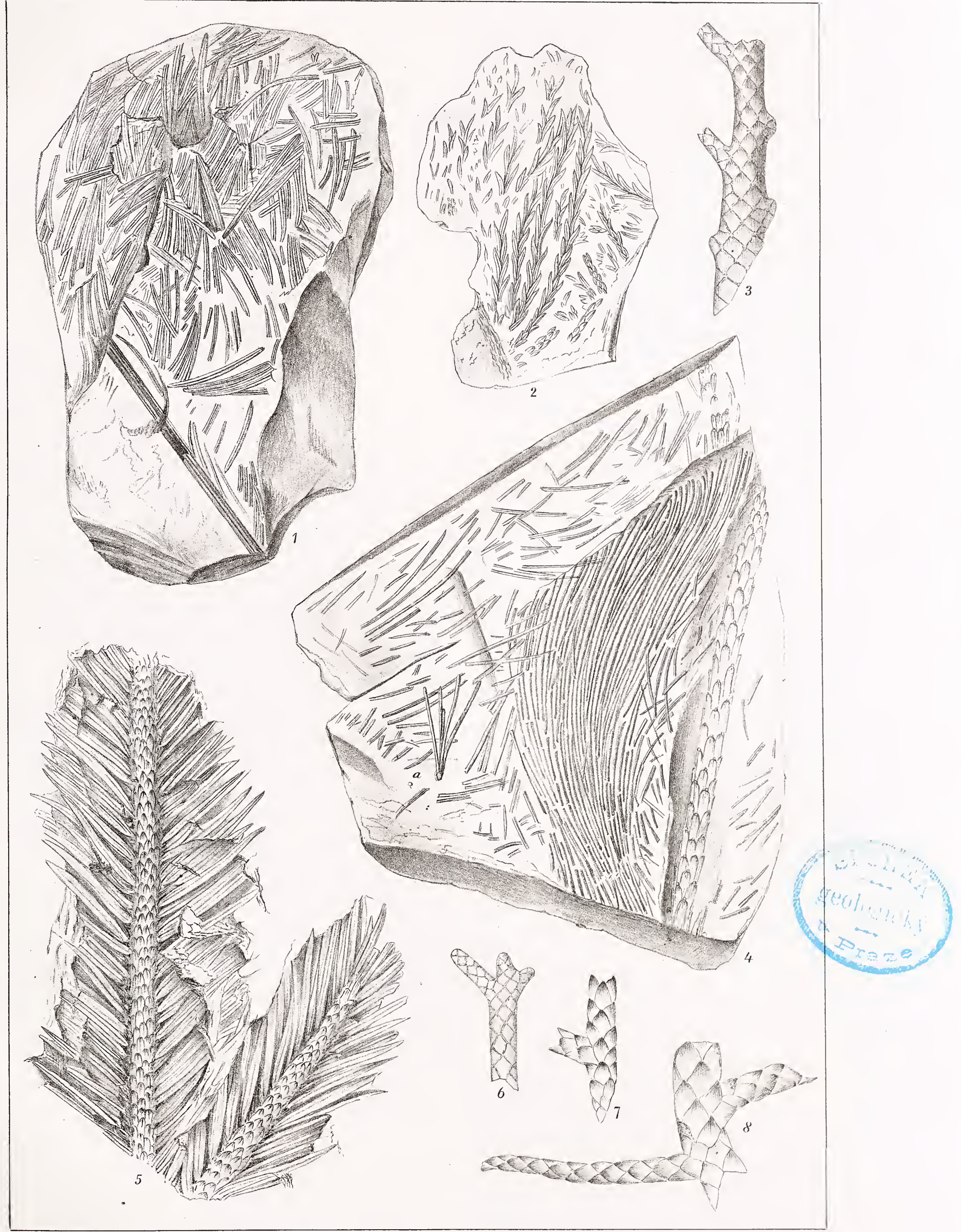

Velenovský del . Langhans lith. 
(c) 


\section{TAFEL VII.}

Pinus protopicea Vel. Seite 31.

Fig. 1. Ein auf Grundlage des Originals Fig. 4 in natürl. Grösse restaurirter Zapfen.

Glyptostrobus europaeus Heer cretaceus Vel. Seite 26.

Aus den Perucer Schieferthonen von Lidic.

Fig. 2. Zahlreiche dünne Ästchen mit Schuppenblättern, in natürl. Grösse.

Fig. 3. Ein jähriges Ästchen etwa dreimal vergrössert; die Schuppenblätter sind verlängert, herablaufend, zweizeilig angeordnet.

Pinus protopicea Vel. Seite 31.

Aus dem Perucer Sandsteine von K a u i i c.

Fig. 4. Ein gebrochener Zapfen ohne Centralspindel, in natürl. Grösse; in der Mitte zahlreiche, sich deckende Fruchtschuppen, von welchen diejenigen bei e) und d) beinahe vollkommen im Umrisse erhalten sind; die seitlichen Schuppen (so bei a) b)) sind gebrochen.

Pinus sulcata Vel. Seite 30 .

Fig. 5. Eine Fruchtschuppe in natürl. Grösse restaurirt.

Pinus protopicea Vel. Seite 31 .

Fig. 6. Eine in natürl. Grösse restaurirte Schuppe im Durchschnitt.

Pinus Quenstedti Heer. Seite 32.

Fig. 7. Ein Blattnadeltheil vergrössert; die tiefe Rinne in der Mitte.

Fig. 8. Blattnadeln in natürl. Grösse.

Glyptostrobus europaeus Heer cretaceus Vel. Seite 26.

Aus den Schieferthonen von Lidic.

Fig. 9. Ein etwa zweimal vergrösserter schuppentragender Zweig; die Schuppen sind mit einem scharfen Kiele versehen.

Fig. 10. Ältere beschuppte Zweigstücke in natürl. Grösse.

Pinus sulcata Vel. Seite 30 .

Aus den Plänerschichten von Schlan. In den Sammlungen des geol. Institutes der böhm. Universität.

Fig. 11. Ein etwa in der oberen Hälfte erhaltener Zapfen, in natürl. Grösse; bei a) b) c) Schildchenabdrücke der unteren Schuppen; bei d) und e) besonders schön abgedrückte Schuppenschildchen, welche breit-rhombisch und unregelmässig gefurcht sind.

Pinus protopicea Vel. Seite 31.

Fig. 12. Ein positiver Wachsabdruck der Zapfenbasis Fig. 4; die Schuppen sind etwa in der Hälfte abgebrochen. 


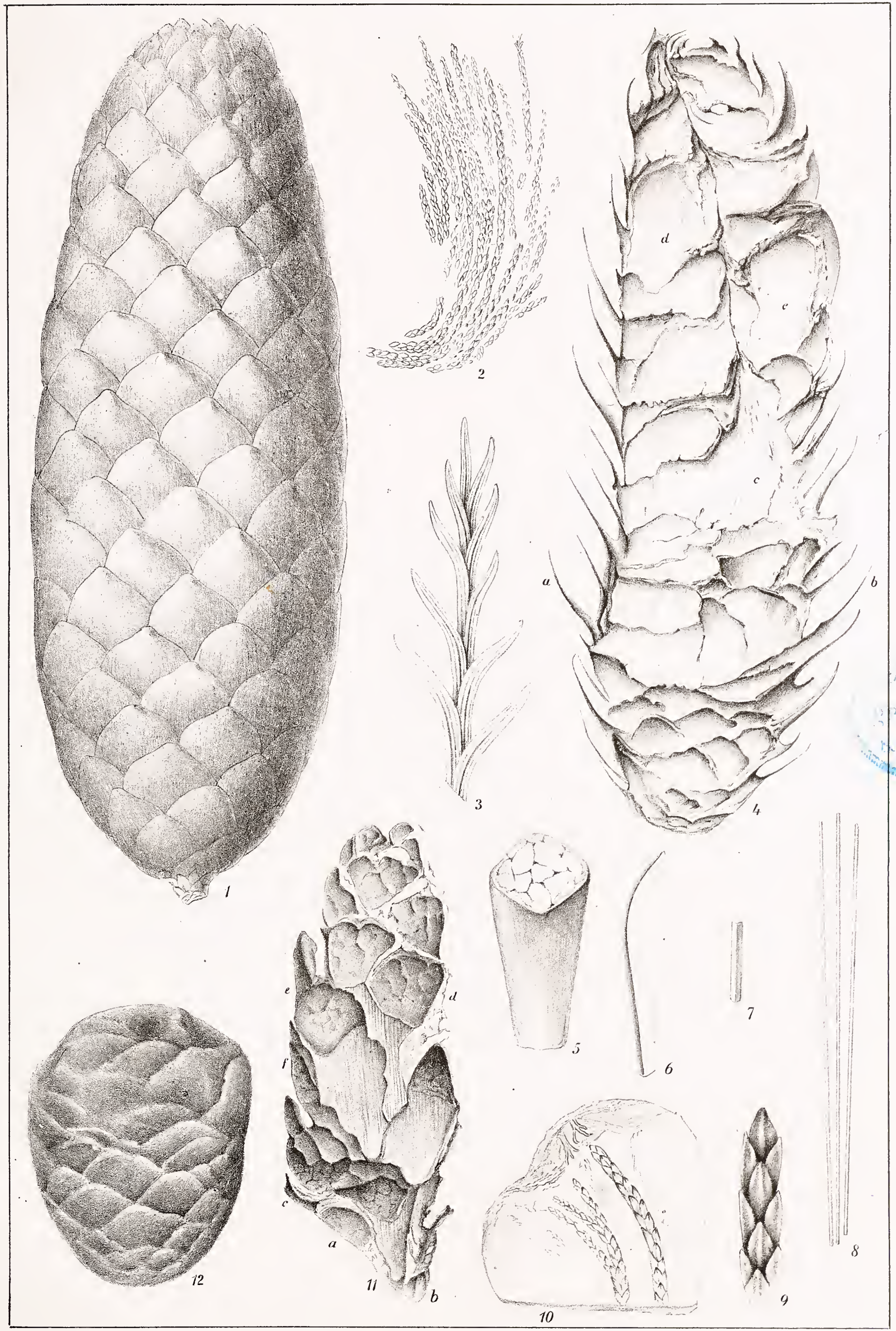

Velenovsliý del . Langhans lith.

K.k.Hoflithogivon A.Haase in Prą 



\section{TAFEL VIII.}

Abies minor Vel. Seite 33.

Aus den Teplicer Schichten von Raudnic.

Fig. 1. Eine Schieferplatte mit unzähligen Blattnadeln, in nat. Grösse.

Libocedrus salicornioides Heer cretacea Vel. Seite 28.

Aus den Perucer Schieferthonen von Lidic.

Fig. 2. Ein kleines Zweigbruchstück mit 3 Gliedern, in natürl. Grösse.

Geinitzia cretacea Ung. Seite 15.

Aus dem Pläner vom Weissen Berg.

Fig. 3. Ein Zweigstück mit gut erhaltenen Blättern und deren Durchschnitten in der Mitte, in natürl. Grösse.

Widdringtonia Reichii Ett. Seite 27.

Fig. 4. Fruchtzapfen einem kurzen Zweigchen aufsitzend, in natürl. Grösse; aus den röthlichen Perucer Schieferthonen von Liebenau.

Fig. 5. Eine Schieferplatte von Vyšerovic mit Blättern von Eucalyptus Geinitzi und einigen Ästchen der Widdringt. Reichii, welchen oben ein vierlappiger Fruchtzapfen aufsitzt; in natürl. Grösse.

Fig. 6. $\quad$ Ein älterer Zweig mit spitzigen Schuppenblättern von Liebenau; in natürl. Grösse.

Cyparissidium gracile Heer. Seite 17.

Aus dem Pläner vom W eis s en Berg.

Fig. 7. Ein beschuppter Zweig, welchem bei a) ein gebrochener Zapfen aufsitzt; in natürl. Grösse.

Sequoia Reichenbachi Gein. sp. Seite 19.

Fig. 8. Ein Zapfenfragment mit deutlich erhaltenen Schuppen; der äussere Umriss ist durch die Kreislinie ergänzt; in natürl. Grösse; aus dem Malnicer Sandsteine.

Fig. 9. Ein beblättertes Ästchen von Vunic, in natürl. Grösse.

Pinus Quenstedti Heer. Seite 32.

Aus dem Schieferthone von Vyšerovic.

Fig. 10. Ein junges Ästchen mit abstehenden Blattnadeln; in natürl. Grösse.

Geinitzia cretacea Ung. Seite 15.

Fig. 11. Ein restaurirtes und zweimal vergrössertes Ästchen mit sichelförmigen Blättern und mit Blattpolstern derselben.

Fig. 12. Blattspuren mit zurückgebliebener Blattsubstanz oder mit einer leeren Höhlung, wie bei $a$ ); vergrössert.

Sequoia fastigiata Sternb. sp. Seite 21.

Aus dem Pläner vom Weissen Berg.

Fig. 13. Ein Fruchtzapfen dem kurzen, beblätterten Ästchen aufsitzend.

Cyparissidium gracile Heer. Seite 17.

Fig. 14. Ein älteres Zweigstück mit zahlreichen, typischen Seitenästchen, in natürl. Grösse; aus dem Pläner vom W eiss en Berg.

Fig. 15. Ein jüngeres Ästchen, in natürl. Grösse, aus dem Pläner von Slavětín.

Widdringtonia Reichii Ett. sp. Seite 27.

Fig. 16. Ein vergrössertes Zweigstück mit treu ausgeführten Blättern.

Cyparissidium gracile Heer. Seite 17.

Fig. 17. Vergrösserung einer Zweigpartie der Fig. 15. 
Velenovský. Die Gymnospermen derböhm. Kreideformation.

Taf. VIII

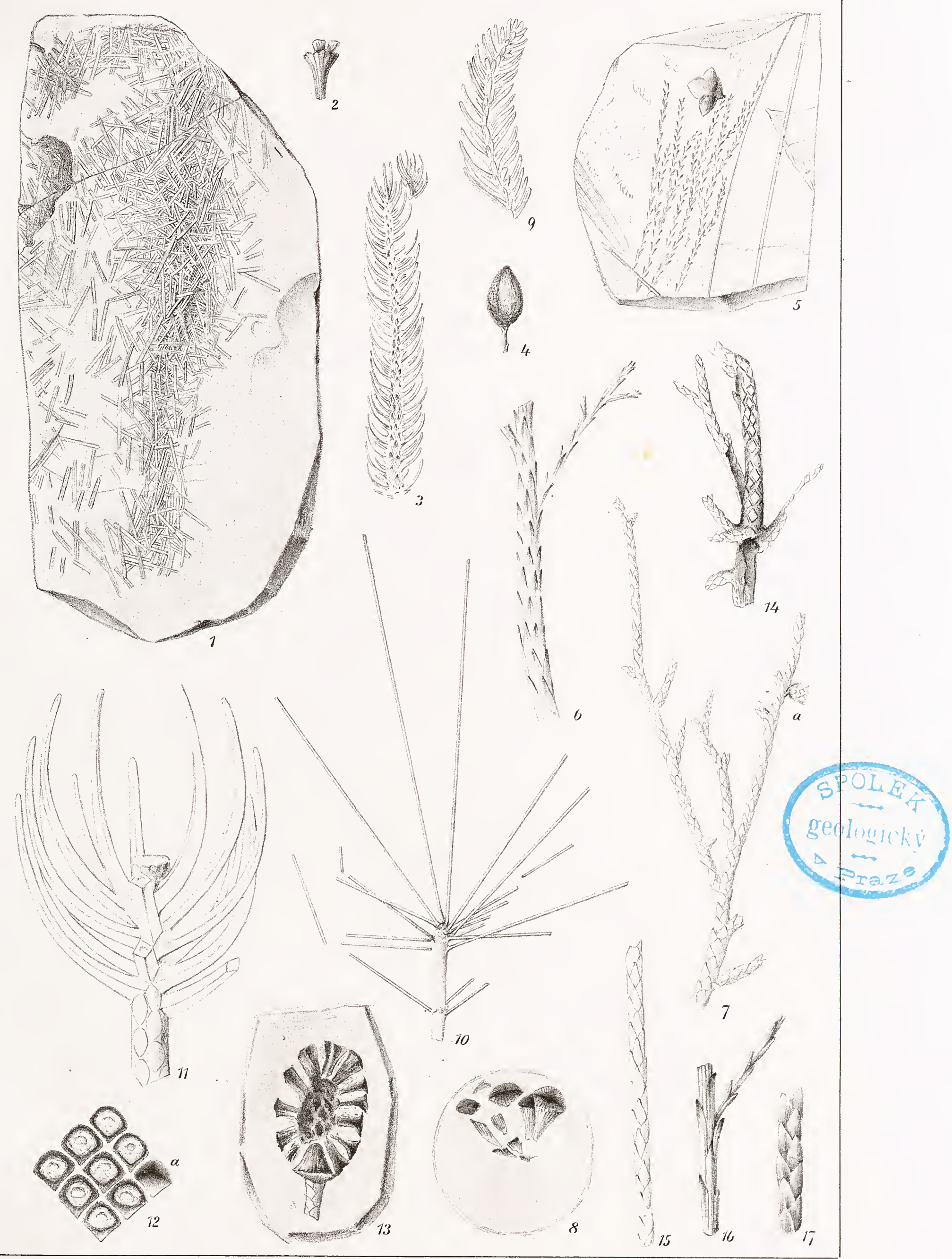

Yelenovský deI langhans lith.

K.k.Iloflithogrvon A.llatse in Pras 
(2) 



\section{TAFEL IX.}

Geinitzia cretacea Ung. Seite 15.

Aus den Plänerschichten vom W eissen Berg.

Fig. 1-2. Grosse Zweige, theilweise noch mit aufsitzenden Blättern und zahlreichen, rundlichen Blattpolstern; in natürl. Grösse.

Sequoia fastigiata Sternb. sp. Seite 21.

Aus den Plänerschichten vom Weiss en Berg.

Fig. 3. Ein gebrochener Fruchtzapfen mit einigen Schildchenabdrücken, in natürl. Grösse.

Fig. 4. Kleine Zweigfragmente mit deutlich erhaltenen, stumpfen Schuppenblättern; in natürl. Grösse.

Sequoia Reichenbachi Gein sp. Seite 19.

Fig. 5. $\quad$ Ein jährliches Ästchen mit schuppentragendem Grunde, in natürl. Grösse; von Vo škobrd bei Poděbrad.

Fig. 5̋a) Zweigfragment mit langen Blättern von Malnic; in natürl. Grösse.

Cyparissidium minimum Vel. Seite 19.

Aus den Perucer Schieferthonen von Landsberg.

Fig. 6. Vergrösserung der Fig. 7.

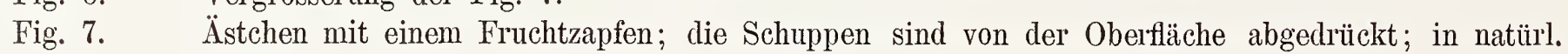
Grösse.

Sequoia rigida Heer. Seite 23.

Aus den röthlichen Schieferthonen von Liebenau.

Fig. 8. Ein blatttragendes, schlecht erhaltenes Ästchen, in natürl. Grösse.

Sequoia fastigiata Sternb. sp. Seite 21.

Aus den Plänerschichten vom Weiss en Berg.

Fig. 9-10. Zweigfragmente mit gut erhaltenen, charakteristischen Schuppen, in natürl. Grösse.

Sequoia Reichenbachi Gein. sp. Seite 19.

Fig. 10a) Ein langblätteriges Zweigfragment von Priesen; in natürl. Grösse.

Sequoia fastigiata Sternb. sp. Seite 21.

Fig. 11. Ein in natürl. Grösse restaurirter Fruchtzapfen.

Sequoia Reichenbachi Gein sp. Seite 19.

Fig. 12. Ein langblätteriges Ästchen von Malnic, in natürl. Grösse.

Fig. 12a). Ein Zweigstück mit Blattresten aus dem Perucer Sandsteine von Nehvizd, in natürl. Grösse.

Fig. 13. Ein Ästchen, welches am besten abgedrückte, lange Blätter trägt; in natürl Grösse; von Vin ar.

Fig. 14. Ein Ästchen aus den Chlomeker Schichten von Kieslingswalde, in natürl. Grösse. 
Velenovský. Die Gymnospermen derböhm. Kreideformation.

Taf. IX.

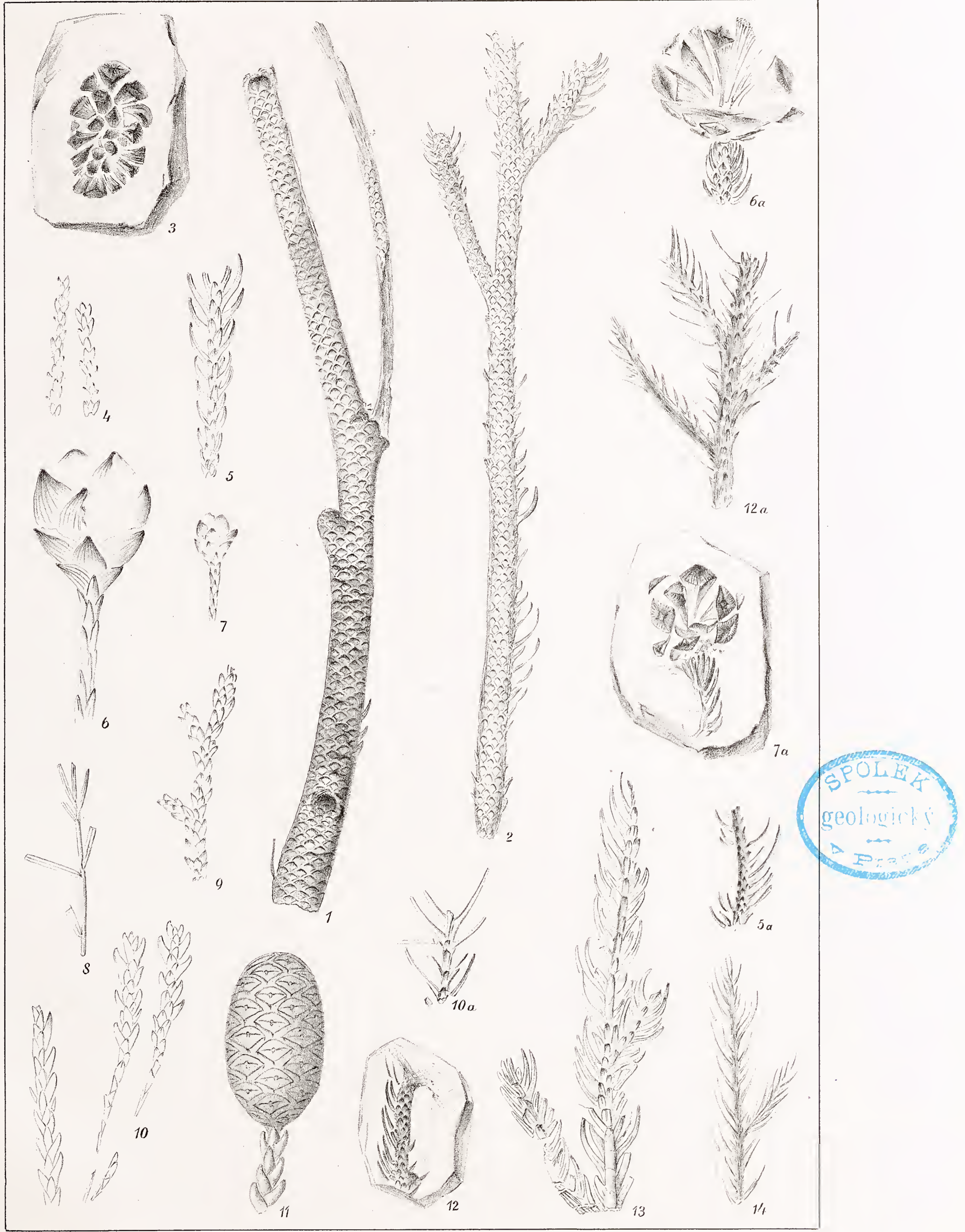

Velenorský del Langhans lith.

K.k.lloflithogir:von A.Haase in Prag. 




\section{TAFEL X.}

Widdringtonia Reichii Ett. Seite 27.

Fig. 1. Ein grösserer Zweig, dessen einzelne Ästchen mit männlichen Zäpfchen enden; in natürl. Grösse ; von Vyšerovic.

Sequoia microcarpa Vel. Seite 24.

Aus den Teplicer Schichten bei Raudnic.

Fig. 2. Ein gebrochener Fruchtzapfen, welcher oben zwei deutliche Samen unter einem Schildchen trägt; natürl. Grösse.

Fig. 3. Dasselbe Zäpfchen in senkrechter Richtung gebrochen, so dass das beblätterte Ästchen, mit dem es in Verbindung steht, $\mathrm{zu}$ sehen ist.

Cyparissidium minimum Vel. Seite 19.

Aus den Perucer Schieferthonen von Landsberg.

Fig. 4. Ein verzweigtes Ästchen in natürl. Grösse.

Sequoia crispa Vel. Seite 22.

Aus den Perucer Schieferthonen von Lipenec.

Fig. 5. Ein zapfentragendes Ästchen, in natürl. Grösse; die Schuppenschildchen sind schön von der Oberfläche abgedrüickt.

Fig. 6. Ein ähnlicher Zapfen, aber etwa in der Mitte gebrochen, so dass die einzelnen Schuppen wahrzunehmen sind; in natürl. Grösse.

Fig. 7. Ein von der Oberfläche abgedrüickter Fruchtzapfen; in natürl. Grösse.

Jumiperus macilenta Heer (?). Seite 29.

Fig. 8. $\quad$ Ein kleines Ästchen von L i e b e n a u.

Sequoia crispa Vel. Seite 22.

Fig. 9. Ein Ästchen mit den charakteristischen, einwärts gebogenen Schuppen; aus den Perucer Schieferthonen von Lipenec; natürl. Grösse.

Sequoia rigida Heer. Seite 23.

Fig. 10. Ein kleines Ästchen in natïrl. Grösse; aus den röthlichen Schieferthonen von Lieb en a u.

Widdringtonia Reichii Ett. Seite 27.

Aus den Perucer Schieferthonen von Vyšerovic.

Fig. 11-12. Grössere Zweigstücke mit kleinen, angedrückten Schuppenblättern; natürl. Grösse.

Libocedrus Veneris Vel. Seite 28.

Fig. 13. Schematische Vergrösserung eines Zweigstückes; siehe die gleich grossen, allmälig herablaufenden und decussirten Blattpaare.

Sequoia crispa Vel. Seite 22.

Fig. 14. Ein schön erhaltenes Ästchen in natürl. Grösse; von Lip en e c.

Libocedrus Veneris Vel. Seite 28.

Fig. 15. Ein Ästchen in natürl. Grösse; die rhombischen Löcher entsprechen einer Blattreihe; von Rau d ni c.

Sequoia crispa Vel. Seite 22.

Fig. 16. Ein langes, nicht verzweigtes Ästchen, in natürl. Grösse; von Lip enec.

Libocedrus Veneris Vel. Seite 28.

Fig. 17. Ein Ästchen mit deutlich decussirten Blattpaaren; natürl. Grösse; aus den Weissenberger Schichten von Gr. Č ernosek. 


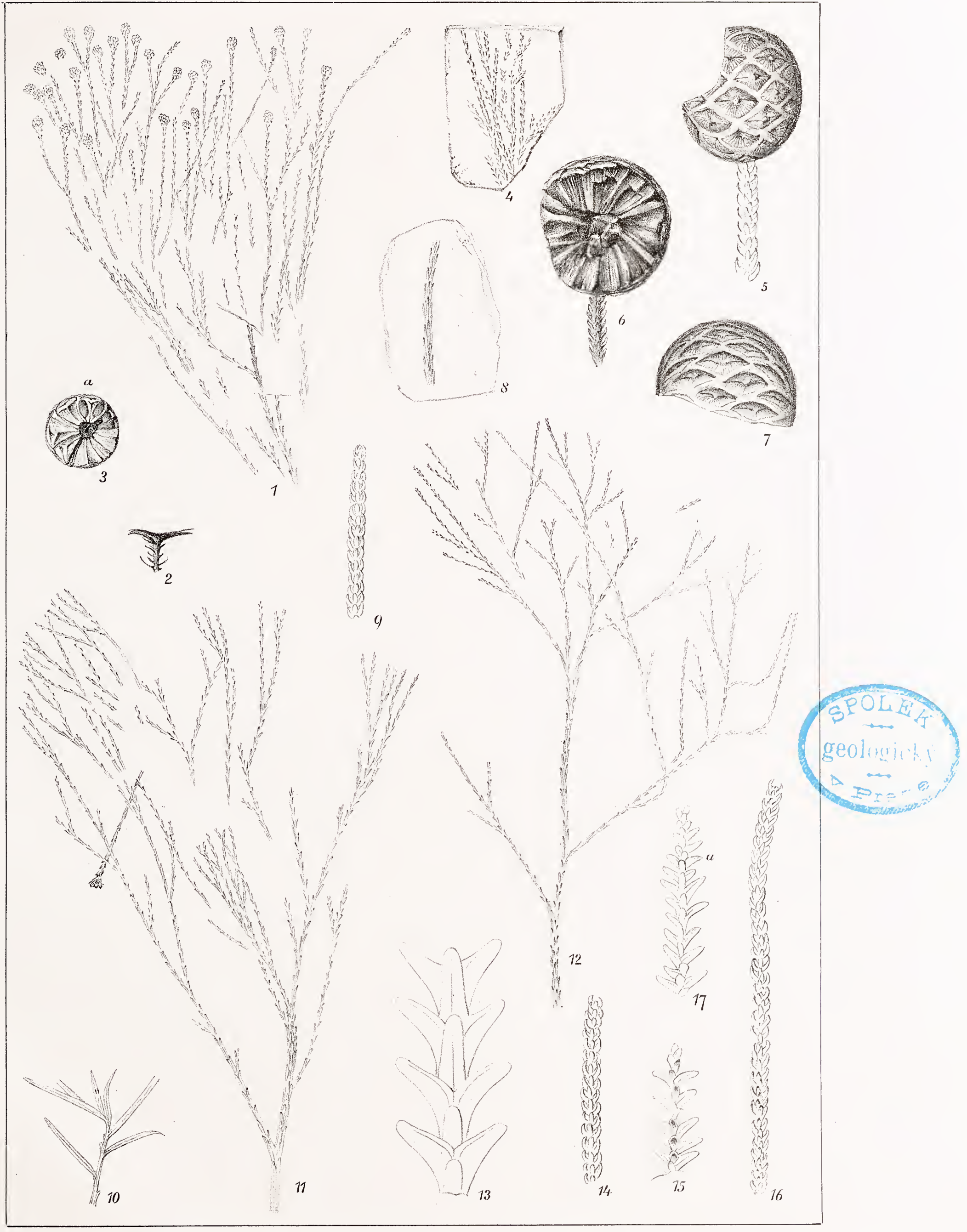






\section{TAFEL XI.}

Sequoia fastigiata Sternb. sp. Seite 21.

Fig. 1. Grosser Zweig mit mehreren gebrochenen Fruchtzapfen; stellenweise sind auf den Ästen noch die Schuppenblätter bemerkbar; bei a) einige Schildchenabdrücke; aus dem Perucer Sandsteine von Hospozín; natürl. Grösse. In den .Sammlungen des geol. Institutes der böhm. Universität.

Fig. 2. Ein beblätterter Zweig von Hrádek; natürl. Grösse.

Juniperus macilenta Heer. Seite 29.

Fig. 3. $\quad$ Ein Ästchen aus den Perucer Schieferthonen von Lip enec; natürl. Grösse.

Fig. 4. Eine Partie der Fig. 6 etwa zweimal vergrössert.

Sequoia rigida Heer. Seite 23.

Fig. 5. $\quad$ Ein jährliches, am Grunde deutliche Schuppenblätter tragendes Ästchen, in natürl. Grösse; aus den Perucer Schieferthonen von Liebenau.

Juniperus macilenta Heer. Seite 29.

Fig. 6. Ein kleines Ästchen aus den Schieferthonen von Vyšerovic; natürl. Grösse.

Ceratostrobus echinatus Vel. Seite 25.

Fig. 7. Ein verzweigtes, deutlich beblättertes Ästchen, in natürl. Grösse.

Fig. 8. Ein Zweigtheil der Fig. 7, etwa dreimal vergrössert; die spitzen Schuppenblätter stehen stark ab; auf dem Zweige zwei Blattpolster.

Fig. 9. Ein Schuppenschildchen aus dem Zäpfchen Fig. 12 etwa viermal vergrössert und treu ausgeführt; unten ist nọch ein Schuppenrest zu sehen.

Fig. 10. Vergrösserte Partie aus dem männlichen Zäpfchen Fig. 13; die Schuppen stehen dicht beisammen und sind parastichisch angeordnet.

Fig. 11. Ein Fruchtzapfen in natürl. Grösse.

Fig. 12. Ein höchst schön erhaltener Fruchtzapfen, der noch einem beblätterten Zweigè aufsitzt; in der Mitte sind die Contouren der Schildchen, am Rande ihre verlängerten Schnäbel zu sehen; in natürl. Grösse.

Fig. 13. ت̈stchen mit einem männlichen Zäpfchen, in natürl. Grösse.

Fig. 14. Eine ganze, restaurirte und etwa dreimal vergrösserte Fruchtschuppe, welche oben mit einem schnabeltragenden Schildchen endet; links eine treue Vergrösserung eines von der Seite abgedrückten Schildchens der Fig. 12.

Fig. 15. Ein beblättertes und zugleich ein männliches Zäpfchen tragendes Ästchen; in natürl. Grösse. 
Velenovský. Die Gymnospermen derböhm. Kreideformation.

Taf. XI.

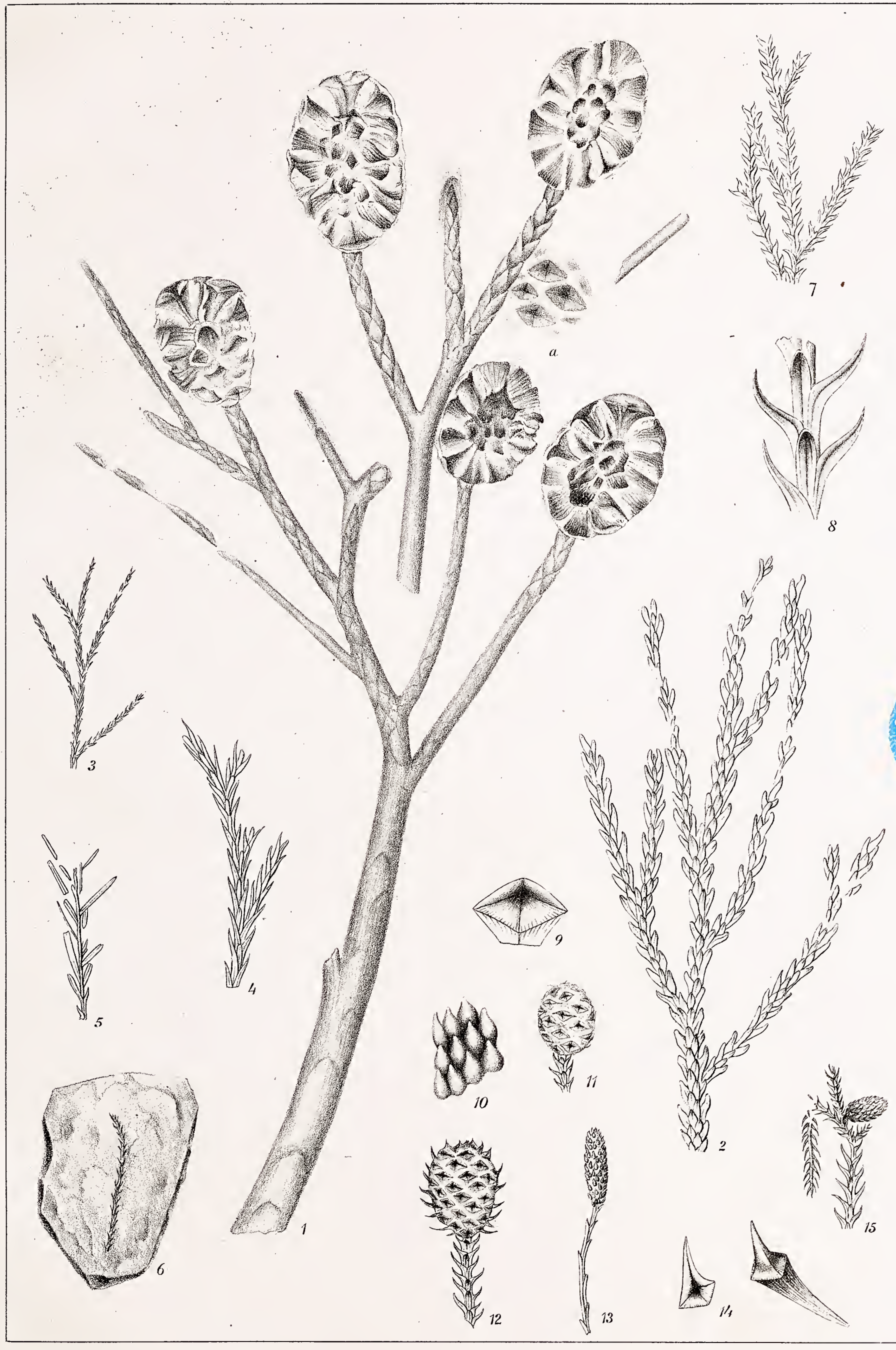

Velenovský del, Langhans lith.

K.k.Iloflithogivon A.Itaasp in Pras 
(9) 
- 


\section{TAFEL XII.}

Dacrydium densifolium Vel. Seite 12.

Aus den Teplicer Schichten von Raudnic.

Fig. 1-2. Zweigfragmente in natürl. Grösse; die parastichische Anordnung der Blätter ist stellenweise sehr deutlich.

Fig. 3. Ein ähnlicher Zweig, vielleicht ein jährlicher Spross, da die untersten Blätter bedeutend verkleinert sind; natürl. Grösse.

Fig. 4. Eine Zweigpartie der Fig. 3 etwa dreimal vergrössert.

Podocarpus cretacea Vel. Seite 13.

Aus den Perucer Schieferthonen von Melník an der Sázava.

Fig. 5. Ein Blatttheil etwa dreimal vergrössert; die Blattränder sind ein wenig umgerollt.

Fig. 6-11. Verschiedene Blattformen mehr oder weniger vollkommen erhalten, in natürl. Grösse.

Sequoia heterophylla Vel. Seite 22.

Fig. 12. Ein jähriges Ästchen mit langen Blättern, in natürl. Grösse; aus den Schieferthonen von Peruc.

Sequoia fastigiata Sternb. sp. Seite 21.

Fig. 13. Ein sehr schön erhaltenes Zweigstück aus dem Pläner vom Weissen Berg; natürl. Grösse; die Blätter treu ausgeführt.

Ceratostrobus sequoiaephyllus Vel. Seite 24.

Aus den Perucer Schieferthonen von Lipenec.

Fig. 14. Eine Schuppe etwa dreimal vergrössert und restaurirt dargestellt; das Schildchen läuft in einen Schnabel aus.

Fig. 15. Ein beblättertes Ästchen, welches mit einem gebrochenen Fruchtzapfen endet; bei a) und b) ein Schuppenschildchen von oben abgedrückt; c) Schuppenschildchen von der Seite abgedrückt, so dass die Schnabel sichtbar werden; d) unterhalb eines Schildchens ist die herablaufende Schuppe zu erkennen; e) ein Schuppenschildchen mit dem Schnabel abgedrückt.

Fig. 16. Ein grosser, beblätterter Zweig in natürl. Grösse. 
Velenovský. Die Gymnospermen derböhm. Kreideformation.

Taf.'XII.

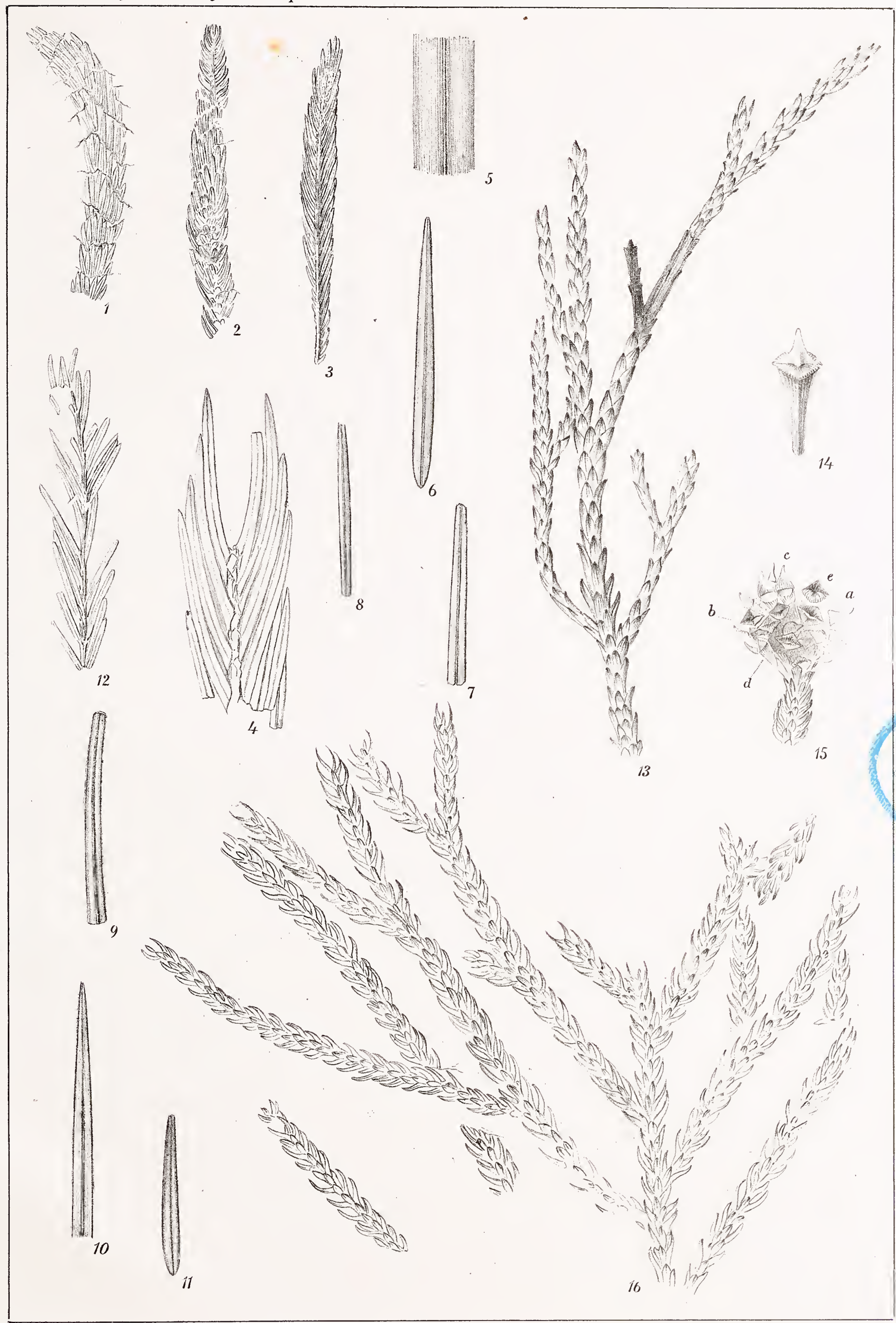

Velenovský del, Langhans lith.

K.k.Iloflithogrevon A.llaase in Pas 



\section{TAFEL XIII.}

Juniperus macilenta Heer. Seite 29.

Fig. 1. Eine Schieferplatte von Vyšerovic, auf welcher zahlreiche Zweigfragmente liegen; bei c) sind die letzteren in grössere Ästchen zusammengestellt; bei a) ein dickeres Zweigstück mit Schuppenblättern; bei b) vielleicht stärkere Holzabdrücke; natürl. Grösse.

Sequoia heterophylla Vel. Seite 22.

Aus den Schieferthonen von Per'uc.

Fig. 2. Jährliche Ästchen, welche bei a) mit wenig entwickelten Blättern besetzt sind; in natürl. Grösse.

Fig. 3-4. Jährliche Sprosse, auf welchen besonders gut die untersten schuppenförmigen Blätter zu sehen sind; natürl. Grösse.

Ceratostrobus echinatus Vel. Seite 25.

Fig. 5. $\quad$ Ein Ästchen aus den Perucer Schieferthonen von Li e be nau.

Sequoia heterophylla Vel. Seite 22.

Aus den Schieferthonen von Peruc.

Fig. 6. Ein grösserer Zweig, welcher nur schuppenförmige Blätter trägt; natürl. Grösse.

Fig. 7. $\quad$ Ein Zweigtheil mit treu ausgeführten Blättern, etwa zweimal vergrössert.

Fig. 8. Ein Zweig, auf welchem bis jetzt fragliche Knospen sitzen.

Fig. 9. Ein grosser, gebrochener Zweig, auf welchem die schuppentragenden Äste mit den einjährigen tragenden Sprossen enden.

Sequoia rigida Heer. Seite 23.

Fig 10. Ein Zweigfragment aus den röthlichen Schieferthonen von Li ebenau. 
Velenovský. Die Gymnospermen derböhm. Kreideformation.

Taf.XIII.

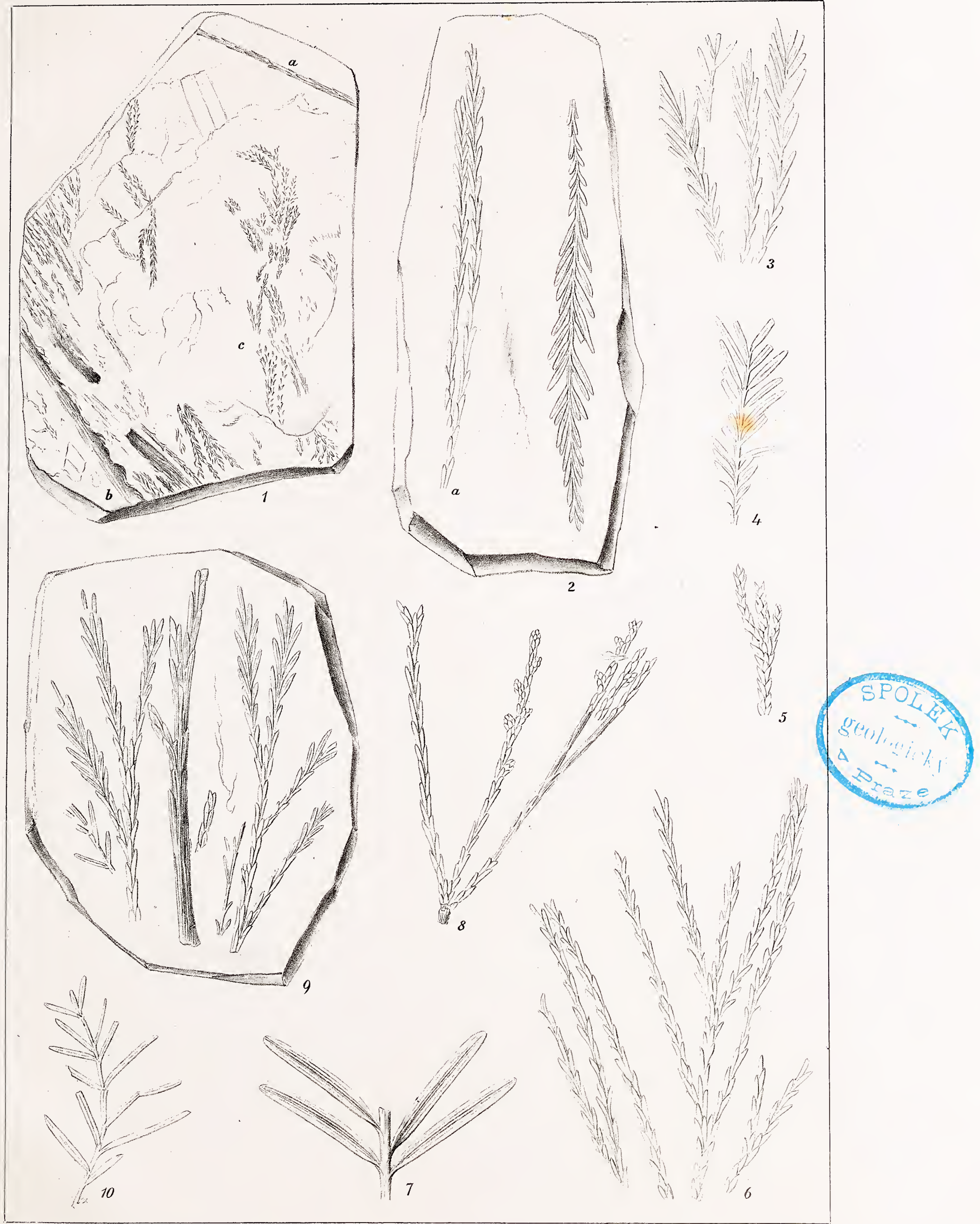

Velenorský del, Langhhans lith.

K.k.iloflithogirevon A.Haase in l'ag 
OSLUCHE

ove ce VPRAZE O $00 \frac{300}{3}$ 

